\author{
Paulo A.V. Borges ${ }^{1 *} \&$ \\ Joerg Wunderlich ${ }^{2}$ \\ ${ }^{1}$ Azorean Biodiversity Group, \\ Departamento de Ciências \\ Agrárias, CITA-A, Universidade \\ dos Açores. Campus de Angra, \\ Terra-Chã; Angra do Heroísmo - \\ 9700-851 - Terceira (Açores); \\ Portugal. \\ Email: pborges@uac.pt \\ ${ }^{2}$ Oberer Häuselbergweg 24, \\ 69493 Hirschberg, Germany. \\ Email: joergwunderlich@ \\ t-online.de
}

submitted December 2005

accepted November 2006

\section{Spider biodiversity patterns and their conservation in the Azorean archipelago, with descriptions of new species}

\begin{abstract}
In this contribution, we report on patterns of spider species diversity of the Azores, based on recently standardised sampling protocols in different habitats of this geologically young and isolated volcanic archipelago. A total of 122 species is investigated, including eight new species, eight new records for the Azorean islands and 61 previously known species, with 131 new records for individual islands. Biodiversity patterns are investigated, namely patterns of range size distribution for endemics and non-endemics, habitat distribution patterns, island similarity in species composition and the estimation of species richness for the Azores. Newly described species are: Oonopidae - Orchestina furcillata Wunderlich; Linyphiidae: Linyphiinae - Porrhomma borgesi Wunderlich; Turinyphia cavernicola Wunderlich; Linyphiidae: Micronetinae-Agyneta depigmentata Wunderlich; Linyphiidae: Erigoninae - Acorigone gen. nov. with its type species Acorigone zebraneus Wunderlich; Clubionidae - Cheiracanthium floresense Wunderlich; Cheiracanthium jorgeense Wunderlich; Salticidae - Neon acoreensis Wunderlich. Other major taxonomic changes are: Diplocentria acoreensis Wunderlich, 1992 (Linyphiidae) is transferred to Acorigone (comb. nov.), Leucognatha Wunderlich 1995 (Tetragnathidae) is not an endemic genus of the Azores but an African taxon and synonymous with Sancus Tullgren, 1910; Leucognatha acoreensis Wunderlich, 1992 is transferred to Sancus. Minicia picoensis Wunderlich, 1992 is a synonym of M. floresensis Wunderlich, 1992. For each species additional information is presented about its known distribution in the islands, its colonisation status, habitat occurrence and biogeographical origin.
\end{abstract}

Key words Araneae, Azores, biodiversity patterns, biogeography, cave species endemic, islands, new taxa, Macaronesian Islands, spiders

\section{Introduction}

Spiders (Araneae) are an important component of arthropod faunas (Wise, 1995), with their predatory behaviour being, for instance, of great relevance for biological control in agroecosystems. Members of this order play an important role in most terrestrial foodwebs, may be very abundant in several habitats and are among the most numerous arthropods from many samples in all kinds of habitats in the Azores (Borges \& Brown, 2001, 2004) and elsewhere (Basset, 1991). Moreover, despite the importance of spiders in terrestrial ecosystems, in both species richness and abundance, this arachnid group is rarely considered in evaluating networks of protected areas (but see Skerl, 1999; Cardoso, 2004; Borges et al., 2005a).

${ }^{*}$ Corresponding author.
Due to the ability of many families of spiders to disperse over long distances using wind currents ('ballooning') these organisms easily colonise isolated island archipelagos like the Azores and should have disproportionally higher species diversity. However, spiders are not a particularly attractive arthropod group for humans, and their current world and Azorean taxonomic knowledge are far from being satisfactory. For instance, in the Azores the rate of new species records and new species description indicates that only recently are we achieving a satisfactory picture of the Azorean spider diversity (see more details below).

The difficulty in spider biodiversity assessment in the Azores seems to be related to the absence of historical expeditions focusing only on this group of arthropods and on the high richness and variability in microhabitats they occupy. Historical investigations include the works of Denis (1964), that reported 70 species for the archipelago, and 


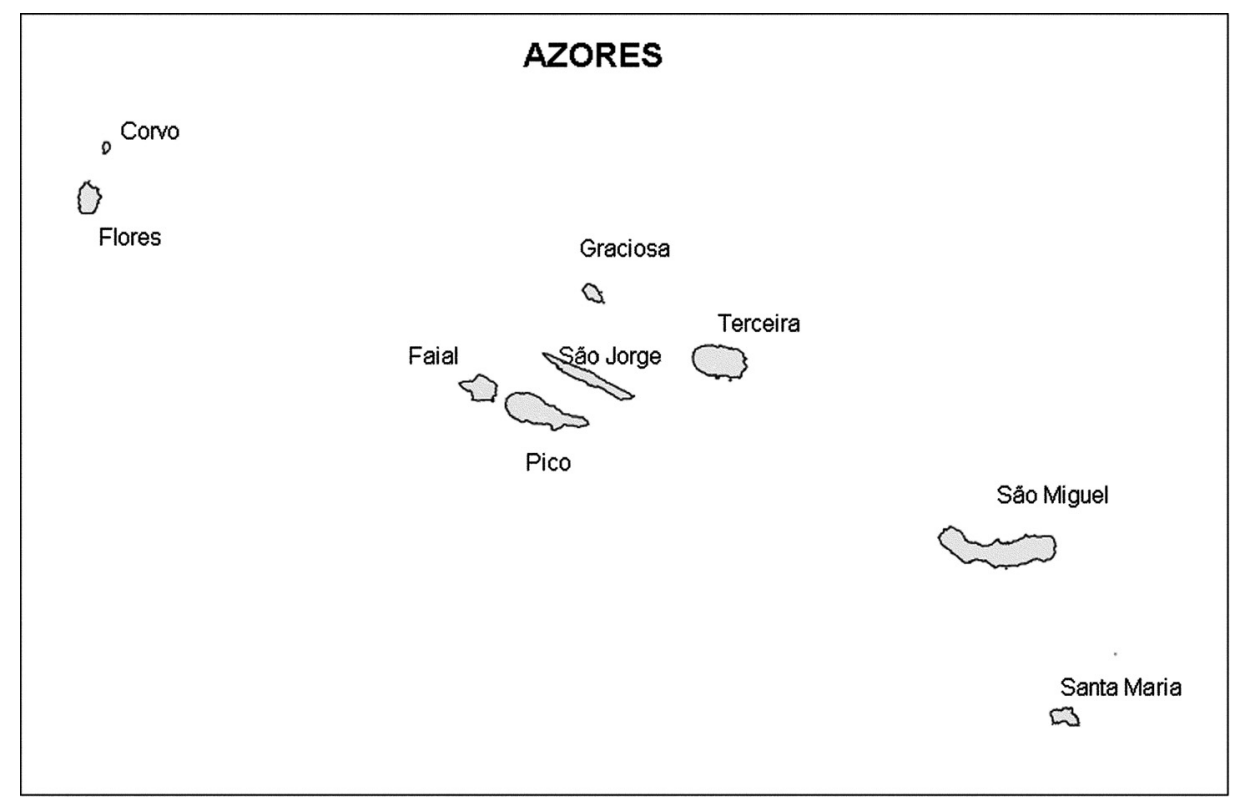

Figure 1 Map of the studied region, showing the nine islands of the Azores.

Wunderlich (1992), who listed 103 species and a few indetermined taxa. Special sampling protocols and a standardised sampling of different habitats are urgently needed for the adequate inventory of spiders and other arthropod groups in the Azores. This contribution is part of a larger study conducted since 1998 in the Azorean islands (Project BALA Biodiversity of the Arthropods of the Laurisilva of the Azores) (see Borges et al., 2000a, 2005a) that aims to survey the Azorean arthropod fauna using standardised sampling protocols at different spatial scales covering most protected areas and native forests in seven of the nine Azorean islands. For this current contribution we use as a starting point the last list of Azorean spiders (Wunderlich, 1992), and include data from recent field studies in pasturelands (Borges, 1999; Borges \& Brown, 1999, 2001, 2004), cavernicolous fauna (Borges \& Oromí, in press), native forest and grassland habitats (Borges et al., 2000b, 2005a), and fruit orchards (Santos et al., 2005). The recently published updated list of Azorean fauna and flora (Borges et al., 2005b) also includes a revised list of Azorean spiders (Borges \& Wunderlich, 2005) that is reproduced with some updates and additional information (e.g. new records, habitat distribution, biogeographical origin) in Appendix 1 (which is available as "Supplementary data" on Cambridge Journals Online: http://www.journals.cup.org/abstract_S1477200008002648) and will be the basis of our biodiversity pattern analysis.

Studies on island biodiversity and island biogeographical patterns for spiders are scarce globally (but see Baert \& Jocqué, 1993; Real et al., 1999; Schoener et al., 2003). Therefore, we are trying to make some headway by investigating some biodiversity patterns in the Azorean spider fauna.

The purposes of this work are: (i) to update all the taxonomy data of the Azorean spider fauna, describing new taxa, listing new records for individual islands and revising nomenclature; (ii) to investigate some biodiversity patterns concerning distribution between islands, habitats, colonisation status and biogeographical origin; (iii) to estimate spider species richness in the Azores; and (iv) to plan some suggestions for the conservation of Azorean spider diversity.

\section{Materials and methods}

\section{Area of study: The Azores}

The Azorean Islands are volcanic in origin being located in the North Atlantic, roughly between the coordinates $37^{\circ}$ to $40^{\circ} \mathrm{N}$ latitude and $25^{\circ}$ to $31^{\circ} \mathrm{W}$ longitude (Fig. 1). This archipelago comprises nine main islands and some small islets and is located at the triple junction between the African-Eurasian and North-American plates, emerging from the Azores Plateau, a topographic and gravity high near the Mid Atlantic ridge (MAR). The archipelago is situated over two tectonic plates: the westernmost islands of Flores and Corvo lie over the American plate and are separated from the eastern islands by the Mid-Atlantic Ridge (MAR); the other seven main islands are located in a large triangular plateau with a complicated structure known as 'Azores Plateau' (Nunes, 1999; França et al., 2003). The distance between the Azores and the European mainland is about $1584 \mathrm{~km}$, calculated from Cabo da Roca (the most westerly point of the European continent). The nine islands are divided into three groups: the occidental group of Corvo and Flores; the central group of Faial, Pico, Graciosa, São Jorge and Terceira; and the oriental group of São Miguel and Santa Maria, plus the Formigas islets (Fig. 1). The largest island is S. Miguel $\left(757 \mathrm{~km}^{2}\right)$, and the smallest is Corvo $\left(17 \mathrm{~km}^{2}\right)$. S. Maria is the southernmost island $\left(37^{\circ} \mathrm{N}, 25^{\circ} \mathrm{W}\right)$, and Flores is the westernmost one $\left(31^{\circ} \mathrm{W}\right)$. The most northerly one is Corvo $\left(39,7^{\circ} \mathrm{N}\right)$. The distance between Corvo and Santa Maria, the islands farthest apart, is about $615 \mathrm{~km}$. Corvo lies approximately at the same distance from the Iberian Peninsula and from Newfoundland. All the information concerning the longitude (long.), latitude (lat.), area, 
maximum altitude, distances from the mainland and geological age of each island are given in Table S1 in Supplementary Material.

The acceptance of the Plate Tectonic Theory and the confirmed volcanic origin of these islands, made the Azores a totally oceanic archipelago. The eastern part of every Azorean island is geologically the oldest. This is a consequence of the particular seismovolcanic mechanisms of this archipelago (Nunes, 1999; França et al., 2003).

Located at a mean latitude of $38^{\circ} 30^{\prime}$ and surrounded by the Atlantic Ocean, the Azores enjoy the benefits of a mild and agreeable climate. The warm Gulf Stream is responsible for quite similar temperatures at sea level in the southeastern as well as in the northwestern islands. The same can be said of humidity levels in the different islands (Agostinho, 1966). A marked oceanic climate with low thermal amplitude and high precipitation and humidity are characteristic of this archipelago.

Discovered by the Portuguese navigators in 1432, the Azores seem already to have been vaguely known, as indicated on older maps. The present Azorean landscape has been strongly modified by its human inhabitants, and only in small areas, where the soil or climate was too rough, have primitive conditions remained unchanged. The population exceeded 300000 in the 1960s, but nowadays only about 260000 people live in these islands (DREPA, 1988). S. Miguel, Terceira and Faial are the most densely populated islands.

According to the recent list of Azorean vascular plants by Silva et al. (2005), there are 947 species and subspecies (68 endemic; $7.2 \%$ of endemism) in the Azorean vascular flora, but only about one $28 \%$ of those are indigenous to the archipelago. The relative importance of introduced taxa by settlers is high in most plant groups. In fact, the percentage of introduced species is one of the highest in a worldwide comparison, even if one considers exclusively oceanic islands (Silva $\&$ Smith, 2004). The predominant native vegetation form is 'Laurisilva', a humid evergreen broadleaf and microphyllous (hereafter short-leaf) laurel type forest that originally covered most of Western Europe during the Tertiary (Dias, 1996). Recent studies, however, support a more recent origin, explained by insular evolution from an ancestral herbaceous condition (Emerson, 2002). Dominant endemic trees and shrubs include short-leaf Juniperus brevifolia (Seub.) Antoine (Cupressaceae) and Erica azorica Hochst. Ex Seub. (Ericaceae), the broadleaf species Ilex perado Ait. ssp. azorica (Loes.) Tutin (Aquifoliaceae), Laurus azorica (Seub.) Franco (Lauraceae) and the shrub Vaccinium cylindraceum J. E. Sm. (Ericaceae). This type of forest is characterised by reduced tree stature (usually up to $5 \mathrm{~m}$, rarely reaching $10 \mathrm{~m}$ ), shaped by the shallow soil and sinuous terrain, which is raised up to tree tops at some points, and lowered five to six metres below at others. A high crown foliage density and thus low canopy openness, as well as a particularly dense cover of moss and liverwort epiphytes is typical of these forests. Some bryophytes also cover leaves in higher altitude humid forests.

In spite of a dominance of non-native habitats in these islands (e.g. pastureland, fruit orchards, exotic trees plantations), in the last ten years NATURA 2000, a European Commission conservation management scheme, was launched covering about $13 \%$ of the area of Azores islands. Selected areas were chosen both for the protection of selected species of birds (Special Protection Areas - SPAs; Portuguese ZPEs; $n=15)$ and for the protection of habitats and (non-bird) species (Special Areas of Conservation - SACs; Portuguese SICs; $n=23$ ).

\section{Spider sampling and databases}

Since 1994 spiders were sampled in a standardised way in different habitats. Data from semi-natural pastures and intensive pastures were collected on three islands (Terceira, Pico and S. Maria) in the years 1994 and 1995 by means of pitfall traps and a 'Vortis' suction sampling machine (see details in Borges, 1999; Borges \& Brown, 1999, 2001, 2004). The bulk of our data comes from project BALA (Biodiversity of the Arthropods from the Laurisilva of the Azores), in which from 1999 to 2005 arthropods were collected by means of pitfall traps in the native forests of seven islands (Corvo and Graciosa excluded) (see details in Borges et al., 2005a), but also in natural grassland and some exotic tree plantations (Ecucalyptus spp., Acacia spp., Pittosporum undulatum and Cryptomeria japonica) (Borges et al., unpubl. data).

Another habitat surveyed was the canopy of both native and endemic trees (see Ribeiro et al., 2005; also BALA project) and of fruit orchards (see Santos et al., 2005; project INTERFRUTA). In the case of project INTERFRUTA data are only available for one island (Terceira). For the canopy arthropod sampling a modified beating tray was used, which consisted of an inverted cloth funnel pyramid, $1 \mathrm{~m}$ wide and 60 cm deep (after Basset, 1999). A plastic bag was placed at the tip where arthropods, leaves and small branches were collected. For each selected plant, a branch was chosen at random, the beating tray placed beneath and the branch hit five times with a beating stick (for more details see Ribeiro et al., 2005; Santos et al., 2005).

Finally, cave fauna was investigated since 1987 in all islands (except Corvo) using not only pitfall traps but also direct search (see details in Ashmole et al., 1996; Borges \& Oromí, 1994, in press).

All data are organised in several databases, one for the cave fauna, one for the pasture fauna, one for the fruit orchard fauna and finally a large database for BALA data that includes both pitfall and canopy samples. Data on new records and taxonomic notes from pasture sampling have already been published (see Borges et al., 1999), and the same applies partially to cave fauna (Wunderlich, 1992; Ashmole et al., 1996; Borges \& Oromí, 1994, in press).

The new taxa and records presented in the current work come mainly from BALA project. All additional material listed and reference to new records is indicated by a SITE CODE that is composed of several letters and numbers as indicated previous to the list of Additional Material per taxon in Table S2 (which is available as 'Supplementary data' on Cambridge Journals Online: http://www.journals.cup.org/ abstract_S1477200008002648). For the geographical location of transects within reserves (UTM coordinates) see Table S3 in Supplementary Material. 


\section{Data analysis}

Spider species were classified in one of three colonisation categories: natives, endemics and introduced. Native species arrived by long-distance dispersal to the Azores and are also known in other archipelagoes and on the continental mainland. Endemic species are those that occur only in the Azores, as a result of either speciation events (neo-endemics) or extinction of the mainland populations (palaeo-endemics). Introduced species are those believed to be in the archipelago as a result of human activities, some of them being cosmopolitan species.

One way to examine patterns of distribution is to plot the frequency histogram of species distributions, that is, a speciesrange-size distribution (Gaston, 1994). To test the occurrence of mainly rare species or/and also a large proportion of common species we applied the Tokeshi (1992) statistical test for bimodality that permits the calculation of the probability under the null hypothesis of the presence of larger numbers of species in the two extreme classes (rare and common) (see Tokeshi, 1992 and Barreto et al., 2003 for more details).

In addition to the species distribution analysis we also analysed two other important components of rarity, namely abundance and habitat affiliation. Taking into consideration that the sampling effort was not the same for all investigated habitats, we used relative abundance within each habitat to get an estimate of the abundance of each species. Thus, for a particular habitat we totalled the number of specimens captured for a species and than divided it by the total number of specimens sampled of all species. With this procedure we could rank species from abundant (common) to scarce (rare) within a particular habitat.

Concerning habitats, in addition to habitat affiliation we also investigated habitat frequency distribution of the spider assemblage and tested the hypothesis that there is a gradient of endemic species richness with regard to habitat disturbance. In order to investigate these three patterns, we organised habitats in a gradient of land-use considering eight different land-uses (habitats) with data on individual islands pooled:

(1) Canopy-Laurel - canopy of native or endemic forest trees and shrubs (data available for all islands except Corvo and Graciosa) (see details on plants sampled in Ribeiro et al., 2005).

(2) Soil-Laurel - epigean soil communities of native forest sampled with pitfalls (data available for all islands except Corvo and Graciosa).

(3) Natural Grassland - epigean soil communities of native high altitude grassland sampled with pitfalls (data available for all islands except Corvo, Faial, Santa Maria and Graciosa).

(4) Caves - lava tubes and volcanic pits communities both at entrances and deep inside (data available for all islands except Corvo and Flores).

(5) Exotic Forest-epigean soil communities of exotic forests sampled with pitfalls (data available only for one island, Terceira).

(6) SN Pasture - epigean soil and grass and herb dwelling communities of semi-natural managed high altitude grassland sampled with pitfalls and a Vortis machine (data available from three islands, Terceira, Pico and Santa Maria).

(7) Pasture - epigean soil and grass and herb dwelling communities of intensively managed high altitude grassland sampled with pitfalls and a Vortis machine (data available from three islands, Terceira, Pico and Santa Maria).

(8) Fruit Orchards - canopy samples of four types of fruit orchard (bananas, orange trees, apple trees and peach trees) (data available only for one island, Terceira) (see details on plants sampled in Santos et al., 2005).

To evaluate the similarity between land-use types in endemic spider species composition we used hierarchical, agglomerative cluster analysis. From among the various available methods we chose the Wards method (with 1- Sörensen similarity), also known as minimum variance or error sums of squares clustering, in which, in each iteration, all possible pairs of groups are compared and the two groups chosen for fusion are those which will produce a group with the lowest variance (Software CAP.- Community Analysis Package v. 3.0; Pisces Conservation Ltd; www.pisces-conservation.com) (see Henderson \& Seaby, 2004).

There is a need to estimate biodiversity in order to conserve as much as possible of the remaining biodiversity. However, some of the available techniques to extrapolate species numbers have major statistical problems. For instance, one of the methods, 'extrapolation from rates of scientific taxonomic description' (see Dolphin \& Quicke, 2001; Cabrero-Sañudo \& Lobo, 2003), could not be applied to our data since sampling effort was not constant through time in the Azores. Another option is the use of the 'geographical distribution of species in better known taxa'. In this case the ratio of species richness of the target taxonomic group to that of a well-known taxon is calculated in a well-known area, and later is applied to the global number of species of the well studied taxon in the area of interest (see Dolphin \& Quicke, 2001). One problem associated with this method is related to the potential differential rates of speciation of indicator taxa in different geographical areas. In our study we examine beetles (Insecta, Coleoptera), butterflies and moths (Lepidoptera) as well-known representative taxa, and the Canaries as the biogeographical area for comparison. We selected the Canary Islands, because they belong to the same biogeographical area as the Azores (Macaronesia), and a comprehensive list of their arthropod fauna is available (Izquierdo et al., 2004). The endemic number of species for the Coleoptera and Lepidoptera of the Azores was obtained from the recent list of Azorean fauna and flora (Borges et al., 2005b, c; Karsholt \& Vieira, 2005). The ratio estimates for endemic Araneae with Coleoptera and Lepidoptera in the Canaries is, respectively, 0.24 and 1.17 .

To have an independent estimate for the potential Azorean endemic spider species richness, we also apply an incidencebased non-parametric estimator, Jackknife1 (see Colwell \& Coddington, 1994): $S_{\max }=S_{o b s}+a(\mathrm{n}-1 / \mathrm{n})$, where $S_{o b s}$ is the number of known species, $n$ is the number of samples $(n=9$ islands in our case) and $a$ the number of species only found in one sample (island) (the so-called 'uniques'). 
The Jackknife 1 estimator was chosen, because it is considered the most robust with incidence (presence/absence data) at larger scales (see Hortal et al., 2006). The estimator was computed using the Software Species Diversity and Richness version 3.0 (Pisces Conservation) (see Henderson \& Seaby, 2002). We also applied to the endemic species dataset (see Appendix S1 in supplementary material on Cambridge Journals Online: http://www.journals.cup.org/ abstract_S1477200008002648) an accumulation curve with island order randomised 100 times to obtain a mean species accumulation curve. The same number of 100 randomisations were also computed to obtain the Jackknife1 estimate generating confidence intervals for the estimated species richness.

All regression analyses were performed with ordinary linear least-squares (OLS) regression. Log10 transformed geographical variables and numbers of species were used for several reasons: (a) to overcome non-constant variance, and non-linearity of the data; (b) because higher $\mathrm{r}^{2}$ values were consistently obtained when using the log-log model; (c) the residuals appeared to show no pronounced patterns in the loglog model; and (d) the biological and ecological interpretations are available from the fitted intercept and slope.

\section{Results}

\section{Description of new species and remarks on selected taxa OONOPIDAE}

Oonopidae are tiny six-eyed and frequently pale spiders; they are easily overlooked. Only a single species of this family has been reported from the Azores, Oonops domesticus Dalmas, 1916, (see Wunderlich, 1992, p. 16). The Mediterranean Orchestina pavesii (Simon, 1873) is known from the Canary Islands. A new species of this genus is described below.

Orchestina furcillata Wunderlich sp. nov. (Fig. 2)

\section{Material}

HOLOTYPE Male: Azores, São Miguel, Atalhada (Transect 2), August 1999, pitfall sample ET22 (P.A.V. Borges et al., leg.); deposited at the University of the Azores ('Arruda Furtado' Collection).

\section{Diagnosis (male; female unknown)}

Pedipalpus (Figs 2c, d): the tibia is the thickest article, the embolus is long, bent and furcate.

\section{Description (Male)}

Measurements (in mm): Body length 1.0, prosoma: Length 0.47 , width 0.35 , leg I: Femur 0.42, patella 0.12, tibia 0.38 , metatarsus 0.4 , tarsus 0.3 , tibia IV 0.35 , femur IV 0.5 , its width 0.12 .

Colour pale yellow brown with black surroundings of the eye lenses.

Prosoma: Thorax higher than the caput, thoracal fissure absent, 6 large eyes (Fig. 2a), median eyes largest. Chelicerae slender, labium concave apically (Fig. 2b). - Legs: sequence of length IV/I/II/III, fairly slender but femur IV strongly thickened as in

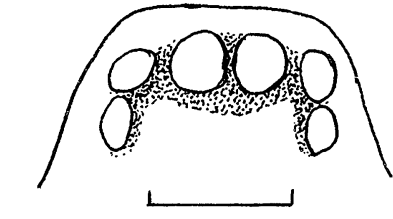

a

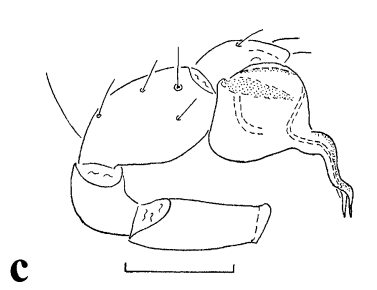

b

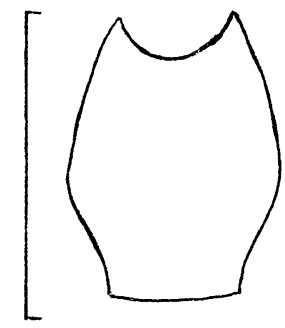

Figure 2 Orchestina furcillata Wunderlich sp. nov., Male; (a) anterior part of the prosoma with eyes; (b) labium, ventral aspect (hairs are not drawn); (c) r. pedipalpus, retrolateral aspect (only few hairs are drawn); (d) embolus with conductors of the r. pedipalpus, proventral aspect; bar $=0.05 \mathrm{~mm}$ in Fig. d, $0.1 \mathrm{~mm}$ in the remaining Figs.

all congenerics. Bristles are completely absent. All metatarsi bear a single trichobothrium, its position on I-II in 0.94 , on IV in 0.55. - Opisthosoma oval, most parts are covered with short hairs but long hairs are present around pedicel and spinnerets. Pedipalpus: See above. The tibia bears two trichobothria. A tiny thin and pointed structure exists ventrally on the embolar furca.

\section{Ecology}

The only known male specimen plus a juvenile specimen were collected in pitfall traps (with Ethylene Glycol) in a native forest dominated by the endemic tree Ilex perado Ait. ssp. azorica (Loes.) Tutin (Aquifoliaceae) with the soil covered by the exotic and invasive plant Hedychium gardnerisheffard ex Ker-Gawl. (Zingiberaceae).

\section{Relationships}

According to the structures of the embolus O. arabica Dalmas, 1916 from the Arabic Peninsula is most closely related; in arabica the pedipalpal tibia is more slender and the embolus is shorter.

\section{Distribution}

Azores: São Miguel.

\section{TETRAGNATHIDAE}

Tetragnathidae is a spider family characterised by the long chelicerae, represented in the Azores with four species, three of which are human introductions. The only native species is the endemic Sancus acoreensis (Wunderlich, 1992).

\section{Sancus Tullgren, 1910 and Leucognatha acoreensis Wunderlich, 1992}

According to Kuntner (pers. comm.), Leucognatha Wunderlich, 1992 is a junior synonym of Sancus, and Leucognatha acoreensis Wunderlich, 1992 from the Azores must be 
called Sancus acoreensis. The only other congeneric species, S. bilineatus Tullgren, 1910, occurs in East Africa, at Mount Kenya. Sancus acoreensis is widely spread all over the Azores, mainly in native habitats, but has not been reported by Denis (1964) just like many other currently known endemic species. While one cannot exclude the possibility of a historical human introduction, this species may be considered as a genuinely Azorean endemic species.

\section{Distribution}

Azores: Flores, Faial, Pico, Terceira, São Miguel and Santa Maria (new to São Jorge).

\section{LINYPHIIDAE}

Linyphiidae are small spiders buiders of sheet webs. This is the spider family most richly represented in the Azores; 36 species are reported, 3 species are reported from the subfamily Linyphiinae, 11 from Micronetinae and 22 from Erigoninae. We give two keys to selected taxa of this family.

\section{Determination}

In the small to tiny Erigoninae the number of leg bristles is reduced: femora, tibia laterally and metatarsi lack bristles, in contrast to the Linyphiinae and most Micronetinae (in $\mathrm{Mi}$ croneta, and some Agyneta species of the Micronetinae also, femoral and metatarsal bristles - in some species even lateral tibial bristles - are absent as in the Erigoninae). Several male Erigoninae possess outgrowths or lobes of the prosoma; an epigynal scapus is absent in this subfamily.

Key to the Azorean genera of the subfamilies Linyphiinae and Micronetinae:

1 Femoral bristles absent .................. 2

- Femoral bristles present ................. 4

2(1) Metatarsi with a dorsal bristle.

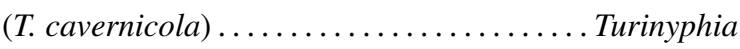

- Metatarsal bristles absent .................... 3

3(2) Male: Tibia of the pedipalpus apically with a transverse row of long and bristle-shaped hairs. Female: Epigynal scapus narrow posteriorly. (M. viaria)........Microneta

- Male: Pedipalpal tibia without such hairs. Female: Scapus wide posteriorly ............... Agyneta s.l.

4(1) Male: Embolus very long and thin, strongly sclerotised (black). Female: Posterior epigynal margin with an outgrowth (parmula), anterior epigynal outgrowth (scapus) absent. (M. johnsoni) ............... Microlinyphia

- Male: Embolus wide, weakly sclerotised (transparent). Female: Epigyne with a larger free opening (Porrhomma) or with a large scapus as in Fig. 8c (Lepthyphantes) ...................... 5

5(4) Metatarsal bristles absent. Lateral cheliceral stridulatory files absent but stridulatory files of coxa I present (Fig. 3b). Male-pedipalpus (Fig. 3d): Paracymbium tooth-less. Female: Epigyne with a distinct free opening, scapus absent. (P. borgesi, a forest spider with small eyes, Fig. 3a)..........................Porrhomma

- Metatarsal bristles present. Lateral cheliceral files
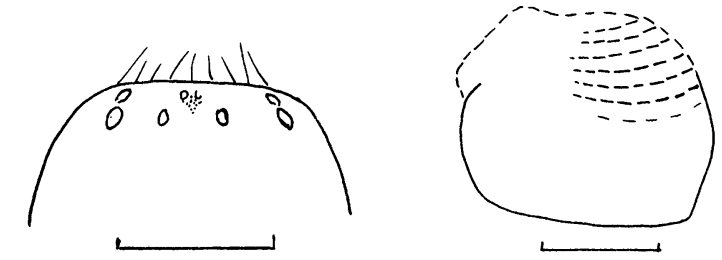

$\boldsymbol{a}$

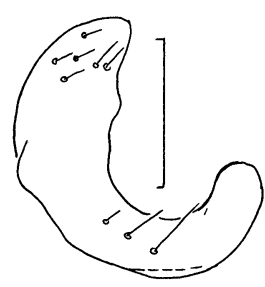

b

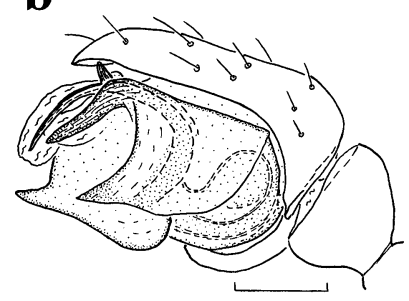

C

d
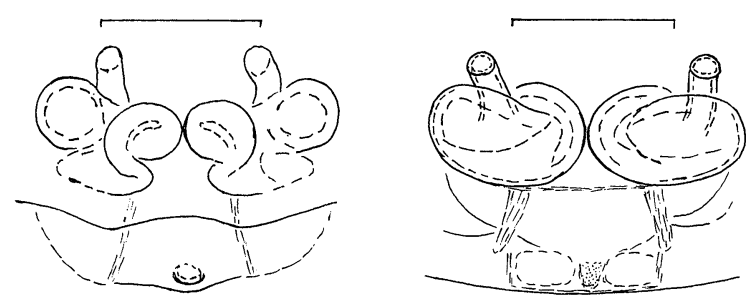

e

f

Figure 3 Porrhomma borgesi Wunderlich sp. nov., Male: (a) position of the eyes; (b) r. coxa I, retrolateral aspect. Note the field of stridulatory files; (c) paracymbium of the r. pedipalpus, retrolateral aspect; (d) r. pedipalpus, prolateral aspect; Female: (e) epigyne; (f) dorsal aspect of the vulva. bar $=0.2 \mathrm{~mm}$ in Fig. a, $0.1 \mathrm{~mm}$ in the remaining Figs.

present, coxal files absent, paracymbium with at least one tooth, epigyne with a large scapus as in

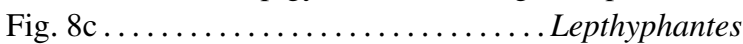

\section{LINYPHIIDAE: LINYPHIINAE \\ Porrhomma Simon, 1884}

This holarctic genus is new to the Azores and the Macaronesian Islands. Numerous species of Porrhomma are cave dwellers; frequently they are weakly pigmented and possess reduced eyes. $P$. borgesi sp. nov. is weakly pigmented and possesses reduced eyes but it is a forest dweller that occurs also in a volcanic pit (see Fig. 3a). The epigean P. pygmaeum (Blackwall, 1834) is one of the rarer species which have large eyes. The stridulatory files of coxa I (usually weaker on II) is an apomorphic character of Porrhomma; such files are strongly reduced or even absent in $P$. pygmaeum. The absence (loss) of stridulatory cheliceral files is another apomorphic character of this genus.

Porrhomma borgesi Wunderlich sp. nov. (Fig. 3)

\section{Derivatio nominis}

The species is named after Paulo Borges who discovered this and many other new species in the Azores. 


\section{Material}

HOLOTYPE Male: Azores, Terceira, Mistérios Negros B (Transect 8), September 1997, pitfall sample ET12 (Alvaro Vitorino \& P.A.V. Borges, leg.); same locality, but June 1997, 1 male paratype (Alvaro Vitorino \& P.A.V. Borges, leg.); Lagoa do Pinheiro (Transect 10), August 1999, pitfall sample TU09, 1 female paratype (Catarina Melo \& P.A.V. Borges, leg.); Caldeira da Serra de Santa Bárbara (Transect 60), July 2001, pitfall sample TU19, 1 female paratype (P.A.V. Borges et al., leg.); Algar do Carvão, 25th November 1999, 1 subad. male paratype (Fernando Pereira \& P.A.V. Borges, leg.). All material is deposited at the University of the Azores ('Arruda Furtado' Collection).

\section{Diagnosis}

Pale spiders, eyes distinctly reduced (Fig. 3a), position of the trichobothrium on metatarsus $\mathrm{I}$ in 0.4 , femoral bristles: I-II bear a dorsal one, I an additional prolateral one. Malepedipalpus (Figs. 3c-d) as in P. pygmaeum, embolus fairly bent and slender, velum indistinct, tip of the embolus near to the dorsal apophysis.

\section{Description}

Measurements (in mm): Body length 1.7-1.8 (2.0 in the female), prosoma: length $0.9-0.95$, width $0.6-0.65$, largest diameter of an posterior median eye 0.02 , leg I: femur 0.65 , patella 0.22 , tibia 0.65 , metatarsus 0.55 , tarsus 0.42 , tibia IV 0.7 .

Colour yellow to light brown, without darkenings. - Prosoma: caput fairly convex, with few hairs, thoracal fissure indistinct, eyes (Fig. 3a) small to tiny, widely spaced, posterior medians largest, lenses of the anterior median eyes absent or almost absent. Chelicerae fairly large, stridulatory files absent, anterior margin with 3, posterior margin with 5 teeth. Legs only fairly long, IV longest, stridulatory files of coxa I (Fig. 3b) well developed. Bristles long, all tibiae bear 2 dorsally, I an additional distal-lateral pair, II a single distallyretrolaterally; femora: see above; metatarsi bristle-less. Trichobothrium absent on metatarsus IV, its position on metatarsus I in 0.4. - Opisthosoma oval. - Male pedipalpus (Figs. 3c-d) as in $P$. pygmaeum (see above), patella with a thin dorsal bristle. Epigyne (Fig. 3e) with a well visible vulva structures, width of the opening almost $0.1 \mathrm{~mm}$. Vulva (Fig. 3f) (very similar to $P$. pallens) with large introducing ducts which are touching medially and widely separated primary and secondary receptacula.

\section{Ecology}

Most specimens were collected by means of pitfall traps, located deep inside very humid laurel forests on Terceira, Pico and São Miguel. One specimen was captured in a volcanic pit (Algar do Carvão at Terceira). In most sites the terrain is basaltic, with a system of cracks and deep holes and the forest floor is covered by a dense carpet of mosses and ferns with little light reaching the ground. However, some specimens were also collected in high altitude natural grassland and in a Cryptomeria japonica plantation in Terceira.

\section{Relationships}

According to the chaetotaxy as well as the relatively short legs, P. pygmaeum (Blackwall, 1834) and P. pallidus Jackson, 1913 (both have a palaearctic distribution and are epigeic species) are the most strongly related species. In contrast to $P$. borgesi both have strongly reduced stridulatory files of the coca I-II. $P$. pygmaeum has large eyes and is well pigmented, its pedipalpal structures are identic, the vulva is different; in P. pallidus, which also has a pale colour and reduced eyes, the embolus is less bent and the vulva is very similar.

\section{Distribution}

Azores: Terceira, Pico and São Miguel.

Turinyphia Van Helsdingen, 1982

\section{Revised diagnosis}

Leg bristles: Femoral and patellar ones absent, tibia I with lateral and dorsal but without ventral ones, usually all metatarsi with a dorsal bristle (according to Schenkel, 1938 it is absent in T. maderiana), thoracal fissure strongly reduced to absent. Bulbus small, lamella characteristica absent, embolus sickleshaped, epigyne simple, with an unfolded scapus.

\section{Type species}

Linyphia clairi Simon, 1884.

\section{Relationships}

A member of the Linyphiinae. In Plesiophantes Heimer, 1981, which JW (see also Wunderlich, 1987) regarded as a senior synonym of Turinyphia, a bristle of femur I, a basal hook of the chelicerae and a lamella characteristica are present, and the embolus is more slender (see Wunderlich, 1995, p. 413). In Frontiphantes Wunderlich, 1987 (Madeira) a long thoracal fissure and a prolateral bristle of femur I are present.

\section{Distribution}

Palaearctic: Southern Europe (T. clairi (Simon, 1884)), Madeira (T. maderiana (Schenkel, 1938)) and Azores (T. cavernicola Wunderlich sp. nov.); Japan: T. yunohamensis (Bösenberg \& Strand, 1906). Turinyphia species - like Frontiphantes and Plesiophantes - may well be relict taxa and palaeoendemics; most species survived in mountain areas, several species survived on islands.

\section{Turinyphia cavernicola Wunderlich sp. nov. (Fig. 4)}

\section{Material}

HOLOTYPE, male and 3 juv. paratypes: Azores, Terceira, Algar do Carvão, 25th November 1999 (F. Pereira \& P.A.V. Borges leg.); same locality but 19-25 November 1999, 5 juv. paratypes (F. Pereira \& P.A.V. Borges leg.); same locality but 10-16 August 1999, 1 juv. paratype (F. Pereira \& P.A.V. Borges leg.); same locality but 29 December 1999 to 5 January 2000, 5 juv. paratypes (F. Pereira \& P.A.V. Borges leg.). All material is deposited at the University of the Azores ('Arruda Furtado' Collection).

\section{Derivatio nominis}

The species is named after its preferred cavernicolous habitat. 

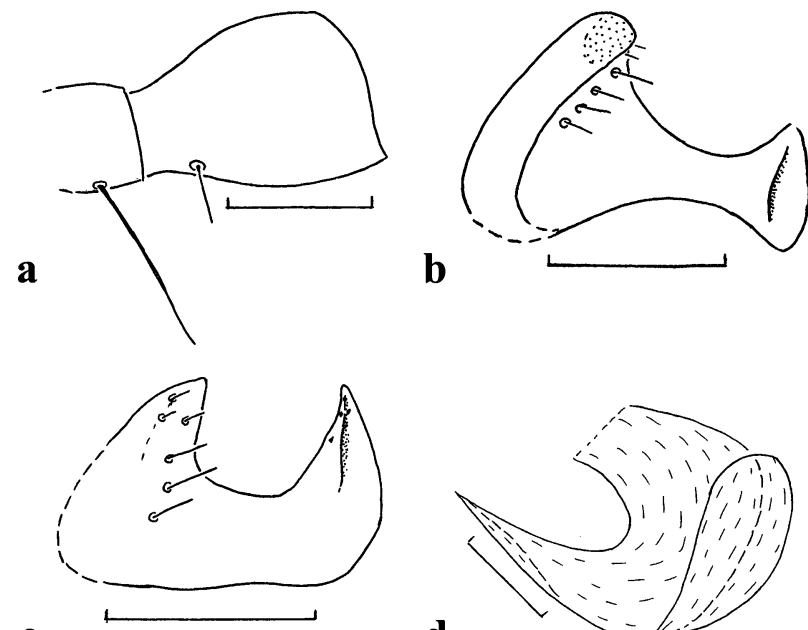

C

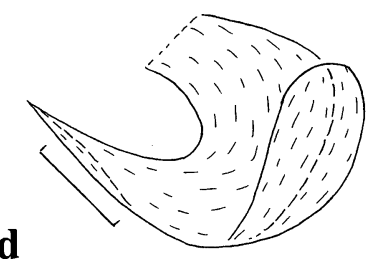

Figure 4 Turinyphia cavernicola Wunderlich sp. nov., Male; (a) patella and tibia of the r. pedipalpus, dorsal aspect; $(b-c)$ paracymbium of the r. pedipalpus, retrodorsal and retrolateral aspect; (d) embolus of the r. pedipalpus, ventral aspect; bar $=0.05 \mathrm{~mm}$ in Fig. $\mathrm{d}, 0.1 \mathrm{~mm}$ in the remaining Figs.

\section{Diagnosis (male; female unknown)}

Pale spiders with long legs and large eyes. Male pedipalpus (Fig 4): tibia with a single trichobothrium only, paracymbium with a tooth-shaped distal hook, embolus basally wide.

\section{Description (male)}

Measurements (in $\mathrm{mm}$ ): Body length 2.0, prosoma: length 0.95 , width 0.85 , leg I: femur 1.8 , patella 0.35 , tibia 1.7 , metatarsus 1.75 , tarsus 1.05 , tibia IV 1.5 .

Colour of prosoma and legs pale, yellow, sternum and opisthosoma (more distinct distally) medium grey; black pigment around the eye lenses. - Thoracal fissure absent, eyes large, posterior row recurved, posterior median eyes separated by 0.4 diameters. Chelicerae slender and slightly diverging, lateral files fairly distinct, anterior margin with 3 large teeth, posterior margin smooth. - Legs long and slender; bristles thin, femora, patellae and tarsi bristle-less, tibiae with 2 dorsal bristles, I with an additional distal pair, II-IV bear a retrolateral one in the distal half. Trichobothrium on metatarsus IV absent, its position on metatarsus I in 0.15. - Opisthosoma slender, covered with short hairs. - Male pedipalpus (Fig. 4; see above) patella short, with a longer bristle, tibia fairly short, with a single trichobothrium.

\section{Ecology}

All specimens are known from a single volcanic pit, Algar do Carvão in Terceira. The species builds webs across small holes in volcanic basaltic rock.

\section{Relationships}

In T. maderiana and T. clairi the tibia of the male pedipalpus bear 3 trichobothria; in $T$. clairi the pedipalpal tibia is longer than the cymbium, in $T$. maderiana metatarsal bristles are absent, in both species the paracymbium is elongated basally. Embolus of T. maderiana: Fig. 5.

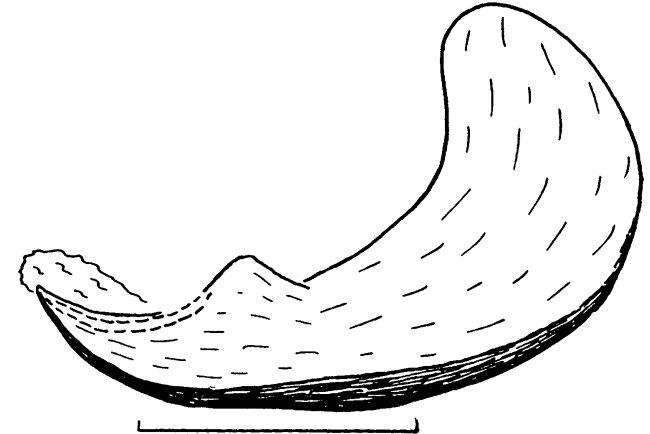

Figure 5 Turinyphia maderiana (Schenkel, 1938) from Madeira, Male, embolus and conductor (distally) of the $r$. pedipalpus, ventral aspect; bar $=0.05 \mathrm{~mm}$.

\section{Distribution}

Azores: Terceira.

\section{LINYPHIIDAE: MICRONETINAE Agyneta Hull, 1911}

We regard Agyneta in a wide sense, including Meioneta Hull, 1920. The intraspecific body colour is very variable in this genus. Four species of this genus were reported earlier from the Azores, a fifth species is described below.

Key to the Azorean species of Agyneta:

1 Position of the trichobothrium on metatarsus I near the end of the article, in c. 0.9. A widely spread species ......................... decora

- Position of the trichobothrium on metatarsus I in the basal half $\ldots \ldots \ldots \ldots \ldots \ldots \ldots \ldots \ldots \ldots \ldots \ldots \ldots \ldots \ldots \ldots$

2(1) Genital organs as in Fig. 6, cymbium not elevated....A. depigmentata sp. nov.

- Genital organs different, cymbium elevated (e.g. Fig. 7) ........................... 3

3(2) Male: lamella characteristica wide, dorsally strongly convex. Female: pedipalpus: femur and patella light in contrast to the black tarsus and tibia. A widespread species........................ rurestris

- Male: Lamella characteristica more slender. Female: pedipalpus unicoloured $\ldots \ldots \ldots \ldots \ldots \ldots \ldots \ldots$

4(3) Male: basal cymbial outgrowth undivided, lamella characteristica fairly slender, apically claw-shaped. Female: epigynal scapus wider than long. A widespread species .................. fuscipalpis

- Male: basal cymbial outgrowth bilobed (Fig. 7), lamella characteristica slender, apically not claw-shaped. Female: epigynal scapus as wide as long (see Wunderlich, 1992: Figs. 376, 378) ................. rugosa

Agyneta (Meioneta) depigmentata Wunderlich sp. nov. (Fig. 6)

\section{Material}

HOLOTYPE, male and 3 juv. paratypes: Azores, Flores, Morro Alto Este (Transect 8) July 1999, pifall sample T29 (Clara Gaspar \& P.A.V. Borges leg.); same locality and date but pifall sample T27, 1 female paratype (Clara Gaspar \& P.A.V. Borges leg.); Ribeira da Fazenda (Transect 4) July 1999, pitfall sample 

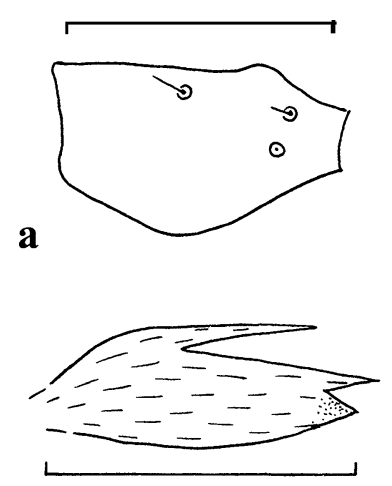

c
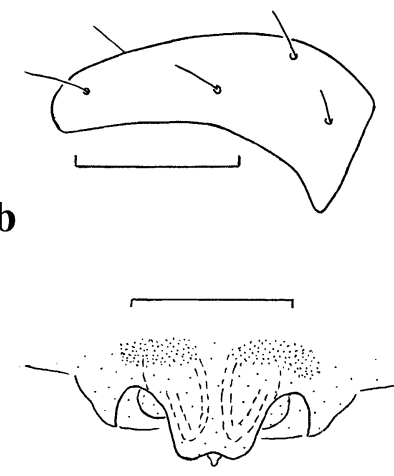

d

Figure 6 Agyneta depigmentata Wunderlich sp. nov., Male: (a) tibia of the r. pedipalpus, dorsal aspect; (b) cymbium of the $r$. pedipalpus, prolateral aspect; (c) lamella characteristica of the r. pedipalpus, retrolateral-ventral aspect; (d) female, epigyne; bar $=0.1 \mathrm{~mm}$.

TU03, 2 females paratypes (Clara Gaspar \& P.A.V. Borges leg.); same locality and date, but pitfall sample ET10, 1 male without opisthosoma paratype and 3 juveniles (Clara Gaspar \& P.A.V. Borges leg.); same locality and date, but pitfall sample TU11, 1 female paratype and 5 juveniles (Clara Gaspar \& P.A.V. Borges leg.). All material is deposited at the University of the Azores ('Arruda Furtado' Collection).

\section{Derivatio nominis}

The species name is based on its pale (depigmented) colour.

\section{Diagnosis}

Pale (depigmented) spiders, position of the trichobothrium on metatarsus I in $c$. 0.4. Male: pedipalpus (Figs. 6a-c): no cymbial outgrowth, bulbus small, lamella characteristica threepointed. Female: epigyne small, as in Fig. 6d, only slightly protruding.

\section{Description}

Measurements (in mm): body length: male 1.1, female 1.7; prosoma (male, female): Length 0.65 , width 0.55 , leg I (male): femur 0.65 , patella 0.2 , tibia 0.68 , metatarsus 0.53 , tarsus 0.42 , tibia IV 0.7; female: tibia I 0.68, tibia IV 0.7.

Colour pale (depigmented), eye region, sternum and opisthosoma ventrally dark grey, female pedipalpus yellow. Prosoma with an indistinct thoracal fissure, eyes large, as in $A$. rugosa Wunderlich, 1992. Male chelicerae diverging but not excavated medially; anterior margin with 4-6 teeth, posterior margin with few small teeth. Female pedipalpus slender. Legs slender, bristles as in A. rugosa except the retrodistal one on metatarsus IV which is absent. Trichobothrium on metatarsus IV absent, its position on metatarsus I in 0.4-0.43. Male pedipalpus (Figs. 6a-c): cymbial outgrowth absent, paracymbium toothless, bulbus small, lamella characteristica three-pointed. Epigyne as in Fig. 6d, scapus small, fairly wide and only slightly protruding.

\section{Relationships}

In the European A. (Meioneta) mollis (O. Pickard-Cambridge) the lamella and the epigynal scapus are slender/narrow.
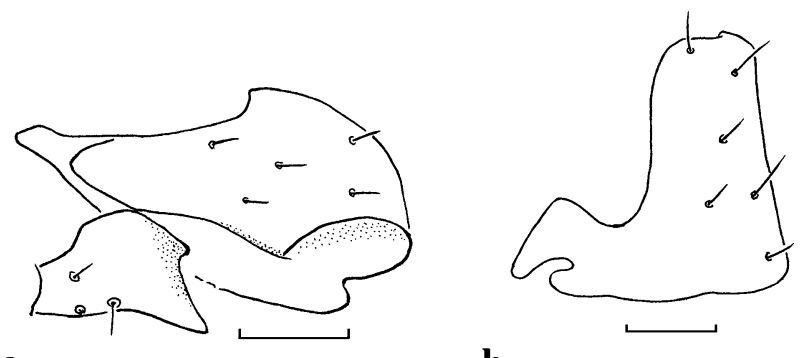

b

Figure 7 Agyneta rugosa Wunderlich 1992, Male: (a) tibia and cymbium of the r. pedipalpus, dorsal aspect; (b) cymbium of the r. pedipalpus, prolateral aspect; bar $=0.1 \mathrm{~mm}$.

\section{Ecology}

The spiders live in native Juniperus brevifolia forest with the soil covered with dense Sphagnum spp. mire, in the higher altitude central plateau of Flores island. It is also common in high altitude natural grassland dominated by native and endemic vascular plants and also bryophytes.

\section{Distribution}

Azores: Flores.

Agyneta rugosa Wunderlich, 1992 (Fig. 7)

\section{Material}

Azores: Faial, Cabeço do Fogo (Transect 2), September 1999, Pitfall sample TU03; 1 male (P.A.V. Borges et al. leg.). Deposited at the University of the Azores ('Arruda Furtado' Collection).

\section{Remarks}

(1) In contrast to the type material, the colour of the specimen from Faial is pale light grey, and a light spot above the spinnerets is absent. (2) Male pedipalpal tibia and cymbium: see Figs. 7a-b. (3) The species may be more closely related to European than to North American species.

\section{Ecology}

Collected in a pitfall trap with TURQUIN attractant in a secondary Juniperus brevifolia - Erica azorica native forest.

\section{Distribution}

Azores: São Miguel and Faial (new to Faial).

\section{Lepthyphantes (Palliduphantes) cf. schmitzi Kulczynski,} 1899 (Fig. 8)

\section{Material}

Açores: Flores, near Santa Cruz, 2 female JW leg. in VII, coll. JW.

\section{Remark}

The determination of the Azorean specimens is unsure (see Wunderlich, 1992, p. 22). JW does not want to exclude the possibility that these females are members of an as yet undescribed endemic Azorean species. Epigyne in three aspects: see Figs 8a-c. 


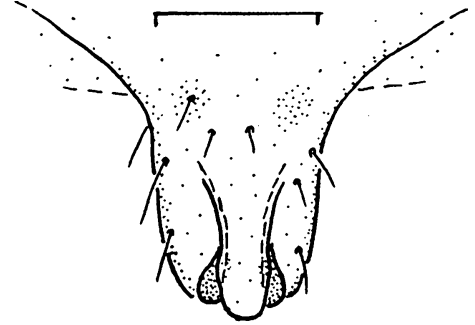

$\mathbf{a}$

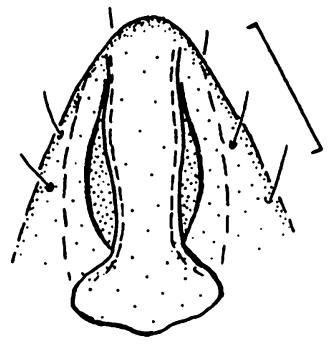

b

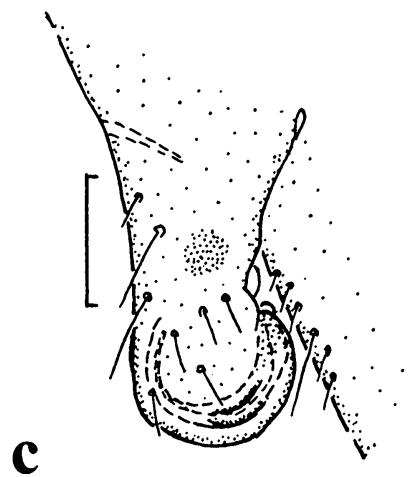

Figure 8 Lepthyphantes? schmitzi Kulczynski, 1899, Female, epigyne, ventral (a) posterior (b) and lateral aspect (c); bar $=0.2 \mathrm{~mm}$.

\section{Distribution}

Azores, all islands except Corvo (new to São Jorge and Santa Maria).

\section{LINYPHIIDAE: ERIGONINAE Acorigone Wunderlich gen. nov}

\section{Diagnosis}

Male with a stridulatory organ between coxae IV and lung covers as in Diplocentria Hull, 1911 (similar to Fig. 9). Prosoma low (clypeus short), chelicerae large, anterior margin with long teeth (Fig. 10b). Sequence of the tibial bristles 2/2/2/1. Trichobothrium on metatarsus IV present (A. zebraneus sp. nov.) or absent (A. acoreensis, new combination). Male pedipalpus (Figs 10c-f): tibia with a ventral apophysis, cymbium with distal bristles, embolus short. The epigyne (Figs $10 \mathrm{~g}-\mathrm{j}$ ) is a wide plate.

\section{Type species}

Acorigone zebraneus gen. nov. et sp. nov. Further species: Acorigone acoreensis (Wunderlich, 1992).

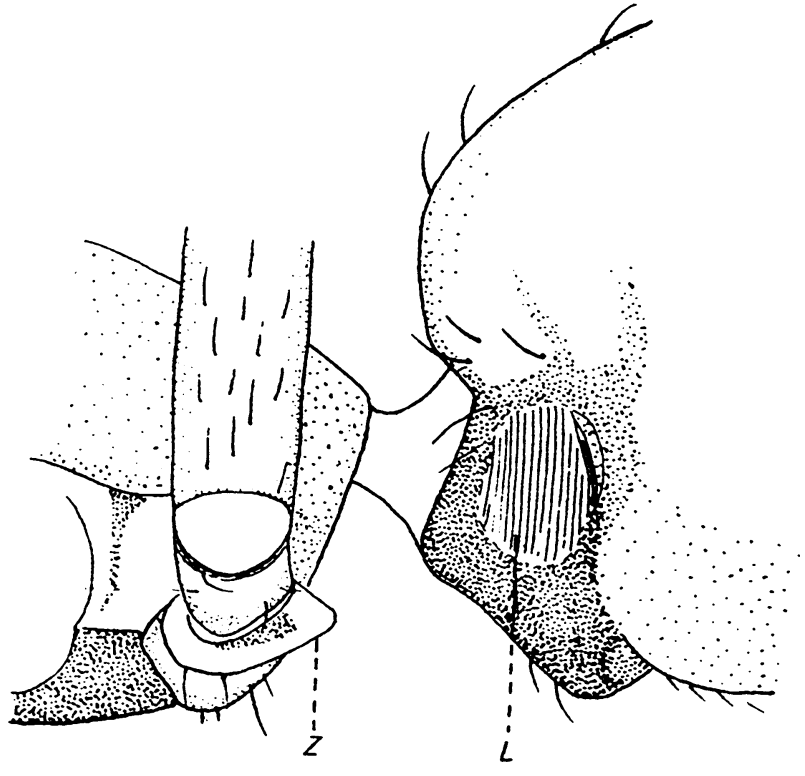

Figure 9 Diplocentria bidentata (Emerton, 1882) (Linyphiidae: Erigoninae) from Europe, left lung cover (L) with stridulatory files and a stridulatory tooth on the left IV coxa (Z) similar to the Azorean genus Acorigone Wunderlich gen. nov. Taken from Wiehle (1960, fig. 787).

\section{Relationships}

According to the genital structures Erigone Audouin (cosmopolitical) and Eperigone Crosby \& Bishop (Nearctic Region) may be most closely related. In these genera stridulatory files of the lung covers are absent, the clypeus is long, denticles of the prosomal margin, the chelicerae and the pedipalpal femur are usually present at least in Erigone, and there is usually a pedipalpal patellar outgrowth in Erigone. In Diplocentria Hull - in which stridulatory files are present on the lung covers (Fig. 9) as in Acorigone - the shape of the paracymbium and the bulbus structures are quite different to Acorigone; apparently their coxal-opisthosomal stridulatory organs evolved convergently.

\section{Distribution}

Azores.

Acorigone zebraneus Wunderlich sp. nov. (Fig. 10)

\section{Material}

HOLOTYPE male: Azores, São Jorge, Topo (Transect 12), August 2000, pitfall sample TU05 (P.A.V. Borges et al., leg.); same locality and date, but pitfall sample TU25, 1 female paratype (P.A.V. Borges et al., leg.). Deposited at the University of the Azores ('Arruda Furtado' Collection).

\section{Derivatio nominis}

The species is named based on markings of the opisthosoma, displaying a distinct yellow dorsal pattern with dark grey stripes.

\section{Diagnosis}

Prosomal length $0.7-0.75 \mathrm{~mm}$, trichobothrium present on metatarsus IV, its position on metatarsus I in 0.9, malepedipalpus as in Figs 10c-f, epigyne as in Figs $10 \mathrm{~g}-\mathrm{j}$. 

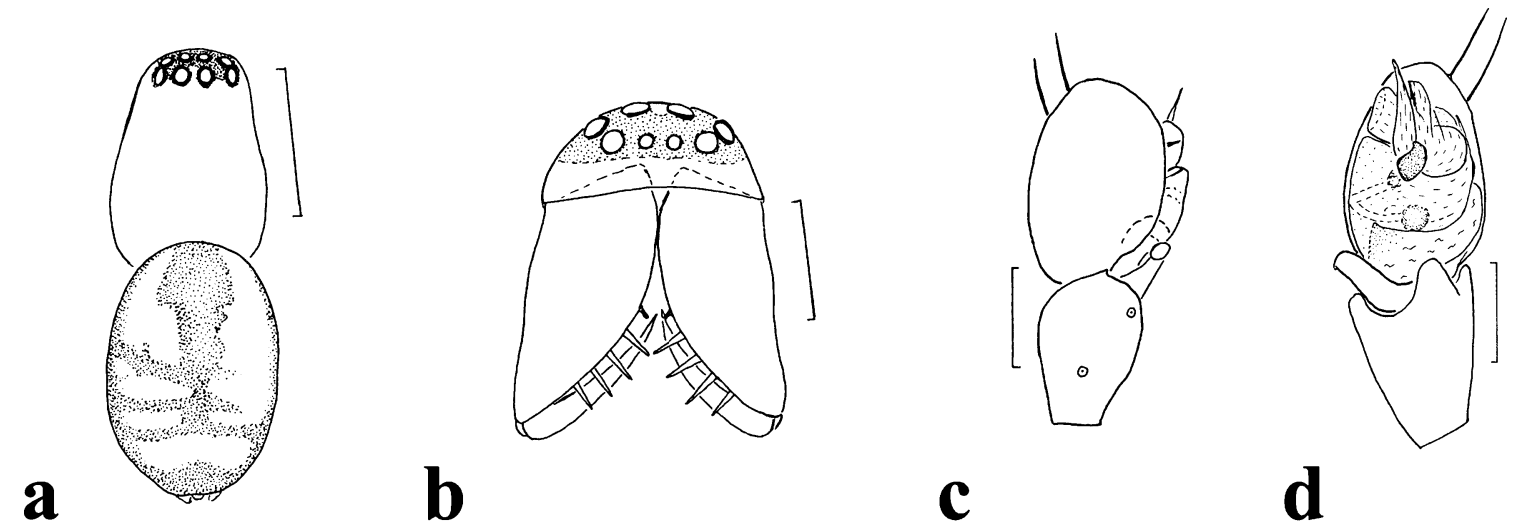

b
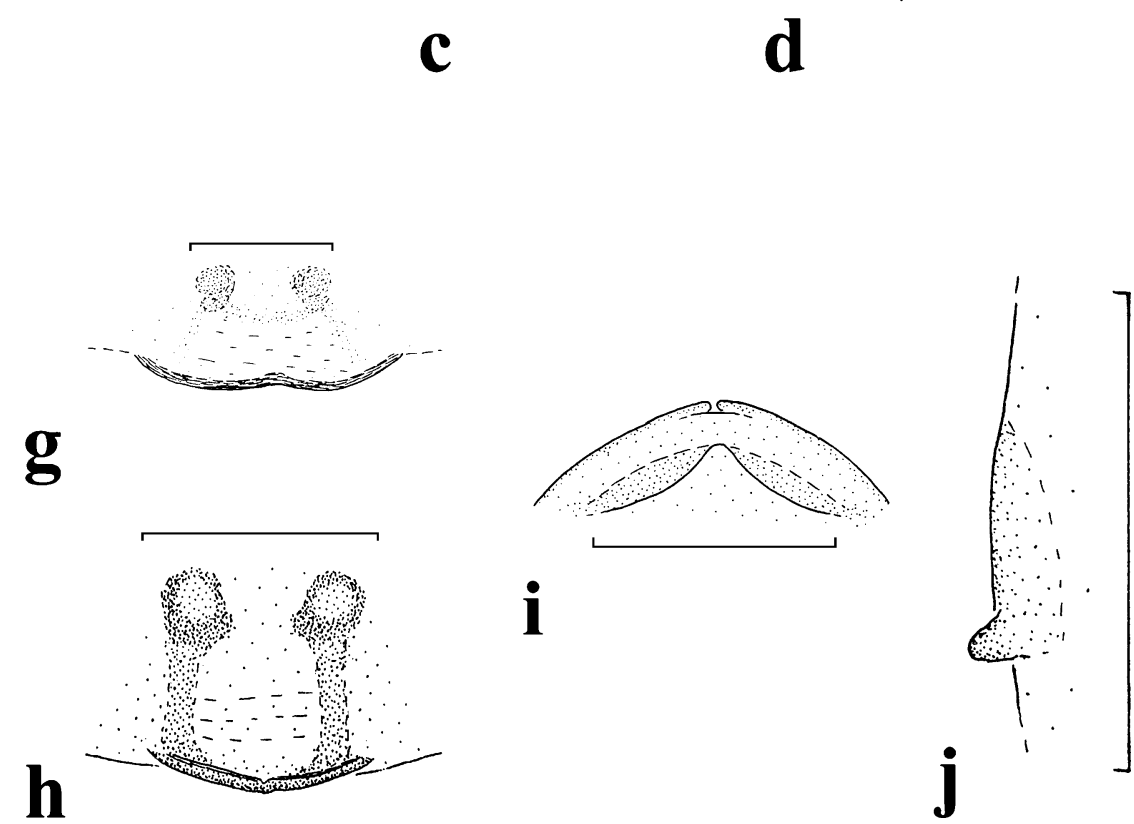

Figure 10 Acorigone zebraneus Wunderlich sp. nov.; Male: Figs (a, c-f), Female: Figs (b, g-j); (a) dorsal aspect of the body; (b) anterior aspect of the prosoma; (c-f) r. pedipalpus, dorsal, ventral, retrolateral and prolateral aspect; (g-h) ventral aspect of the epigyne showing its variability; (i) posterior aspect of the epigyne; (j) outline of the epigyne; bar $=0.5$ in Fig. a, $0.2 \mathrm{~mm}$ in Fig. b, $0.1 \mathrm{~mm}$ in the remaining Figs.

\section{Description}

Measurements (in mm): Body length: male 1.25, female 1.4; prosoma: length in male 0.7 , in female 0.75 , width in male 0.5 , in female 0.55 , leg I male (female): femur $0.6(0.62)$, patella $0.2(0.22)$, tibia $0.5(0.6)$, metatarsus $0.52(0.53)$, tarsus $0.32(0.33)$, tibia IV $0.7(0.72)$.

Colour: Prosoma and legs yellow to yellow brown, eye field and sternum dark grey, opisthosoma dorsally with distinct yellow and dark grey stripes (Fig. 10a), ventrally predominantly yellow.

Prosoma: The male prosoma is somewhat deformed (Figs 10ab), long, margin smooth, thoracal fissure indistinct, eyes fairly large, posterior row straight, anterior medians smallest, posterior medians separated by almost one diameter. Chelicerae large, lateral files fairly distinct, anterior margin with 5 large teeth, posterior margin with $4-5$ teeth. - Female pedipalpus long and spiny. - Legs fairly long, hairy. Sequence of the thin dorsal tibial bristles $2 / 2 / 2 / 1$. The male oax IV bears a distinct and pointed stridulatory outgrowth. Position of the metatarsal trichobothrium on I in 0.9 , on IV in $0.81-0.84$. - Opisthosoma oval, scarcely covered with short hairs. Lung covers very large, basally with stridulatory files in the male. Female: the epigyne (Figs $10 \mathrm{~g}-\mathrm{h}$ ) is a wide plate, its posterior margin is bulging. Epigyne variability is shown in Fig. 10h. Male pedipalpus (Figs 10c-f): patella slightly longer than wide, tibia with two trichobothria, pointed disto-apically, with two ventral apophyses; cymbium with two prodistal bristles, paracymbium short, embolic division with three projections, embolus small.

\section{Ecology}

All specimens were collected with pitfall traps in high altitude native forest dominated by Ilex perado ssp. azorica, Juniperus brevifolia and Vaccinium cylindraceum. The forest ground is dominated by native grasses and bryophytes.

\section{Relationships}

In the smaller A. acoreensis (Wunderlich, 1992) (see below), the opisthosoma is unicoloured, the posterior eye row is procurved, a trichobothrium on metatarsus IV is absent, its position on metatarsus $\mathrm{I}$ is in $c$. 0.5 , most leg articles (except femora, especially tibiae) are dark grey in both sexes, the genital structures are different. 


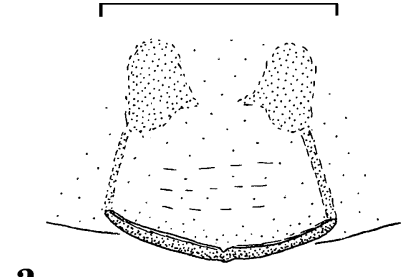

a

Figure 11 Acorigone acoreensis Wunderlich sp. nov., Female, epigyne, ventral (a) and posterior (b) aspect; bar $=0.1 \mathrm{~mm}$

\section{Distribution}

Azores: São Jorge.

Acorigone acoreensis (Wunderlich, 1992) (comb. nov.) (Fig. 11)

1992 Diplocentria acoreensis Wunderlich, Beitr. Araneol., 1: 387, figs. 446-448.

\section{Revised diagnosis}

Prosomal length c. $0.55 \mathrm{~mm}$, trichobothrium on metatarsus IV absent, its position on metatarsus I in $0.5-0.61$, legs dark grey in both sexes; male pedipalpus: see Wunderlich (1992: Figs 447-448), epigyne: Figs 11a-b.

\section{First description of the female and additional remark}

Measurements (in $\mathrm{mm}$ ): body length 1.15, prosoma: Length 0.57 , width 0.4 , leg I: femur 0.38 , patella 0.14 , tibia 0.3 , metatarsus 0.25 , tarsus 0.24 . Eyes and cheliceral teeth as in the male. A stridulatory outgrowth on coxa IV and files on the lung covers are absent. - Except for the femora, all leg articles (especially the tibiae) are dark grey in both sexes. The epigyne (Figs 11a-b) is an almost triangular plate, the posterior margin is strongly sclerotised, the receptacula seminis are visible as dark spots.

\section{Ecology}

This species is very common both in forest floor and canopy samples in native Laurisilva forests. In canopies it was sampled on several plants: Erica azorica, Ilex perado ssp. azorica, Juniperus brevifolia, Laurus azorica, Vaccinium cylindraceum and Myrsine africana.

\section{Relationships}

See above.

\section{Distribution}

Azores: Terceira and new to Flores, Faial, Pico, São Jorge and São Miguel.

\section{Minicia Thorell, 1875}

In the Canary Islands there exists a radiation in the genus Minicia. The previously known Macaronesian species were described/revised by Wunderlich $(1987,1992)$.

Species from the Canary Islands:

M. gomerae Schmidt, 1975: La Gomera, La Palma and probably El Hierro.
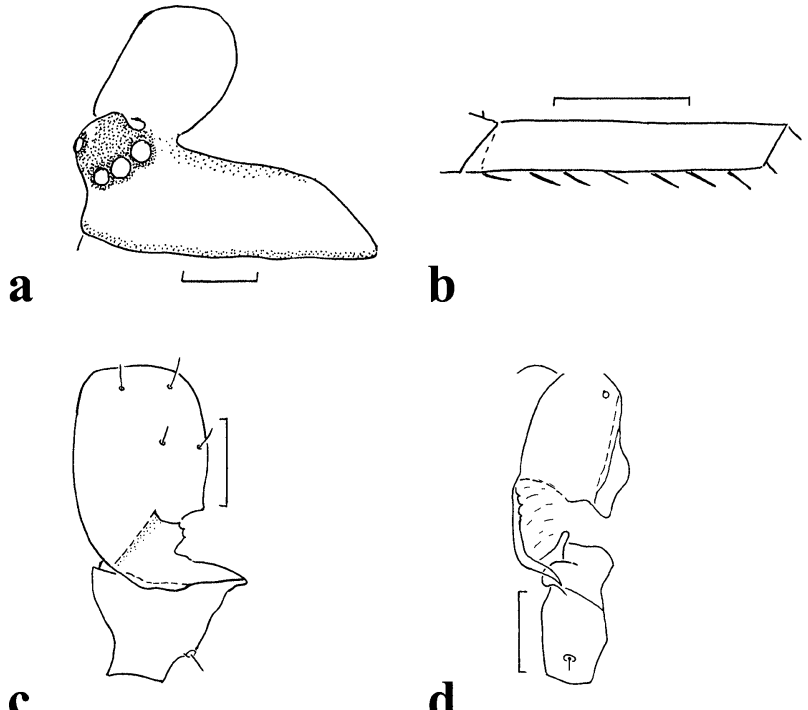

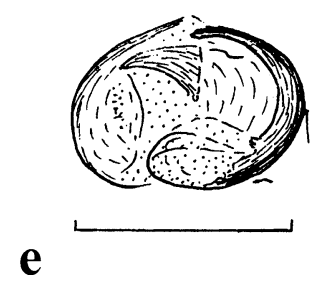

Figure 12 Minicia floresensis Wunderlich, 1992, Male: (a) prosoma, lateral aspect; (b) r. tibia I, tetrolateral aspect (hairs not drawn); (c-d) r. pedipalpus, tibia and cymbium, dorsal and retrolateral aspect; (e) r. embolic division, apical aspect; bar $=0.2 \mathrm{~mm}$ in Figs $a-b, 0.1 \mathrm{~mm}$ in the remaining Figs.

M. grancanariansis Wunderlich, 1987: Gran Canaria. M. tenerifensis (Wunderlich, 1979): Tenerife.

In the Azores two species from Flores (Minicia floresensis Wunderlich, 1992) and Pico (Minicia picoensis Wunderlich, 1992) were described, but specimens recently collected on other islands (Terceira, São Jorge and São Miguel) showed that there is only one species in the Azores with some intraand inter-population variability.

Minicia floresensis Wunderlich, 1992 (Fig. 12)

\section{New synonyms}

Minicia picoensis Wunderlich, 1992: Pico

1992 Minicia sp. indet. 2 sensu Wunderlich, Beitr. Araneol., 1: 393-394).

\section{Diagnosis}

Tibiae I-II bear two rows of ventral bristles, which are strongly developed in the female but weak in the male (Fig. 12b). Sequence of the dorsal tibial bristles 1/1/1/1 (rarely tibia I with 3 dorsal bristles). Metatarsus IV with a trichobothrium, its position on I in 0.9.0.95. Opisthosoma usually with dorsal markings. Male: prosomal lobes present, they are species-specific. Male pedipalpal tibia with three apophyses, cymbium with a long and pointed outgrowth which is directed backwards 
retrolaterally (Figs 12c-d). Apical aspect of male embolic division from a male from Terceira is shown in Fig. 12e. Female tibia I may bear 3 to 6 pairs of long ventral bristles.

This is a highly polymorphic species with some intraand inter-population variability in the male pedipalpus.

\section{Ecology}

The spiders live in the vegetation near the ground (e.g. Calluna vulgaris), but also in canopies of medium sized specimens of Erica azorica, Ilex perado ssp. azorica, Juniperus brevifolia, Laurus azorica, Vaccinium cylindraceum and Myrsine africana.

\section{Distribution}

Azores: Flores, Pico and new to São Jorge, Terceira and São Miguel.

Oedothorax fuscus (Blackwall, 1834)

2000 Oedothorax fuscus, - Açoreana, 9 (2): 131

\section{Ecology}

The spiders may be frequent on wet meadows near water (photobiont-hygrophil). However, they are more frequent in semi-natural and managed pastureland where they may be very abundant. Occasionally some specimens could be found in canopies of native and exotic trees as aeronautics.

\section{Distribution}

Palaearctic including the Azores: Santa Maria, Terceira, Pico and new to Flores, Faial, Graciosa, São Jorge and São Miguel (see also Appendix S1 which is available as 'Supplementary data' on Cambridge Journals Online: http://www.journals.cup.org/abstract_S1477200008002648).

\section{Walckenaeria Blackwall, 1833}

Several endemic species of the genus Walckenaeria occur in the Canary Islands (see Wunderlich, 1992), but only the European W. unicornis (O. Pickard-Cambridge, 1861) has been recorded in the Azores (Pico) (see Wunderlich, 1992, pp. 24-25). Below the first endemic species of this genus is reported from the Azores, a species, which erroneously was believed to be a member of the genus Savigniorrhipis; its male is described here for the first time.

The sequence of the tibial bristles in Walckenaeria is usually $2 / 2 / 1 / 1$ but $2 / 2 / 2 / 2$ in some species from the Canary Islands; in $W$. grandis the sequence is $1 / 1 / 1 / 1$ as in $W$. cyprusensis Wunderlich, 1995 from Cyprus, W. aebea Millidge 1983 from North America and in some African species. Distinct opisthosomal markings as in W. grandis (Fig. 13b) are quite unusual in Walckenaeria.

Walckenaeria grandis (Wunderlich 1992) (comb. nov.) (Figs 13a-d)

1992 Savigniorrhipis grandis Wunderlich, Beitr. Araneol., 1: 396, fig. 489 (female).

\section{Material}

HOLOTYPE male: Azores, Terceira, Lagoinha, Serra de Santa Bárbara (Transect 6), June 1999, pitfall sample TU11, (Clara Gaspar \& P.A.V. Borges leg.); same locality and date but pit-

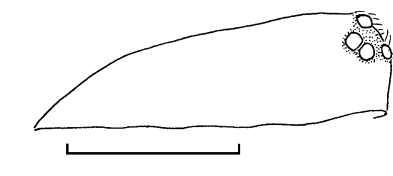

a

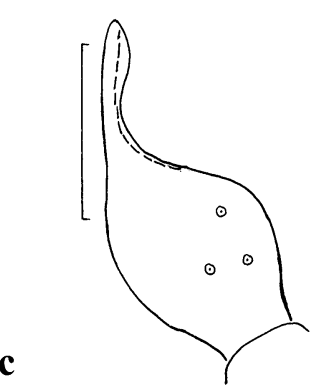

b
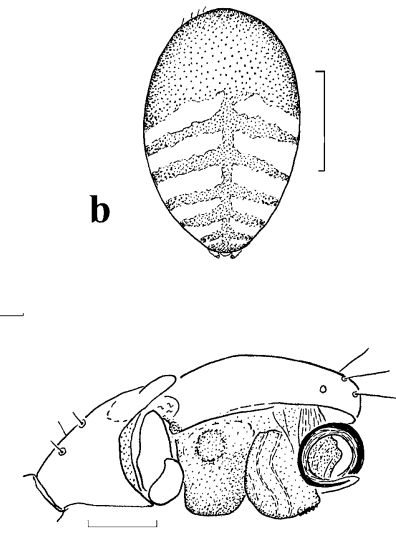

d
Figure 13 Walckenaeria grandis (Wunderlich, 1992), Male: (a) prosoma, lateral aspect; (b) opisthosoma, dorsal aspect; (c) tibia of the right pedipalpus, dorsal aspect; (d) r. pedipalpus, retrolateral aspect (only three cymbial hairs are drawn); bar $=0.5 \mathrm{~mm}$ in Figs $\mathrm{a}-\mathrm{b}, 0.1 \mathrm{~mm}$ in Figs $\mathrm{c}-\mathrm{d}$.

fall sample T17, paratype (Clara Gaspar \& P.A.V. Borges leg.); same locality and date but pitfall sample TU11, 1 female paratype (Clara Gaspar \& P.A.V. Borges leg.); São Jorge, Topo (Transect 12), August 2000, pitfall sample TU23, 1 male and 1 female paratype (P.A.V. Borges et al., leg.). Deposited at the University of the Azores ('Arruda Furtado' Collection).

\section{Diagnosis}

Sequence of the tibial bristles $1 / 1 / 1 / 1$, opisthosoma with transverse dorsal stripes (Fig. 13a), position of the metatarsal I trichobothrium in $0.6-0.65$.

\section{Description (of the male)}

Measurements (in mm): body length 1.7-2.1, prosoma: length $0.85-1.0$, width $0.65-0.75$, leg I: femur 0.8 , patella 0.25 , tibia 0.65 , metatarsus 0.5 , tarsus 0.4 , tibia IV 0.8 .

Colour: Prosoma and legs light to medium brown, opisthosoma (Fig. 13b) dorsally grey with dark grey transverse stripes, ventrally light grey. - Prosoma similar to the female, without a lobe. Legs fairly long, all tibiae with a single short dorsal bristle, their position on I-II in the basal half. The large tarsal claws bear long teeth as in other congeneric species. All metatarsi bear a trichobothrium, its position on $\mathrm{I}$ is in 0.6-0.65. - Opisthosoma (Fig. 13b) oval, covered with short hairs. - Pedipalpus (Figs 13c-d): patella fairly short, tibia with three trichobothria, the embolus describes a spiral of medium size.

Female: see Wunderlich (1992: 396, fig. 489).

\section{Ecology}

Although it occurrs in native forest floor, it is also frequent in high altitude natural grassland dominated by Azorean endemic grasses. The species was also collected in Juniperus brevifolia canopy.

\section{Relationships}

In the not closely related $W$. vigilax (Blackwall) from Europe, a prosomal lobe is absent; the pedipalpal tibial apophysis and the epigyne of $W$. vigilax are similar to $W$. grandis, but the sequence of the tibial bristles is $2 / 2 / 1 / 1$, the position of the 


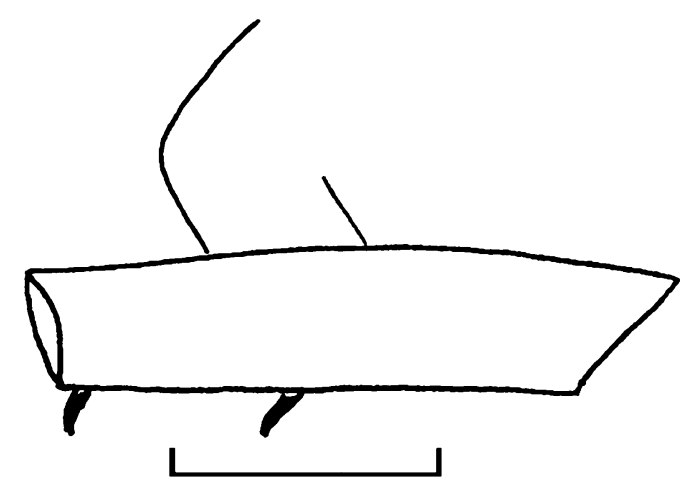

Figure 14 Argenna lucida (Simon, 1874), Male, r. metatarsus I, proventral aspect. Number ( $0-3)$ and position of the short ventral spines are quite variable; $b a r=0.1 \mathrm{~mm}$.

metatarsal I trichobothrium is near the middle of the article, the opisthosoma is dorsally uniformly dark grey and the spiral of the embolus is larger than in W. grandis.

\section{Distribution}

Azores: Terceira and new to Flores, Pico and São Jorge.

\section{DICTYNIDAE}

Argenna Thorell, 1869

JW regards Altella Simon, 1884 as a synonym of Argenna Thorell, 1869 (see Wunderlich, 2004: 1429), the Argenna lucida-group; see Platnick (1998: 641) (sub Altella).

\section{Remark}

In JW's opinion - according to its genital structures - Altella lathysoides Denis, 1937 from Algeria is a member of Lathys Simon ,1884 (comb. nov.)

Two species of the Argenna lucida group from the Canary Islands (Tenerife) are known from the female sex only: $A$. media (Wunderlich, 1992) and A. pygmaea (Wunderlich, 1992) (both sub Altella) (comb. nov.).

Argenna lucida (Simon, 1874) (comb. nov.) (Fig. 14)

In both sexes all tibiae bear a short dorsal-basal bristle as well as a long and strong mid-ventral bristle on tibia III (at least in the female there may be a pair of such bristles); the male metatarsus I bear 0,1 or 1.1 short proventral spine(s) (Fig. 14).

\section{Ecology}

It is found exclusively in Sphagnum spp. bogs at medium to high altitude on the Azores.

\section{Distribution}

Europe, including the Azores: Terceira (new to the Azores).

\section{CLUBIONIDAE}

\section{Cheiracanthium C. Koch, 1839}

Some recent authors place Cheiracanthium in the Miturgidae, but I (JW) agree with Deeleman-Reinhold (2001, p. 85), who regards this genus as a member of the Clubionidae (according to Deeleman-Reinhold (2001) as a member of the Eutichurinae).
In Cheiracanthium the thoracal fissure is strongly reduced or even absent, leg I is distinctly the longest, the cymbium has a retrobasal cymbial spur (Figs 15d and 16b), a small hook exists on the male coxa I (Fig. 15a). The structures of the bulbus are very similar or even identical in several species, e.g. in the species which are described below; the male chelicerae and the vulvae are more different.

C. erraticum (Walckenaer, 1802) and C. mildei C.L. Koch, 1864 were known from the Azores, C. canariense Wunderlich, 1987 is endemic to the Canary Islands, C. albidulum (Blackwall, 1859) is endemic to Madeira, C. floresense sp. nov. and $C$. jorgeense sp. nov. occur as island endemics in the Azores. These species are most closely related to the European C. seidlitzi C.L. Koch 1864; in C. seidlitzi the bulbous structures are as in $C$. floresense and $C$. jorgeense, but the cheliceral hump is more slender in $C$. seidlitzi and in a more distal position (comp. Figs 15b and 17).

Below the differences are presented in a key to related species.

Key to the west-palaearctic males of Cheiracanthium which possess a medial-basal cheliceral hump:

1 Opisthosoma dorsally unicoloured......... elegans

- Opisthosoma dorsally with a redbrown longitudinal

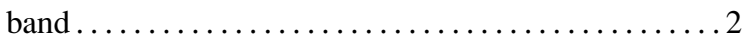

2(1) The opisthosomal band consists of patches in the posterior half. Retrolateral apical branch of the tibial apophysis longer than the prolateral branch ......... pelasgicum

- The opisthosomal band is usually contiguous. Both apical branches of the tibial apophysis equal in length (Fig.

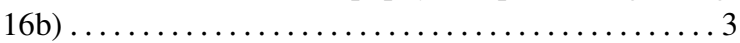

3(2) Medial cheliceral hump in a more basal position (Figs 15b-c). Azores . .................... 4

- Medial cheliceral hump in a more distal position, more slender (arrow in Fig. 17a). Vulva (Fig. 17b). S-Europe ................. seidlitzi

4(3) Dorsal cymbial surface concave (Fig. 15d). Epigyne/ vulva (Figs $15 \mathrm{f}-\mathrm{g}$ ) ................ floresense

- Dorsal cymbial surface straight (Fig. 16b), cymbial outgrowth thicker (Fig. 16b). Female unknown........ jorgeense

Cheiracanthium floresense Wunderlich sp. nov. (Fig. 15)

\section{Material}

HOLOTYPE male and 5 juveniles paratypes: Azores, Flores, Caldeira Funda, 13. VII. 1999, Ilex perado ssp. azorica sample IL07 (Clara Gaspar \& P.A.V. Borges leg.); same locality and date, but Ilex perado ssp. azorica sample IL10, 1 female and 4 juv. paratypes (Clara Gaspar \& P.A.V. Borges leg.). Deposited at the University of the Azores ('Arruda Furtado' collection).

\section{Derivatio nominis}

The species is named after the island Flores where it is an exclusive endemic.

\section{Diagnosis}

Opisthosoma with a long dorsal redbrown band which may be fragmented in the distal half in juveniles and widened in the 

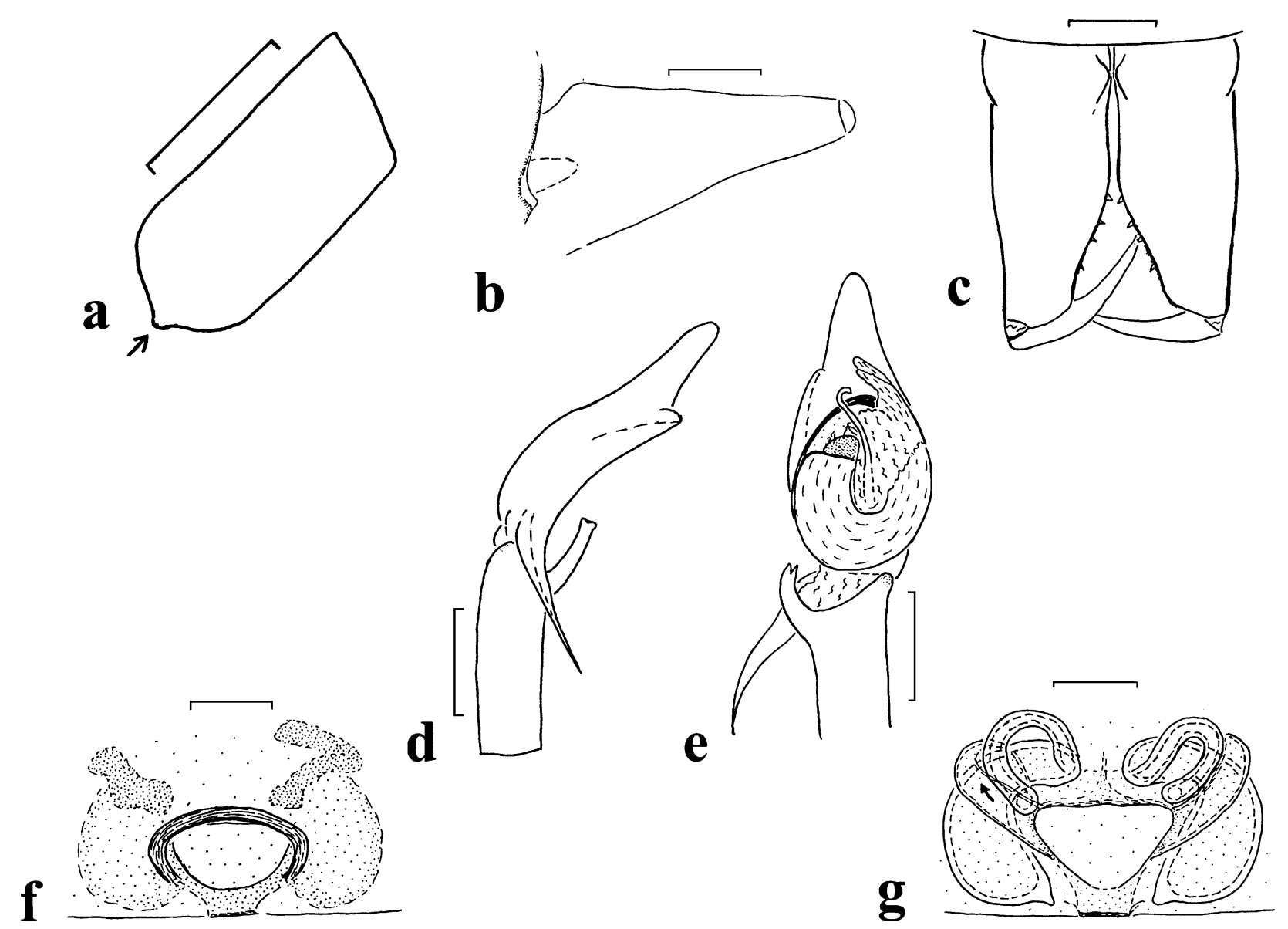

Figure 15 Cheiracanthium floresense Wunderlich sp. nov.; (a) male, ventral aspect of the l. coxa I. Note the coxal hook (arrow) which exists in males of Cheiracanthium; (b) male, retrolateral and slightly dorsal aspect of the r. chelicera (the shape is as in C. jorgeense sp. nov.); (c) male, anterior aspect of the chelicerae, (not all teeth are observable); (d) male, retrolateral and slightly dorsal aspect of tibia and cymbium of the r. pedipalpus; (e) ventral aspect of the male pedipalpus; ( $f$ ) female epigyne; $(\mathrm{g}$ ) ventral aspect of the vulva (the arrow indicates to the introducing opening); bar $=0.5 \mathrm{~mm}$ in Figs a-e, and $0.2 \mathrm{~mm}$ in Figs $\mathrm{f}-\mathrm{g}$.

distal half in the male. Male chelicerae (Figs 15b-c) with a blunt medial-basal hump of various shapes. Male pedipalpus (Fig. 15d-e): tibia with a long apophysis which is divided apically (both 'branches' are equal in length), cymbium with a concave dorsal margin and a long retrobasal outgrowth, bulbus as in jorgeense sp. nov. (Fig. 16b). Female: epigyne (Fig. 15f) with an oval opening, a triangular inner part; the introducing ducts surround the receptacula seminis more than $11 / 2$ times (fig. 15g).

\section{Description}

Measurements (in $\mathrm{mm}$ ): Body length: male 6.6-8.2, female 8.3-9.5; prosoma: length male 3.3 , female $3.3-4.2$, width male 2.5, female 2.5-3.0; leg I (male): femur 4.8, patella 1.6, tibia 5.2, metatarsus 5.0, tarsus 2.25, tibia IV 3.3; free observable dorsal part of the male chelicerae 2.75 ; female: tibia I 4.0 , tibia IV 2.8 .

Colour: Prosoma orange to yellow brown, chelicerae darkened distally or apically (male), sternal margin darkened, female pedipalpus darkened distally, legs yellow brown, tips of the metatarsi and tarsi darkened, opisthosoma: see above. - Prosoma: eyes small and widely spaced, male chelicerae basally with a blunt medial hump and variable diverging as in Figs
$15 \mathrm{c}$ and 16a; teeth of the female furrow margins: 3 on the anterior margin, 2 on the posterior margin, similar in the male. Legs hairy and slender, in the male the tibia is especially longer and more slender than in the female. Bristles: femur I-II 1 prolaterally (in the female absent on II), III-IV a distal pair and few addionally, tibia I bears a ventral pair in the distal half, II may bear a proventral bristle and additionally a prolateral one in the distal half, no ventral bristles on tibiae III and IV, metatarsus I with a ventral pair in the basal half as well as apicals, metatarsus II a retroventral bristle or a pair in the basal half as well as apicals and occasionally a prolateral one in the distal half. Numerous bristles are present on legs III-IV. Coxal hook: Fig. 15a. - Opisthosoma slender, with short hairs. Genital organs: See the diagnosis.

\section{Relationships}

In C. seidlitzi C.L. Koch, 1864 of S-Europe the cheliceral hump is more slender and in a more distal position (Fig. 17a), the structures of the bulbus are identical. Epigyne and vulva (Fig. 17b) are distinctly different, the opisthosomal colour is quite similar. $C$. jorgeense sp. nov. is most related, see below. 


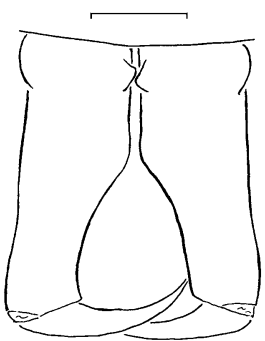

a

Figure 16 Cheiracanthium jorgeense Wunderlich sp. nov., Male: (a) anterior aspect of the chelicerae (teeth not observable); (b) retrolateral and slightly dorsal aspect of the $r$. pedipalpus; bar $=0.5 \mathrm{~mm}$.

\section{Ecology}

Very common in native forest in the canopies of Ilex perado ssp. azorica, Juniperus brevifolia, Laurus azorica, Vaccinium cylindraceum and Calluna vulgaris.

\section{Distribution}

Azores: Flores.

Cheiracanthium jorgeense Wunderlich sp. nov. (Fig. 16)

\section{Material}

HOLOTYPE male and 2 juv. paratypes: Azores, São Jorge, W Santo Amaro forest, July 1999 (JW leg.). Deposited at University of the Azores ('Arruda Furtado' collection).

\section{Derivatio nominis}

The species is named after the island São Jorge where it is an exclusive endemic.

\section{Diagnosis (Male; female unknown)}

Opisthosoma with a long dorsal redbrown band. Male chelicerae (Fig. 16a) with a blunt medial-basal hump of variable shape. Pedipalpus (Fig. 16b): tibia with a long apical apophysis which is divided apically (both 'branches' are equal in length), cymbium with a concave dorsal margin and a slender retrobasal outgrowth. Bulbus as in Fig. 16b (see also C. floresensis).

\section{Description (Male)}

Measurements (in $\mathrm{mm}$ ): body length 5.5, prosoma: length 2.7, width 2.00; leg I: femur 3.5, patella 1.2, tibia 4.1, metatarsus 3.9 , tarsus 1.8 , tibia IV 2.5 , free observable dorsal cheliceral part 1.8 .

Colour: prosoma orange brown, chelicerae apically darkened, sternal margin darkened, legs yellow brown, with the tips of metatarsi and tarsi black darkened, opisthosoma yellow grey, dorsally with a long dorsal band. - Prosoma: eyes small and widely spaced. Male chelicerae (Fig. 16a) basally-medially with a blunt hump, distally divergent. The chelicerae bear 4 teeth of the furrows (the number may be intraspecifically variable). - Legs slender, bristles and hook of coxa I as in $C$. floresense. - Opisthosoma slender, with short hairs. - Malepedipalpus: See the diagnosis.

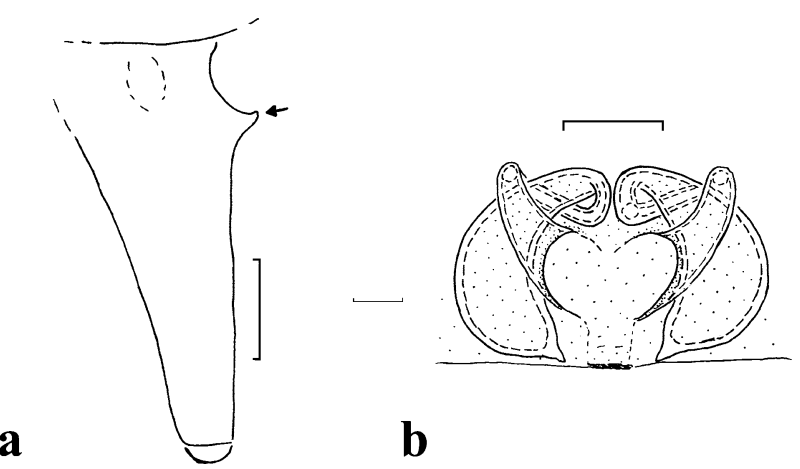

Figure 17 Cheiracanthium seidlitzi C.L. Koch, 1864 from Crete (coll. JW); (a) male, r. chelicera, retrolateral and slightly dorsal aspect. The arrow indicates to the cheliceral hump; (b) female, vulva, ventral aspect; bar $=0.5 \mathrm{~mm}$ and $0.2 \mathrm{~mm}$.

\section{Relationships}

In C. seidlitzi C.L. Koch, 1864, of Southern Europe, the cheliceral hump is more slender and in a more distal position (Fig. 17b). The structures of the bulbus are identical in both species, the opisthosomal colour is quite similar. In the most closely related $C$. floresense sp. nov. the cheliceral hump is as in $C$. floresense, the bulbus structures are identical in both species but the surface of the cymbial margin is concave in C. floresense, and the cymbial outgrowth is more slender. The pedipalpal tibial apophysis is as in $C$. floresense.

\section{Ecology}

Several juveniles of Cheiracanthium sp. (probably C. jorgeense) were sampled in native forest, mainly in canopies of Ilex perado ssp. azorica, Juniperus brevifolia and Vaccinium cylindraceum.

\section{Distribution Azores: São Jorge GNAPHOSIDAE}

Leptodrassus albidus Simon, 1914 (Fig. 18)

2000 ?Leptodrassus albidus,-Borges et al., Açoreana, 9 (2): 133.

\section{Material}

Azores, Santa Maria, S. Bárbara (sown pasture, $290 \mathrm{~m}$ altitude), 3-10.V.1994, 1 male, same locality but 19-26.X.94, 1 male (P.A.V. Borges leg.). Deposited at University of the Azores ('Arruda Furtado' collection).

\section{Remarks}

This species is characterised by its genital structures (Fig. 18); Figs $18 \mathrm{a}-\mathrm{b}$ are taken from Italian specimens. In the Italian male (Fig. 18b) the embolus is straight and more blunt than in the single Azorean male and the conductor is wider (Fig. $18 \mathrm{c})$. The shape of the pedipalpal tibial apophyis and the median apophysis are identical. The weak differences of embolus and conductor may represent intraspecific variation. Epigyne: Fig. 18d.

\section{Ecology}

In the Azores: pastures. 
a

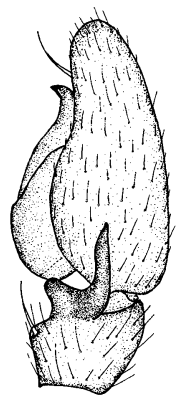

\section{C}

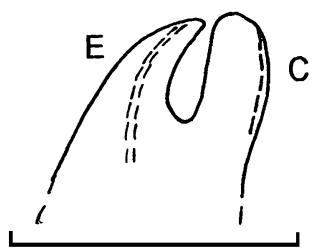

Figure 18 b

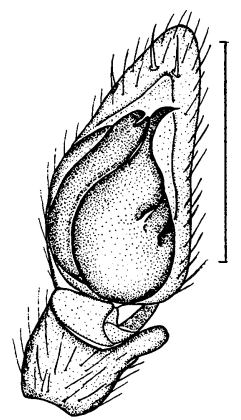

a
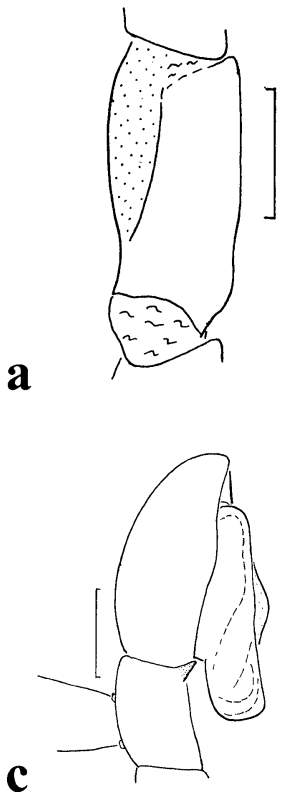

b

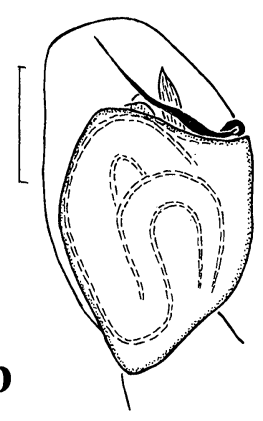

d

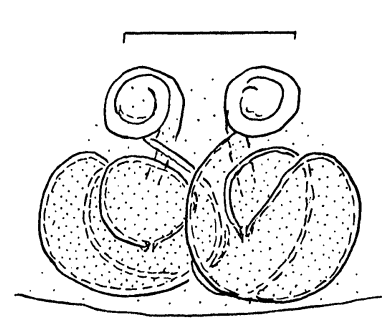

Figure 19 Neon acoreensis Wunderlich sp. nov.; (a) femur of the l. male pedipalpus, retroventral aspect; note the ventral depression; (b) r. male pedipalpus, ventral aspect; (c) r. male pedipalpus, retrolateral aspect; (d) female, vulva, dorsal aspect; bar $=0.1 \mathrm{~mm}$. $\mathrm{E}=$ embolus); (d) Epigyne; bar $=0.1 \mathrm{~mm}$ in Fig. c, $0.5 \mathrm{~mm}$ in the remaining Figs.

\section{Distribution}

Southern Europe, Azores (new to this archipelago): S. Maria.

\section{Zelotes tenuis (C. L. Koch, 1866)}

2000 Trachyzelotes sp. nov., -Borges et al., Açoreana, 9: 133 (wrong det.).

\section{Material}

Azores, Santa Maria, Fontinhas (semi-natural pasture, $430 \mathrm{~m}$ altitude), 26.X-1994, 1 male (Suction sample) (P.A.V. Borges leg.); Casas Velhas (semi-natural pasture, $360 \mathrm{~m}$ altitude), 24.X.1994, 1 male and 1 female (Suction sample) (P.A.V. Borges leg.); Fontinhas (semi-natural pasture, $430 \mathrm{~m}$ altitude), 3-10.V.1994, 1 male (pitfall sample) (P.A.V. Borges leg.) (In JW collection); Santo Espírito (sown pasture, $300 \mathrm{~m}$ altitude), 7-14.VII.1994, 1 female (pitfall sample) (P.A.V. Borges leg.); Casas Velhas (semi-natural pasture, $360 \mathrm{~m}$ altitude), 7 14.VII.1994, 1 female (pitfall sample) (P.A.V. Borges leg.). Material deposited at University of the Azores ('Arruda Furtado' collection), if not otherwise noted.

\section{Remarks}

In this species the body colour is very variable: from light yellow grey to dark brown. The genital organs are identical to the drawings given by Levy (1998, pp. 78-81).

\section{Ecology}

In the Azores: pastures.

\section{Relationships}

JW has with him both sexes of an undescribed closely related species from one of the Canary Islands, Tenerife.

\section{Distribution}

Mediterranean, Azores (new to this archipelago): Santa Maria; USA: California.

\section{THOMISIDAE}

Up to now three Azorean species of the genus Xysticus C. L. Koch, 1835 have been reported.

\section{Xysticus cribratus Simon, 1885}

\section{Remark}

The species was reported from Terceira by Ashmole et al. (1996, p. 20).

\section{Distribution}

Palaearctic, Sudan; Azores: Terceira.

\section{SALTICIDAE}

Up to now no endemic Azorean species of the family Salticidae has been described. No other species of the holarctic genus Neon Simon, 1876 is known from the Macaronesian Islands.

Neon acoreensis Wunderlich sp. nov. (Fig. 19)

1964 Neon reticulatus,-Denis, Bol. Mus. Mun. Funchal, 18 (68): 74 (subad. male).

1992 Neon ?convolutus,-Wunderlich, Beitr. Araneol., 1: 37, 521, fig. 854 (female).

2000 Neon sp. nov.,-Borges et al., Açoreana, 9 (2): 133.

\section{Material}

HOLOTYPE male: Azores, Santa Maria, S. Bárbara (sown pasture, $290 \mathrm{~m}$ altitude) 9.V.94 (Suctiob sample) (P.A.V. Borges leg.); São Jorge, Pico do Arieiro (Transect T05), July 
1999, pitfall sample ET10, 1 male paratype (Borges et al., leg.); São Jorge, Faja dos Cubres, 1 male paratype JW leg in VIII (coll. JW - SMF); Flores, Ribeira da Fazenda (Transect T04), July 1999, pitfall samples ET14 and ET18, 1 female and 1 juv. paratypes (Clara Gaspar \& P.A.V. Borges leg.); Flores, same locality, but pitfall samples TU19, 1 female paratype (Clara Gaspar \& P.A.V. Borges leg.); Flores, Encosta da Caldeira Funda (Transect T07), July 1999, Juniperus brevifolia sample JU07, 1 female paratype (Clara Gaspar \& P.A.V. Borges leg.); Flores, Caldeira Funda (Transect T12), July 1999, Erica azorica sample ER09, 1 female paratype (Clara Gaspar \& P.A.V. Borges leg.); Faial, Cabeço do Fogo (Transect T02), September 1999, pitfall sample TU01, 1 female paratype (Borges et al., leg.). Material deposited at University of the Azores ('Arruda Furtado' collection), if not otherwise noted.

\section{Derivatio nominis}

The species is named after the Azorean archipelago.

\section{Diagnosis}

Male: pedipalpus (Figs 19a-c): tibial apophysis short, tegular apophysis fairly large, smooth, embolus slender, slightly bent. Female: epigyne see Wunderlich (1992, Fig. 854); the introducing openings are directed sidewards; vulva: Fig. 19d.

\section{Description}

Measurements (male/female in $\mathrm{mm}$ ): body length $1.5 / 2.0$, prosoma: length $0.75 / 0.9$, width $0.6 / 0.65$; leg I (male): femur 0.3, patella 0.22 , tibia 0.28 , metatarsus 0.21 , tarsus 0.19 , tibia IV 0.3 . Female: tibia I 0.3 , tibia IV 0.35 .

Colour very variable: Light yellow to black brown, with black surroundings of the eyes, opisthosoma yellow, and almost without grey markings, to grey, legs weakly to distinctly annulated, leg I except the tarsus fairly darkened, the three distal female pedipalpal articles are darkened. - Prosoma about 1.25 times longer than wide, thoracal fissure indistinct, clypeus narrow, with few long medial hairs, chelicerae small, their margins smooth. - Legs stout, tibia I thickened. Bristles: male: all femora bear 3 thin dorsal bristles, tibia I 3 ventral pairs, tibia II ventrally 1 or 1.1 , metatarsi I-II 2 ventral pairs; III and IV: only apical metatarsal bristles. All metatarsi bear 2 trichobothria, all tarsi bear a single trichobothrium, their position near the middle in the basal half on I-II, in the distal half on IV. Male pedipalpus (Figs 19a-c): see above; femur ventrally excavate; the origin of the tegular apophysis is near the base of the embolus. Epigyne: see Wunderlich (1992: Fig. 854), the introducing openings are directed sidewards. Vulva: Fig. 19d.

\section{Relationships}

Neon reticulatus (Blackwall, 1853) is most closely related but is larger (body length $2.0-3.2 \mathrm{~mm}$ ), the tegular apophysis possesses tiny 'denticles'. According to the genital structures Neon convolutus Denis, 1937 (North Africa) is not strongly related to $N$. acoreensis.

\section{Ecology}

Widely distributed in several native habitats like the forest floor and canopy of several endemic trees, but also in natural grassland, semi-natural pasture and Sphagnum spp. bogs.

\begin{tabular}{|c|c|c|c|c|}
\hline Families & TOTAL & END & NAT & INTR \\
\hline Agelenidae & 5 & & & 5 \\
\hline Anyphaenidae & 1 & & & 1 \\
\hline Araneidae & 7 & 1 & & 6 \\
\hline Clubionidae & 7 & 2 & 1 & 4 \\
\hline Corinnidae & 1 & & 1 & \\
\hline Dictynidae & 4 & 1 & 1 & 2 \\
\hline Dysderidae & 1 & & & 1 \\
\hline Filistatidae & 2 & & & 2 \\
\hline Gnaphosidae & 9 & & & 9 \\
\hline Linyphiidae & 36 & 11 & 4 & 21 \\
\hline Lycosidae & 2 & 1 & & 1 \\
\hline Mimetidae & 3 & & & 3 \\
\hline Nesticidae & 1 & & & 1 \\
\hline Oecobiidae & 2 & & & 2 \\
\hline Oonopidae & 2 & 1 & & 1 \\
\hline Pholcidae & 1 & & & 1 \\
\hline Pisauridae & 1 & 1 & & \\
\hline Salticidae & 11 & 1 & 3 & 7 \\
\hline Scytodidae & 1 & & & 1 \\
\hline Segestriidae & 1 & & & 1 \\
\hline Sicariidae & 1 & & & 1 \\
\hline Tetragnathidae & 4 & 1 & & 3 \\
\hline Theridiidae & 15 & 3 & 1 & 11 \\
\hline Thomisidae & 3 & & 1 & 2 \\
\hline Zodariidae & 1 & & & 1 \\
\hline Total & 122 & 23 & 12 & 87 \\
\hline
\end{tabular}

Table 1 The number of endemic (END), native (NAT), introduced (INTR) and total spider species per family in the Azores.

\section{Distribution}

Azores: Flores, Faial, Pico, São Jorge, Terceira, São Miguel and Santa Maria (new record to Pico and São Jorge).

\section{Overall diversity and biogeographical notes}

A total of 122 species of spiders (Araneae) belonging to 90 genera and 25 families are reported from the Azores (Table 1; Appendix $\mathrm{S} 1$ in supplementary material). The family Linyphiidae is the richest in species (36 spp.; 30.0\%). However, members of 20 European families are absent: Leptonetidae, Telemidae, Palpimanidae, Eresidae, Hersiliidae, Uloboridae, Theridiosomatidae, Anapidae s. 1., Pimoidae, Oxyopidae, Zoropsidae, Argyronetidae (= Cybaeidae), Amaurobiidae, Titanoecidae, Liocranidae, Cithaeronidae, Zoridae, Trochanteriidae, Philodromidae and Sparassidae (= Heteropodidae). Not a single species of the infraorder Mygalomorpha has colonised the Azorean islands. This faunal disharmony is also evident when one considers that only very few taxa of certain families, which are diverse in genera throughout continental Europe, can be found in the Azores: Dysderidae, Oonopidae, Pholcidae, Lycosidae, Zodariidae, Corinnidae and Thomisidae.

As shown in Appendix S1 in supplementary material, in addition to the eight new species described above, eight 


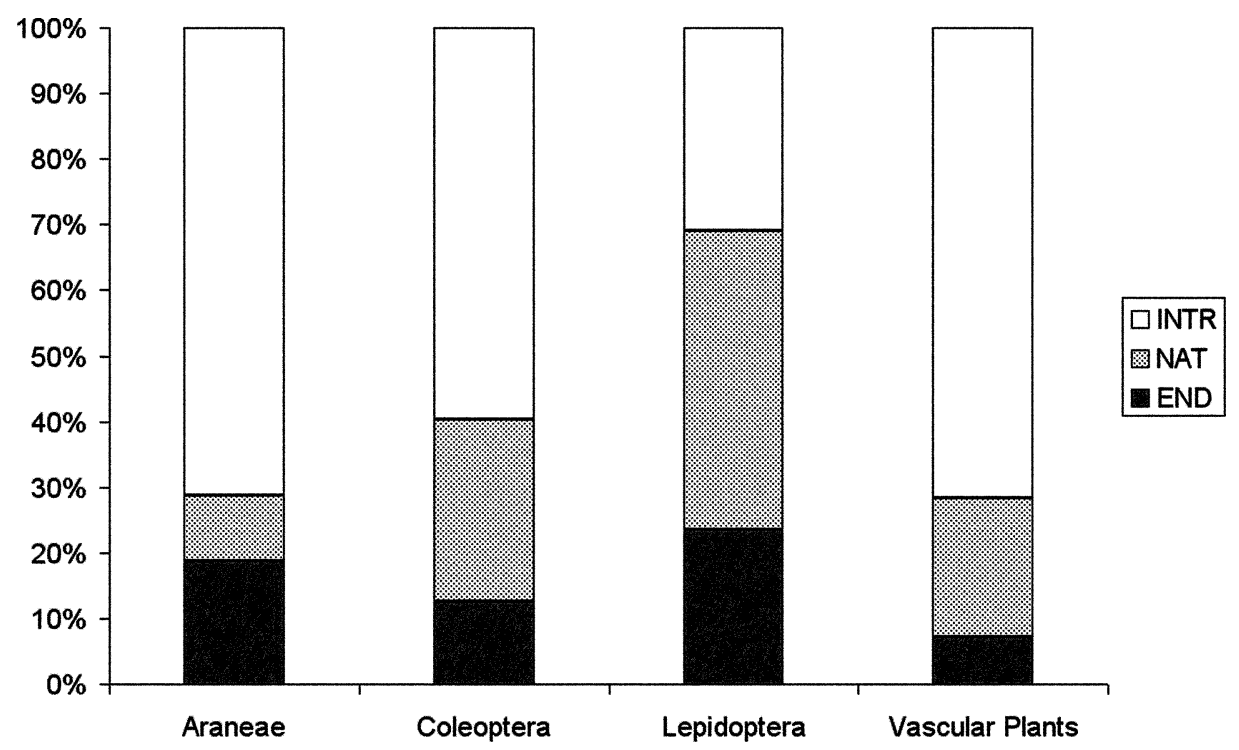

Figure 20 Relative contribution of endemic (END), native (NAT) and introduced (INTR) species with regard to spiders (Araneae), beetles (Coleoptera; data from Borges et al., 2005c), butterflies and moths (Lepidoptera; data from Karsholt \& Vieira, 2005) and vascular plants (data from Silva et al., 2005) of the Azores.

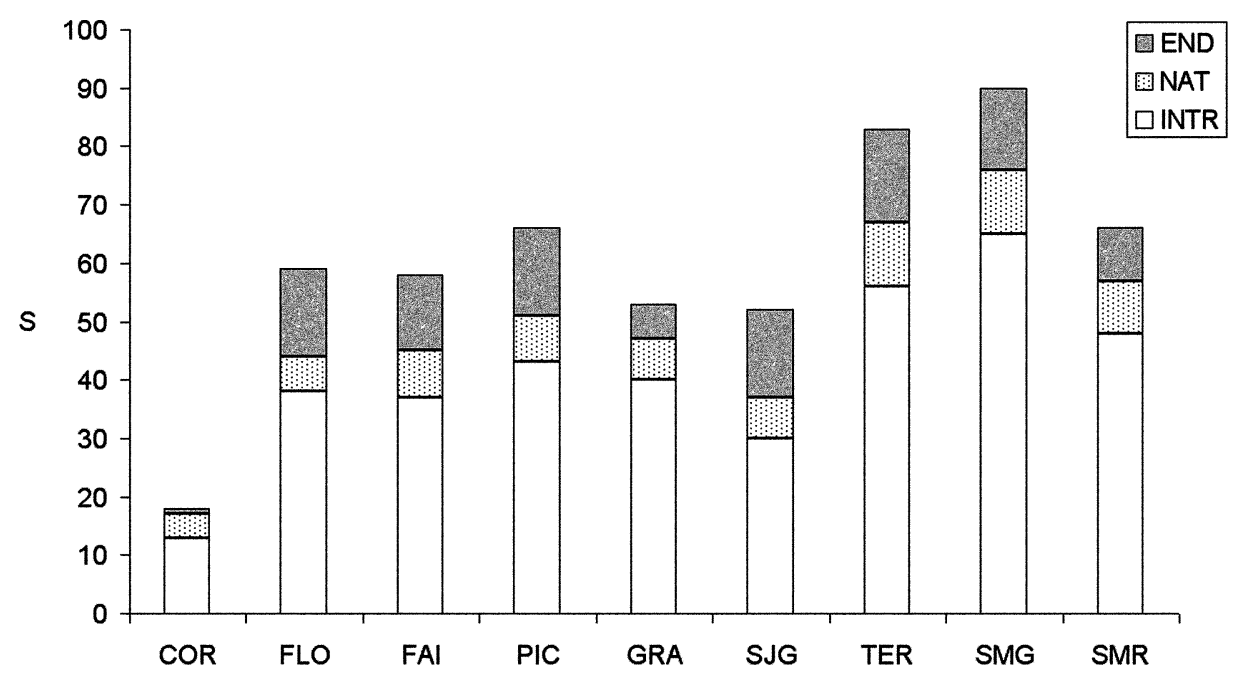

Figure 21 Species richness of endemic (END), native (NAT) and introduced (INTR) spider species in the nine islands of the archipelago.

species are new records for the Azorean islands (marked with *). For 61 previously known species, many new records are added for individual islands (a total of 131 new records). If we add those records to that of the 16 new taxa ( 8 new records plus 8 new species), a total 206 new records for individual islands are given, which represents a $52 \%$ increase in data on the species distribution on the nine islands. Detailed data on the 206 new records is available upon request from the first author and is available in the database of the Insect Collection deposited at the University of the Azores (Dep. Agriculture) ('Arruda Furtado' Collection).

Most of the species (c. 71\%) were probably introduced as a consequence of human activities (Table 1). This means that the indigenous fauna consists of only 35 species, of which $66 \%$ are endemics.

In the Azores the proportion of exotic species in the spider fauna is comparable only to the high proportion of exotic vas- cular plants (see Fig. 20). The diversity of introduced species is particularly high in spiders (Araneae), while among butterflies and moths (Lepidoptera) the indigenous fauna dominates. Beetles (Coleoptera) have $40 \%$ of indigenous species (natives and endemics), which show a similar proportion to the overall arthropod assemblage (see also Borges et al., 2005d).

The overall richness per island is shown in Fig. 21, from which it becomes obvious that the islands with the greatest human populations (São Miguel, Terceira) are also those richest in spider species. The bias in sampling could explain in part this pattern, which could also have other biogeographical explanations. In fact, the indigenous spider species richness is well explained by the area of the islands (Fig. 22) (model: log $\mathrm{S}=0.34+0.41 \log$ Area; $\left.\mathrm{R}^{2}=0.83 ; \mathrm{p}=0.0005\right)$. The slope (z) of the species-area relationship (SAR) is within the upper limit of the range of empirical values in SAR curves in oceanic islands (average $\mathrm{z}=0.35$; see Rosenzweig, 1995), which could 


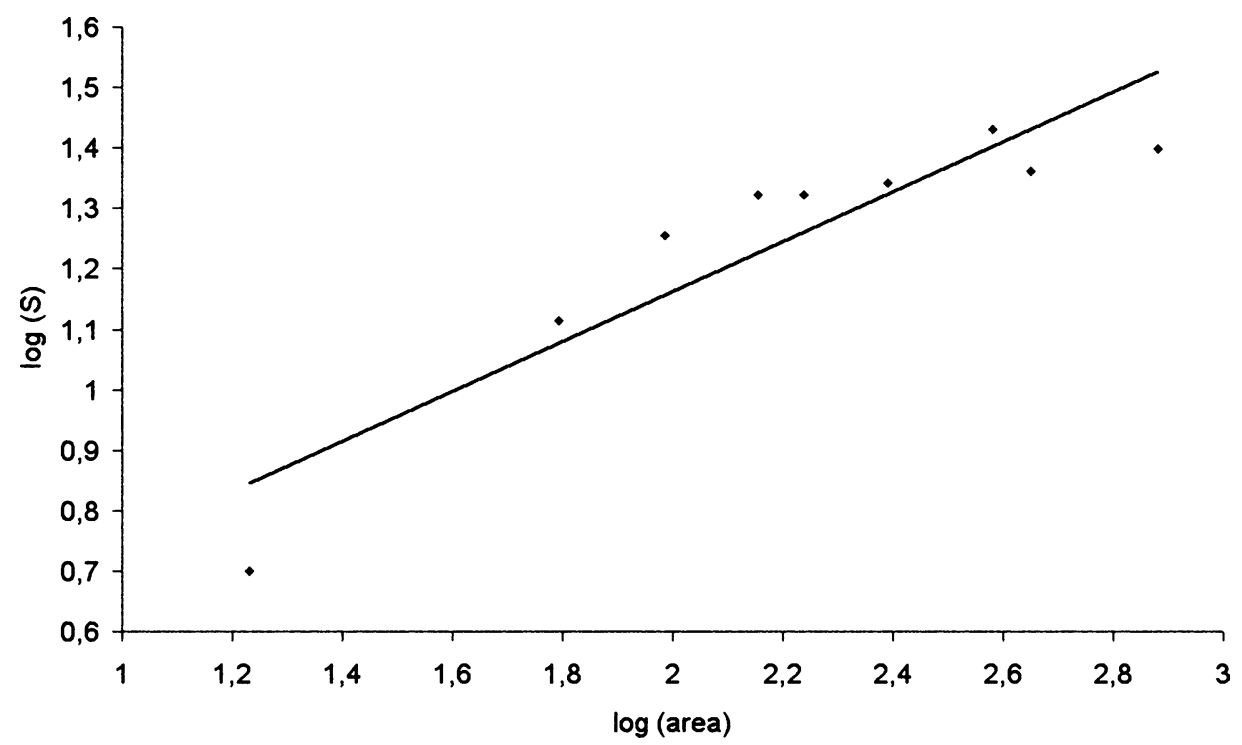

Figure 22 Relationship between the logarithm of species richness of indigenous spiders and the logarithm of island area.

be a consequence either of a presumed dispersal limitation, or of species interactions and consequently a lack of suitable local adaptations. Other alternatives are: (i) the low sampling effort in the small islands which elevates artificially the slope of the SAR; (ii) the historical extinction of many indigenous species in small islands (e.g. Corvo, Graciosa, Santa Maria) eroded by major land-use changes in historical times, which resulted in a current poor representation of native forest in those islands.

\section{Endemic Araneae}

A total of 23 species $(=19 \%)$ are Azorean endemics (Table 1). Endemic genera are Acorigone Wunderlich gen. nov. and Savigniorrhipis Wunderlich, 1992 (both Linyphiidae: Erigoninae). The 23 endemic spider species comprise $43 \%$ of the Azorean endemic arachnid fauna (there are 53 endemic species of Acari, Pseudoscorpiones and Araneae in the Azores; Borges et al., 2005d) and 9\% of the Azorean endemic arthropod fauna (total = 267 spp.; Borges et al., 2005d).

The spider fauna of some, mainly tropical, regions is still not well studied, and therefore some apparently endemic Azorean taxa may be discovered in the future in other parts of the world. An example is the genus Sancus Thorell, 1910 from Kenya, an older synonym of Leucognatha Wunderlich, 1992, which was described from the Azores. A second example: a revision of numerous species of the genus Orchestina, which has a cosmopolitan distribution and is sorely needed, and Orchestina furcillata sp. nov. from São Miguel may be a species introduced by humans. Two species were originally supposed to be Azorean endemics: Zelotes oceanus (Simon) proves to be a synonym of the Mediterranean Trachyzelotes lyonneti (Savigny \& Audouin), and Achaearanea acoreensis (Berland) was discovered later in Madeira, in North America (Colorado) and in Portugal (the Azores and Madeira are both Portuguese). On the other hand, there may be more endemic Azorean spiders in caves and in laurel forests (see also below).
Linyphiidae, especially members of the subfamily Erigoninae, are the most frequent aeronauts. Remarkable is the fact that there are no endemic species of the family Gnaphosidae and the genera Dysdera, Pholcus and Oecobius in the Azores (but there are non-endemics of these taxa) although they are rich in species in the Mediterranean, and there are distinct radiations of these genera in Madeira and in the Canary Islands.

Denis (1964, p. 69) reported 6.4\% endemic spider species in the Azores; now we know 23 species (= 19\% of the Azorean spider fauna) in 10 families and 19 genera, which are endemic to the Azores; their number and percentage has more than tripled. Most of the endemics were collected and described during the past decades (see also below). Eleven of these endemic species (about 48\%) (see Table 2) are members of the family Linyphiidae. Interestingly, in the three families listed in Table 2 the percentage of endemics within the family is somewhat similar (between 20 and 30\%).

Only a single endemic Azorean species is known in each of the families Oonopidae, Tetragnathidae, Araneidae, Dictynidae, Lycosidae, Pisauridae and Salticidae (see Table 1; Appendix S1 which is available as 'Supplementary data' on Cambridge Journals Online: http://www.journals.cup.org/ abstract_S1477200008002648). This stands in stark contrast to the spider fauna of the Canary Islands (see Izquierdo et al. 2004) in which Araneidae comprises 4 endemic species, Dictynidae 8 endemic species, Lycosidae 16 endemic species, and Salticidae 12 endemic species. Families particularly rich in endemic taxa in the Canary Islands (Dysderidae, Gnaphosidae, Oecobiidae, Pholcidae) have no endemic counterparts in the Azores.

\section{Colonisations and radiations in the Azorean islands}

Numerous species have been introduced by humans and they successfully colonised the Azores within the past 500 years (previously no humans were known to have settled in the 


\begin{tabular}{lccclc}
\hline Family & $\begin{array}{l}\text { Total number } \\
\text { of species }\end{array}$ & $\%$ & $\begin{array}{l}\text { Endemic } \\
\text { species }\end{array}$ & $\begin{array}{l}\text { \% endemics } \\
\text { in the } \\
\text { family }\end{array}$ & $\begin{array}{l}\text { \% of the } \\
\text { endemic } \\
\text { species }\end{array}$ \\
Linyphiidae & 36 & $29.51 \%$ & 11 & $30.56 \%$ & $47.83 \%$ \\
Theridiidae & 15 & $12.30 \%$ & 3 & $20.00 \%$ & $13.04 \%$ \\
Clubionidae & 7 & $5.74 \%$ & 2 & $28.57 \%$ & $8.70 \%$ \\
\hline
\end{tabular}

Table 2 The families with at least two endemic species.

Azores). These species are known from different regions of the world, several are even cosmopolitan, and have certainly been transported frequently by planes and ships from one island to others. In contrast to these species (see below) the ancestors of the Azorean endemics were 'natural colonisers'.

(a) Natural colonisations and 'dispersal success' (concerning indigenous species): how many successful natural colonisations took place in the Azores? There are 23 endemic species (of 19 genera and 10 families) known in the Azores (Appendix S1 which is available as 'Supplementary data' on Cambridge Journals Online: http://www.journals.cup.org/ abstract_S1477200008002648). The two endemic species of Agyneta are not closely related, so we assume two colonisations of this genus. There are three 'radiations'/splittings of two species each within a genus (Acorigone, Cheiracanthium, Rugathodes). Thus there were apparently at least 20 (23-3) natural colonisations by spiders in this archipelago within the past c. 8 million years (roughly the oldest age of this archipelago). That means that on average only 2.5 successful colonisations occurred every million years. In the Canary Islands, Wunderlich (1995, p. 389) found about double the number of colonisations, the highest number in El Hierro, few in Fuerteventura. In the insect order Coleoptera Borges (1992) found on average, concerning indigenous species, one successful colonisation per 41237 years $=c .24$ in one million years. That means, concerning these mostly flying insects, more than 24 successful colonisations occurred every one million years, almost ten times more than in spiders. Of course, we have to take into consideration that the worldwide number of described species of beetles is about ten times higher than the number of spider species. So the 'spreading (dispersal) success' of flight for beetles may have been almost the same as that of the ballooning for spiders in these isolated islands, and apparently the spiders' 'aeronautic spreading success' is quite remarkable (see also below)!

We have to consider that we do not know the number of extinct endemic species of earlier Azorean colonisations, and some more species may be discovered (see also below); so there really may have been more than 19 natural colonisations. The following facts support the assumption that probably numerous endemic Azorean spider species became extinct as a result of the competition of introduced spider species during the past centuries. In fact, several of the non-endemic species are frequent and/or widely distributed in the Azores (see below). An intrageneric competition between endemic and introduced species has not yet been studied, but may be involved e.g. for the genera Agyneta (Linyphiidae) and Cheiracanthium (Clubionidae). (b) Speciation and 'radiations': Speciation, sibling species: in certain closely related Azorean spider species the structures of the bulbi show only slight or even no differences; these species may be called 'sibling species'. As pointed out by Wunderlich (1972, p. 422), especially in the family Linyphiidae, closely related species exist in which the bulbus or even the whole pedipalpus is identical, but non-genitalic (somatic) structures and the female genitalia are different. In the following we discuss one genus of the family Linyphiidae (Porrhomma) and one genus of the family Clubionidae (Cheiracanthium):

(1) The structures of the whole pedipalpus of the Azorean Porrhomma borgesi are identical with the pedipalpal structures of the European P. pygmaeum but there are clear differences in the size of the eyes, the colour of the body and the distinctness of the coxal stridulatory files.

(2) The bulbi of the two Azorean species of Cheiracanthium, $C$. florescense and $C$. jorgeense (female unknown) as well as the European $C$. seidlitzi are identical, but the shape of the cymbium, the male chelicerae as well as the epigyne/vulva, at least in $C$. floresense and $C$. seidlitzi, are different.

There are few and only weak 'radiations' in Azorean spiders, if we compare them with radiations in the Canary Islands (see Wunderlich, 1995). We know only three cases of clear radiation within the same genus:

- Rugathodes Archer, 1950 (Theridiidae): the cavernicolous $R$. pico in Pico and Faial and the free-living $R$. acoreensis in most islands, including Pico and Faial. Both are sister species (see Wunderlich, 1992, pp. 415-417). Probably the stem specimen(s) arrived on the older islands (Santa Maria and São Miguel), later $R$. acoreensis spread to other islands, and a population adapted as a cave-dweller ( $R$. pico);

- Acorigone Wunderlich, gen. nov. (Linyphiidae: Erigoninae): A. acoreensis (Wunderlich, 1992) on Flores, Pico, Faial, São Jorge, Terceira and São Miguel and A. zebraneus Wunderlich sp. nov. on São Jorge. In this case São Miguel could well have been the 'catcher' of the stem specimen(s); later a stem population has probably been drifting to occidental islands. Acorigone acoreensis is a species restricted to the laurel forests (both in soil and canopy) and has probably spread between the islands through ballooning;

- Cheiracanthium C. L. Koch, 1839 (Clubionidae): C. floresense Wunderlich sp. nov. on Flores and $C$. jorgeense Wunderlich sp. nov. on São Jorge. Where did the stem specimen(s) arrive? São Jorge is the larger island and is situated east of the distribution of their stem species and is 
probably most closely related to C. seidlitzi C.L. Koch 1864 in southwestern Europe. Most populations of the Cheiracanthium taxa in the Azores were found in the canopies of Ilex perado ssp. azorica, Laurus azorica and Vaccinium cylindraceum, usually rolling the leaves to build the web. Probably the common and aggressive Cheiracanthium erraticum (Walckenaer) led to the extinction of the endemic Cheiracanthium taxa in the other islands.

(c) Spider colonisers which were introduced by humans: plants and animals have been introduced from many parts of the world to the Azores by humans over hundreds of years, and the Azorean fauna and flora contains numerous exotic species, the percentage of introduced vascular plant species being one of the highest at world level, even if one considers only oceanic islands (Silva \& Smith, 2004) (see also below). We assume that most of the non-endemic spider species (if not all) were transported to the isolated Azores by humans (see Wunderlich, 1992: 194f , 1995, p. 390). Our assumption is based on the following findings:

(1) in the family Gnaphosidae (9 Azorean species) which contains only very few aeronauts we find not a single endemic species, and most species occur in a limited number of islands;

(2) the pronounced aeronautic Linyphiidae (36 species) comprises the highest number of Azorean endemics: 11 species $(=30 \%)$;

(3) several introduced Azorean species like Dysdera crocota C. L. Koch, 1838 (Dysderidae) and Pholcus phalangioides (Fuesslin, 1775) (Pholcidae) are known to having been transported by humans all over the world, and are widely distributed in the Azores (see below; d3);

(4) in contrast to the Azores certain members of Dysdera and Pholcus colonised Madeira and the Canary Islands a long time ago and radiated there (the origin of Dysdera crocota - as well as that of the whole genus and family is the Mediterranean area; the origin of Pholcus phalangioides is unknown). If ancestors of these species came to the remote Azores a long time before humans, these species would probably have created endemics or even radiations there, as they did in the other Macaronesian archipelagos which are nearer to the mainland. Ancestors of Dysdera crocota caused the evolution of D. lanzetotensis Simon, 1907 in the Canarian island Lanzarote which is only about $100 \mathrm{~km}$ away from the mainland (Africa). Dysdera crocota occurs in all Azorean and all other larger Macaronesian islands. However, an undescribed endemic Dysdera species is known from Pico island (P. Oromí, pers. comm.);

(5) not a single endemic spider species of the Azores shows a close relationship to nearctic species in contrast to three non-endemic Erigoninae (see below) which certainly come from North America and were introduced only recently (see below);

(6) most probably some species colonised the Azores only recently and are likely to have been transported by humans, e.g.:
- Oedothorax fuscus (Blackwall, 1834) (Linyphiidae: Erigoninae) was not reported by Denis (1964). Denis studied collections up to the year 1957 and was still not found by either J. Wunderlich or P.A.V. Borges before 1990, but it was reported by Borges et al. (2000, p. 132) as being 'very common in managed pastures' in three Azorean islands (Terceira, Pico and Santa Maria). This palaearctic species is now known to occur in most Azorean islands, but it is unknown in Madeira and the Canary Islands (see Izquierdo et al., 2005);

- Erigone autumnalis Emerton, 1882 (Linyphiidae: Erigoninae) was also not reported by Denis (1964) or earlier authors visiting the Azores, but it was found by Wunderlich in the year 1987 on four Azorean islands, and later by Borges (1999), and found to be very common in pastureland. A few years later this nearctic species was reported on the mainland of Europe (Switzerland);

- Eperigone Crosby \& Bishop, 1928 (Linyphiidae: Erigoninae) is apparently an autochthonous genus of North America. Several species of this genus are currently spreading - e.g. E. trilobata (Emerton, 1882) to Europe and South Africa few decades ago and some have already a cosmopolitan distribution. E. bryantae Ivie \& Barrows and $E$. fradeorum (Berland) were not reported from the Azores by Denis (1964) or earlier authors but were collected on several Azorean islands by Wunderlich in the year 1987.

- Achaearanea acoreensis (Berland, 1932) (Theridiidae): see above and below.

Apparently these species colonised most if not all of the Azorean islands during a few decades in a fast dispersal, jumping from one island to the others ('island hopping'), transported by humans and travelling as aeronauts. This human influence could be easily observed in the positive correlation between introduced species richness and the human population in each island (regression model: $\log \mathrm{S}=0.62+0.24 \log$ human population; $\mathrm{R}^{2}=0.80 ; \mathrm{p}=0.001$ ) (Fig. 23). In spite of the fact that other geographical factors (e.g. area, habitat diversity) could also explain part of the observed variation in exotic spider species richness (Borges, unpublished data), human population in each island is also a nice surrogate of both commercial activities and habitat disturbance.

(d) Origin of the colonisers and their ancestors:

(d1) Origin of selected endemic Azorean taxa:

Remarks: close relationships of certain Azorean endemics, e.g. of both endemic genera, are still uncertain or even unknown; in the following we discuss the relationships of selected taxa (see also Wunderlich, 1992: 213):

- Orchestina furcillata Wunderlich sp. nov. (Oonopidae): the most closely related species may be $O$. arabica Dalmas, 1916 which occurs in Arabia.

- Gibbaranea occidentalis Wunderlich, 1989 (Araneidae): most closely related is G. gibbosa (Walckenaer, 1802) from Europe.

- Porrhomma borgesi Wunderlich sp. nov. (Linyphiidae): the most closely related species are the epigaeic palaearctic P. pygmaeum (Blackwall, 1834) and P. pallidum 


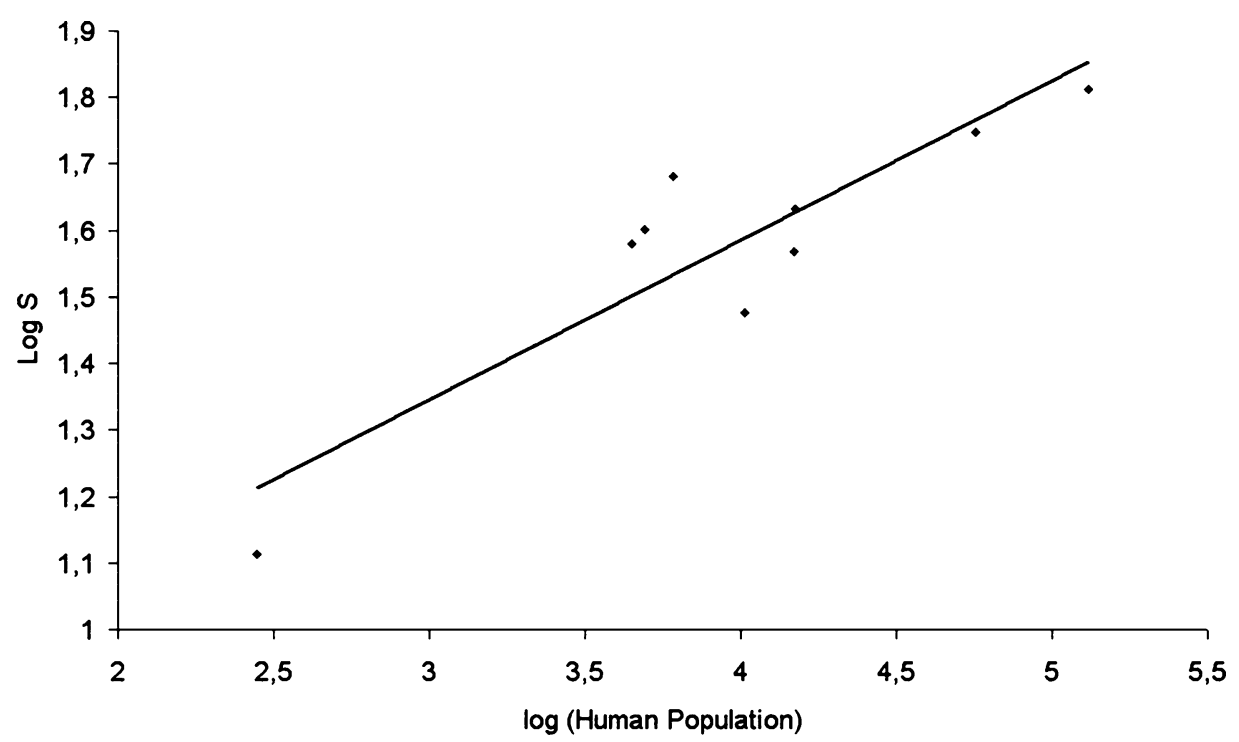

Figure 23 Relationship between the logarithm of introduced spider species richness and the logarithm of human population.

Jackson, 1913 which are not known in the Macaronesian Islands.

- Turinyphia cavernicola Wunderlich sp. nov. (Linyphiidae): the most closely related species are $T$. clairi (Imon, 1884) from Southern Europe and T. maderiana (Schenkel, 1938) from Madeira. Madeira may have been a 'stepping stone' for the ancestor of this cave-dwelling Azorean species. An epigean Azorean species of Turinyphia is unknown.

- Agyneta rugosa Wunderlich, 1992 (Linyphiidae): probably the European A. equestris (C.L. Koch) and A. gulosa (C.L. Koch) are most closely related.

- Lepthyphantes acoreensis Wunderlich, 1992 (Linyphiidae): L. todillus Simon, 1929 (South France) and $L$. speculae Denis, 1959 (Libanon) are most closely related.

- Typhochrestus acoreensis Wunderlich, 1992 (Linyphiidae): most closely related is T. hesperius Thaler, 1984 from the Canarian island Tenerife. This species lives at high altitude (Canadas and Teide, up to $3050 \mathrm{~m}$ ) and can easily balloon from this high area to distant regions which are far away.

- Minicia floresensis Wunderlich, 1992 (Linyphiidae): most closely related to the Azorean species is M. candida Denis, 1946 from Southwest France (see Wunderlich, 1992, pp. 245, 391).

- Lasaeola oceanica Simon, 1833 (Theridiidae): most closely related is Lasaeola testaceomarginata (Simon, 1881) from South Europe.

- Rugathodes acoreensis Wunderlich, 1992 and R. pico (Merrett \& Ashmole, 1989) (Theridiidae): most closely related are R. madeirensis Wunderlich 1987 from Madeira and $R$. bellicosum (Simon, 1873) from Europe and Russia (see Wunderlich, 1993).

- Pardosa acoreensis Simon, 1883 (Lycosidae): most closely related is P. proxima (C. L. Koch, 1848) from Europe and the Canary Islands.
- Pisaura acoreensis Wunderlich, 1992 (Pisauridae): most closely related are $P$. quadrilineata (Lucas, 1838) from Madeira and the Canary Islands and the palaearctic $P$. mirabilis (Clerck, 1757).

- Cheiracanthium floresensis Wunderlich sp. nov. and $C$. jorgeensis Wunderlich sp. nov. (Clubionidae): closely related is C. seidlitz C.L. Koch, 1864 from the Mediterranean.

- Neon acoreensis Wunderlich sp. nov. (Salticidae): the holarctic Neon reticulatus (Blackwall, 1853) is closely related.

To summarise:

(1) There are no convincing nearctic or neotropical relationships in the Azorean endemic spiders, although the Azores are situated midway between Europe and North America;

(2) Most of the 14 groups (at least 13) of spiders which are treated above show relationships to Western Palaearctic taxa.

(3) Madeira - for Rugathodes and probably in Turinyphia and Pisausa - and the Canary Islands - for Typhochrestus and probably in Lepthyphantes, Pardosa and Pisaura may have been 'stepping stones' between the Western Palaearctic genera to those in the Azorean areas and taxa.

(d2) Origin of the Azorean Macaronesian endemics (see list in Appendix S1 which is available as 'Supplementary data' on Cambridge Journals Online: http://www.journals.cup.org/abstract_S1477200008002648):

- From Madeira or from the Canary Islands: Oecobius similis (Oecobiidae), Microlinyphia johnsoni (Linyphiidae), Macaroeris diligens (Salticidae) and Theridion musivivum (Theridiidae);

- From the Canary Islands: Lathys dentichelis (Dictynidae), Bianor wunderlichi (Salticidae) and Trachelas macrochelis (Corinnidae);

- From Madeira: Entelecara schmitzi, Lepthyphantes schmitzi, Lepthyphantes miguelensis (Linyphiidae), 
Clubiona decora (Clubionidae) and Macaroeris cata (Salticidae).

These species are reported as native (see Appendix S1 which is available as 'Supplementary data' on Cambridge Journals Online: http://www.journals.cup.org/abstract_ S1477200008002648), but we can not discharge the hypothesis that some of them are in the Azores as a consequence of human interference. Some of these species occur mainly in native forests, like Lathys dentichelis (Dictynidae), Lepthyphantes miguelensis (Linyphiidae) and Macaroeris cata (Salticidae) and should have arrived by long-distance dispersal long before human colonisation. For instance, L. miguelensis (Linyphiidae) is the most common and frequent spider in the pitfall samples in native forests from the archipelago, being replaced in non-native habitats by the introduced ecologically related species L. tenuis (Linyphiidae). The same pattern occurs with Lathys dentichelis (Dictynidae) that is common in the canopies of most endemic and native trees but is replaced by Nigma puella (Dictynidae) in the canopies of many introduced trees.

(d3) Origin of other non-endemic (introduced) species:

Numerous species possess a wide or even cosmopolitan distribution; they are not listed below.

- North America (Nearctic) (see above: spiders which are introduced by humans), 5 species only:

THERIDIIDAE: Achaearanea acoreensis was apparently introduced from North America, probably in the first decades of the 20th century;

SALTICIDAE: Phidippus audax was recently collected in Santa Maria by the local naturalist Dalberto T. Pombo and is probably a recent introduction from North America;

LINYPHIIDAE: Erigone autumnalis, Eperigone bryantae and Eperigone fradeorum.

- Holarctic, 7 species:

TETRAGNATHIDAE: Tetragnatha extensa; ARANEIDAE: Araneus angulatus, Neoscona crucifera; LINYPHIIDAE: Erigone atra, Microctenonyx subitaneus, Microneta viaria; GNAPHOSIDAE: Micaria pallipes.

- Western Palaearctic and Palaearctic (most often Europe), 49 species:

FILISTATIDAE: Filistata insidiatrix, Pritha nana; OONOPIDAE: Oonops domesticus; SEGESTRIIDAE: Segestria florentina; TETRAGNATHIDAE: Metellina merianae; ARANEIDAE: Zygiella $x$-notata (introduced also to America), Agalenatea redii, Argiope bruennichi, Mangora acalypha; LINYPHIIDAE: Agyneta decora, A. fuscipalpis, A. rurestris (introduced also to Greenland), Erigone dentipalpis, Erigone promiscua, Lepthyphantes tenuis (introduced to different regions), Oedothorax fuscus (introduced to North Africa), Walckenaeria unicornis; MIMETIDAE: Ero aphana, Ero flammeola, Ero furcata (introduced also to North America); THERIDIIDAE: Achaearanea simulans, Argyrodes nasicus, Argyrodes rostratus, Enoplognatha mandibularis,
Neottiura bimaculata, Steatoda nobilis (known from NorthAfrica); DICTYNIDAE: Argenna lucida (= Altella lucida), Nigma puella; AGELENIDAE: Tegenaria pagana, Tegenaria parietina, Textrix caudata, Lycosoides coarctata; LYCOSIDAE: Arctosa perita; ANYPHAENIDAE: Anyphaena accentuata; CLUBIONIDAE: Cheiracanthium erraticum, Clubiona terrestris; GNAPHOSIDAE: Leptodrassus albidus, Scotophaeus blackwalli (also introduced to North America), Trachyzelotes lyonneti, Zelotes aeneus, Zelotes longipes, Zelotes tenuis; THOMISIDAE: Xysticus cribratus, Xysticus nubilus; SALTICIDAE: Chalcoscirtus infimus, Heliophanus kochi, Menemerus semilimbatus, Salticus mutabilis, Synageles venator.

\section{Patterns of biodiversity and conservation remarks}

In the Azores the current number of 122 species is about one quarter of that known from the Canary Islands $(S=477$; Izquierdo et al., 2004), and if we consider the endemic species the proportion is even smaller (23 species in the Azores and about 306 in the Canaries). For the Madeira archipelago, about 161 species are listed (about 55 endemic; 34\%) (Cardoso \& Crespo, in press).

Arachnids (that include spiders) in the Azores make up about $14 \%$ of the total Arthropod species number in contrast to the $8 \%$ in the world (Fig. 24). If we consider the endemic species, that proportion is even higher (20\% in the Azores) but comparable to the Canaries (Fig. 24). This indicates that arachnids are better at dispersing to islands than other arthropods. Aeronautic spiders may have been drifting to the Azorean islands by means of wind currents, but spiders and egg sacs may have been transported to the Azores also in the plumage and hairs of birds and bats (see Wunderlich, 1992, 1995). Therefore, arachnids in general and spiders in particular make up a relatively important component of the Azorean arthropod biodiversity.

A complete census of species in an area is rarely feasible, except for highly conspicuous and closely studied taxa such as birds and vascular plants. Assessment is therefore usually based on samples of the population, but the species count then depends on sampling efforts (Colwell \& Coddington, 1994). The absolute rate at which the existing species inventory is growing in the Azores may be assessed by considering the rate at which new species are being described. The cumulative discovery curve for the endemic species of spiders presented in Fig. 25 illustrates the considerable time taken to acquire this knowledge, as measured by the number of published descriptions of endemic species. There is a clear sigmoidal curve, with a lag in the earliest phase of species discovery. By 1990 only $17 \%$ of the listed species had been recorded, and in 2000 only $65 \%$ of the species had been described. To reach $90 \%$, the descriptions included in this paper need to be included (Fig. 25). This reflects in part the recent interest in the Azorean fauna by foreign entomologists and to a greater extent the laborious work performed at the University of the Azores with regard to attracting collaborative work. The creation of the Arthropod collection, 'Arruda Furtado' (Dep. Agriculture, Terceira), while gathering many type specimens of Azorean endemic arthropod species, was also an important 

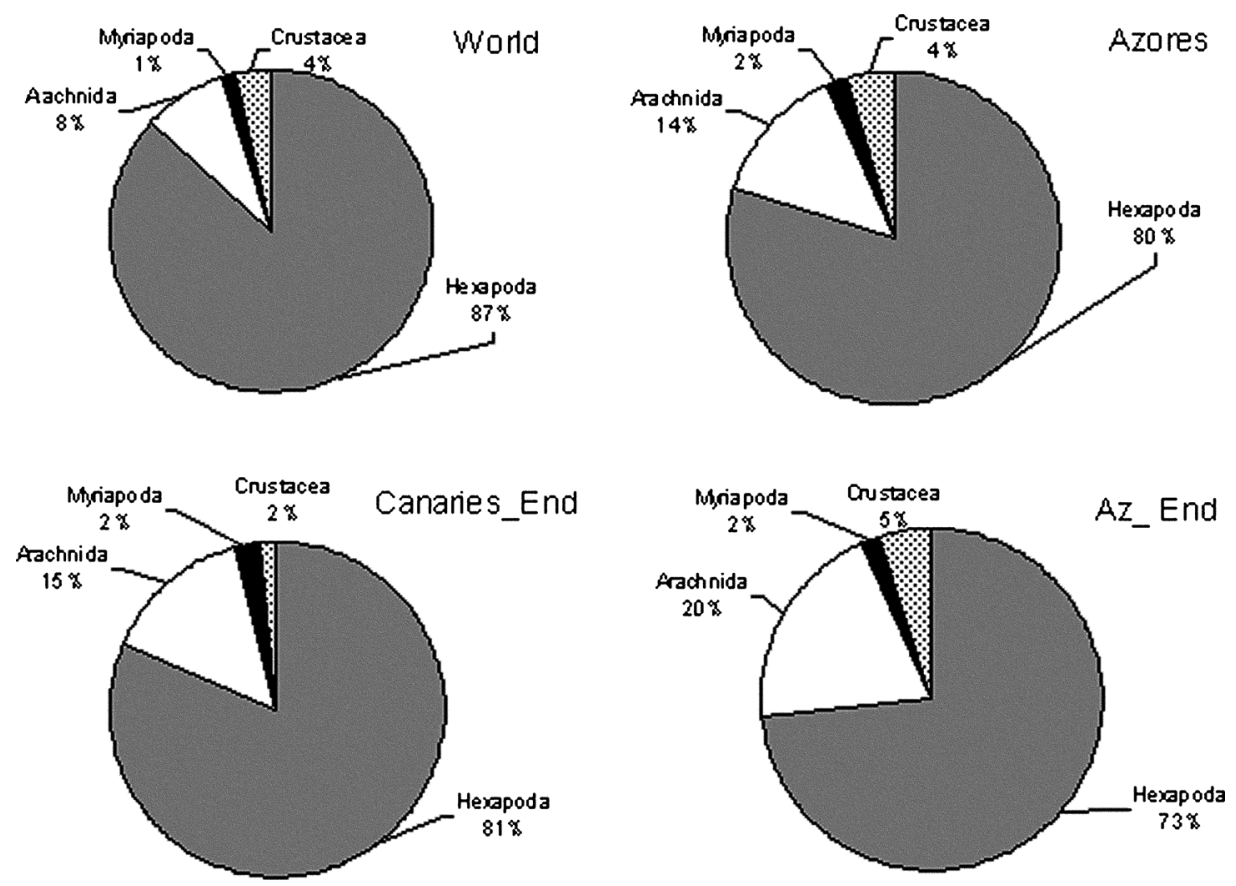

Figure 24 Proportion of the main groups of arthropods in the world (according to Hammond, 1992), the Canaries (data from Izquierdo et al., 2001) and in the Azores. End = endemics.

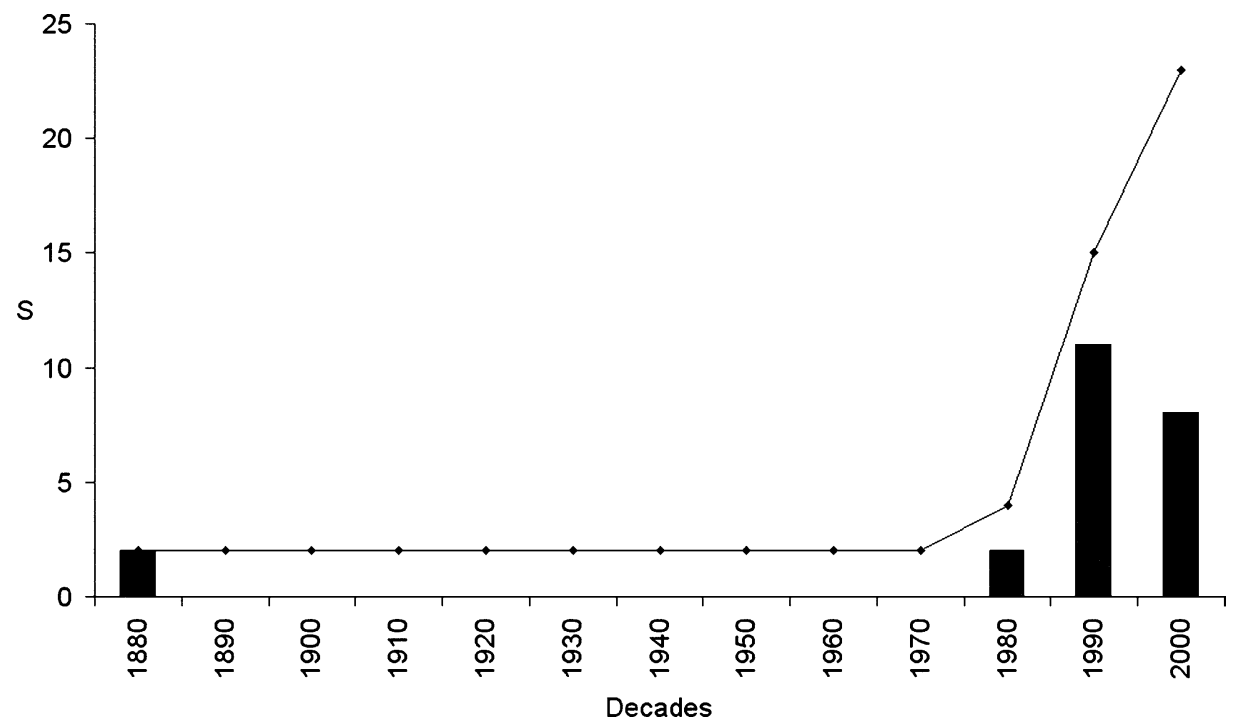

Figure 25 Cumulative spider endemic species discovery curve in the Azorean archipelago. Data points are plotted cumulatively by decade and represent the number of species (S) added to spider fauna based upon data of scientific description.

step towards the development of the Azorean entomological science.

However, the 23 species of endemic arthropods currently known in the Azores is a poor estimate of the estimated number, $29.22( \pm 2.59)$, as established when using the incidence nonparametric estimator Jackknife1 (Fig. 26), or 44.38 when applying the 'ratio method with Lepidoptera as indicator group' (see Table 3). However, when applying the 'ratio method with Coleoptera as indicator group' the estimate obtained (16.09) is lower that the currently observed number of Azorean endemic spider species. This implies that the rate of speciation among Azorean beetles was lower than in spiders and consequently more species of endemic beetles should have been expected taking into account the patterns observed in the Canary Islands. The estimates derived from the Araneae-Lepidoptera ratio (Table 3) are probably an overestimation, due to a higher rate of speciation of Canarian spiders. Therefore, we consider the estimate derived from Jackknife1 as our conservative estimate of the potential number of endemic spider species in the Azores. The incidence-based estimator used considers the island endemics as 'uniques', and the result obtained implies that only about $79 \%$ of Azorean endemic spiders have already been discovered. This pattern could be explained by the recent efforts in surveying the Azorean arthropod species and the lack of knowledge about the distribution of some current 'uniques'. 
274 Paulo A.V. Borges \& Joerg Wunderlich

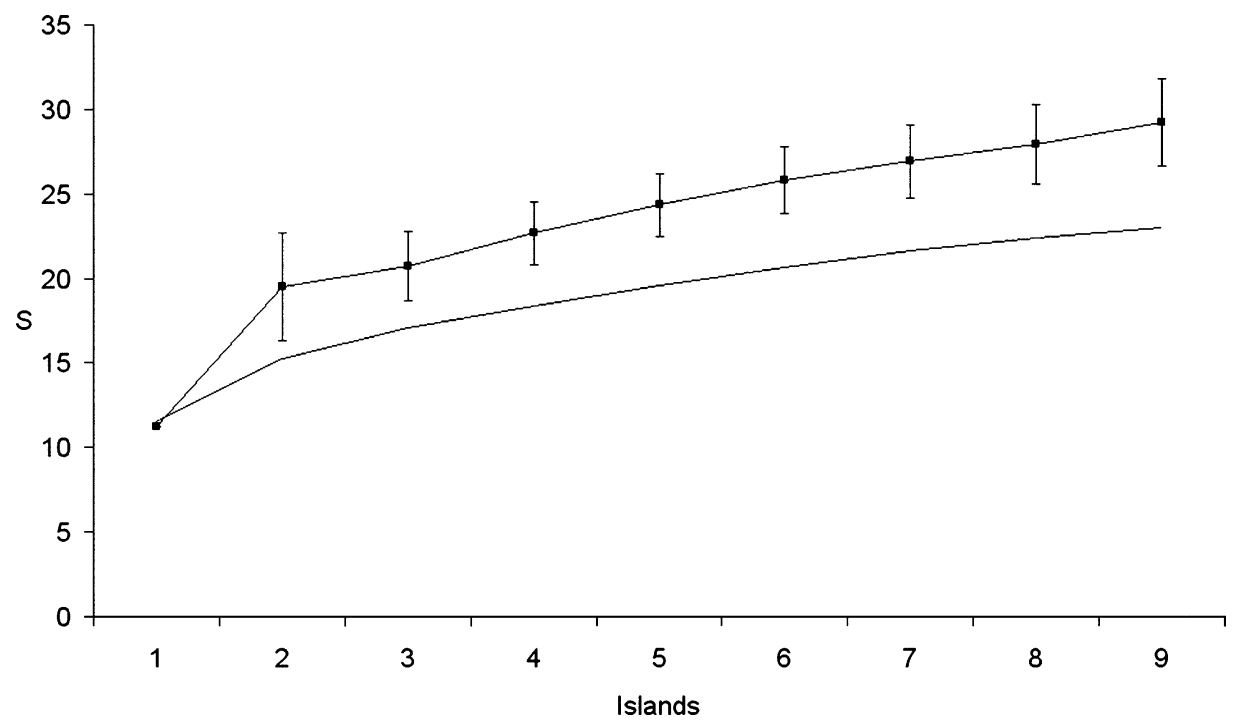

Figure 26 Accumulation curve (average of 100 random curves) (smooth line) and predicted number of endemic spider species (S) $\left({ }^{ \pm} 1\right.$ s.d.) using the incidence-based non-parametric estimator Jackknife1 with 100 randomisations.

\begin{tabular}{|c|c|c|c|c|c|}
\hline \multirow[b]{2}{*}{ Geographical area } & \multicolumn{3}{|c|}{ Number of endemic species } & \multicolumn{2}{|c|}{ Ratio of endemic Araneae to } \\
\hline & Araneae & Coleoptera & Lepidoptera & Coleoptera $^{\mathrm{a}}$ & Lepidoptera $^{\mathrm{b}}$ \\
\hline Azores & 23 & 66 & 38 & 0.35 & 0.61 \\
\hline Canaries & 306 & 1255 & 262 & 0.24 & 1.17 \\
\hline Azores Predicted - a & 16.09 & & & & \\
\hline Azores Predicted - b & 44.38 & & & & \\
\hline
\end{tabular}

Table 3 The numbers of endemic species of Araneae, Coleoptera and Lepidoptera in the Azores and the Canary Islands, plus the ratio of endemic Araneae to Coleoptera and Lepidoptera and the estimated number of Araneae in the Azores (see text for further explanations).

These 'unique' species can be considered as the rarest species, since they occur on only one island. A total of seven endemic species is known from only one island and two further species are known from only two islands. Therefore, nine endemic species (39\%) are restricted, but the species-rangesize distribution for the endemics shows a bimodal pattern (Fig. 27), in which to the left hand mode is added a right hand mode generated by the widespread group of species that occurs in almost all islands. In fact, five endemic species (22\%) are common, occurring in at least eight islands and generating a significant right hand mode $\left(\mathrm{P}_{\mathrm{r}}=0.05\right)$, in addition to the significant left hand mode $\left(P_{1}=0.005\right)$ generated by the rare species. A 'unimodal model' was obtained for the introduced species $\left(\mathrm{P}_{1}<0.0001 ; \mathrm{P}_{\mathrm{r}}>0.05\right)$, while for the native species the right and left modes are non-significant $\left(\mathrm{P}_{1}>0.05 ; \mathrm{P}_{\mathrm{r}}>\right.$ 0.05) (Fig. 27). This implies that most introduced species are also restricted, which is explained by non inter-island spreading after their introduction to a particular island or inadequate sampling efforts in focal habitats altered by humans.

The lack of population studies and demographic monitoring makes it difficult to characterise the threatened status of Azorean endemic spider species. Despite this limitation, we still have some recent information from the standardised studies performed in pastureland (Borges, 1999; Borges \& Brown,
1999, 2001, 2004), native habitats (Borges et al., 2005a; Borges et al., unpublished data), exotic plantations (Borges et al., unpubl. data) and fruit orchards (Santos et al., 2005). Habitat loss and invasive species are considered as the principal threats to Azorean native fauna (see Martins, 1993; Borges et al., 2006). Therefore, we may ask which Azorean endemic spider species are most sensitive to habitat loss and degradation.

To answer that question we could define eight possible land-use types ('Habitats' in general terms) that have been surveyed intensively for arthropods in the Azores since 1994 (see Methods). A total of 81 of the 122 Azorean spiders were sampled in at least one of the eight land-use types. Remarkably, almost all indigenous species are included (22 endemics in 23 possible and 11 natives in 12 possible). The 41 species not sampled are, almost all, introduced species associated with human buildings, gardens and other non-native particular habitats. In Table 4 we show the distribution of each endemic species with their relative abundance in the eight land-use types with the exception to caves where no abundance data are available. Most of the endemic species occur in only one or two land-use types (mainly native; see Table 4), but four endemic species occur in at least five land-use types (Fig. 28). In Fig. 29 we show that there is a clear separation between native habitats 


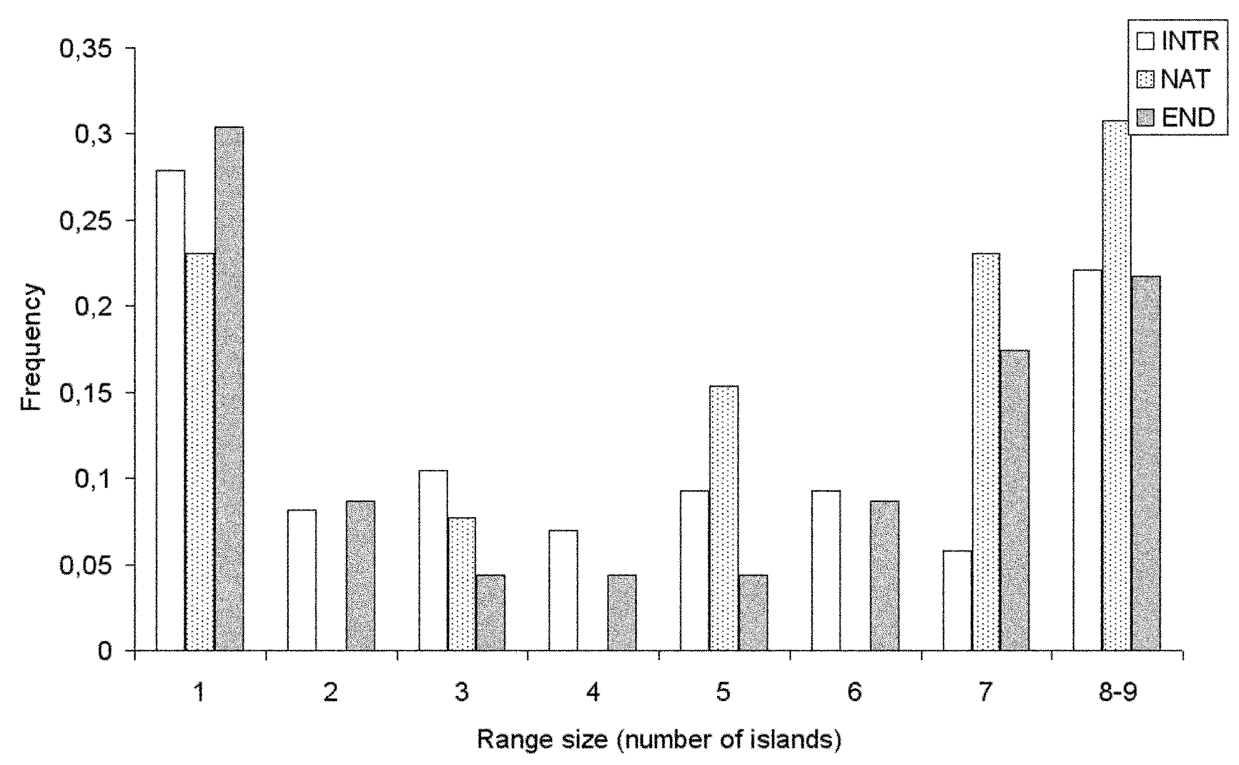

Figure 27 Frequency histogram of species distributions showing the proportion of endemic (END), native (NAT) and introduced (INTR) spider species known in the nine Azorean islands.

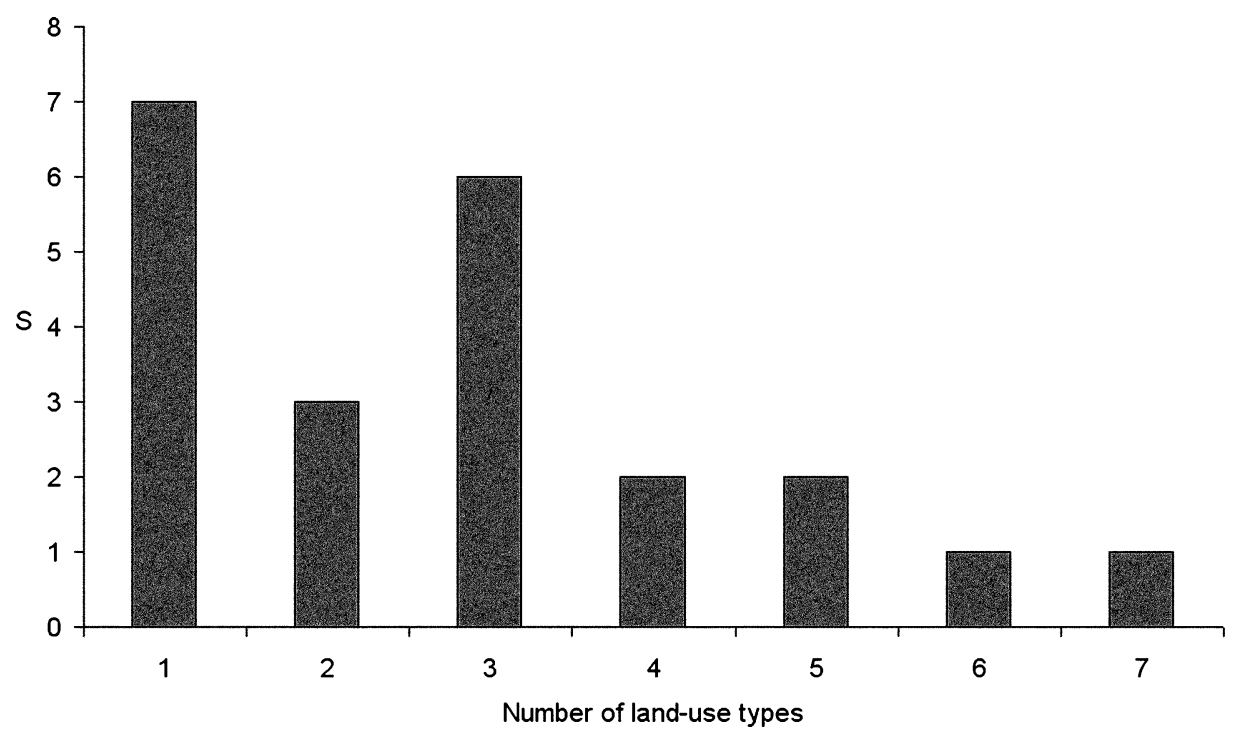

Figure 28 Frequency histogram of species distributions showing the number of endemic spider species known in the eight land-use types.

and non-native habitats in terms of endemic spider species composition. Caves are included in the non-native habitats since in spite of having two specialised species (Rugathodes pico and the new Turinyphia cavernicola Wunderlich, sp. nov.) the other endemic spiders occur in entrances and are habitat generalist spiders.

When one looks for patterns of species richness in this gradient of land-use degradation with complex native lowdisturbed habitats (native forest canopies, native forest soil, natural grassland), medium disturbed habitats (semi-natural pasture, exotic tree plantations) and highly disturbed habitats (intensive pasture, fruit orchards), one observes that the proportion of spider endemic species decreases and the proportion of introduced spider species increases with the increase in habitat disturbance (Fig. 30a). The proportion of native species remains more or less constant in this gradient. This pattern is mainly a consequence of the decrease of the absolute number of endemic species with habitat disturbance, since the number of non-endemic species remains more or less constant in the various habitats (Fig. 30b).

Moreover, the relative abundance of indigenous fauna also decreases with the disturbance regime associated with the investigated land-use gradient (Fig. 31). Notably, when plotting the ratio of the abundance of endemic plus native (indigenous) species to introduced species, one notices a clear dominance of indigenous species in canopy communities $(10 \times$ more specimens) (Fig. 31). In native forests epigean communities and natural grassland communities the indigenous fauna is only $2.77 \times$ and $2.49 \times$, respectively, more abundant than introduced fauna. In the highly disturbed semi-natural and 


\begin{tabular}{|c|c|c|c|c|c|c|c|c|c|}
\hline Family & Species & 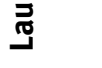 & $\overline{\widetilde{త}}$ & 茾 & త্ర & ํㅗ & $\bar{n}$ & 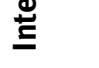 & 폰 \\
\hline Lycosidae & Pardosa acoreensis Simon, 1883 & 0.001 & 0.152 & 0.416 & $\mathrm{P}$ & 0.194 & 0.043 & 0.016 & \\
\hline Theridiidae & Rugathodes acoreensis Wunderlich, 1992 & 0.066 & 0.026 & 0.002 & $\mathrm{P}$ & 0.013 & & 0.000 & \\
\hline Araneidae & Gibbaranea occidentalis Wunderlich, 1989 & 0.059 & 0.001 & & & & 0.000 & & \\
\hline Pisauridae & Pisaura acoreensis Wunderlich, 1992 & 0.003 & 0.003 & 0.001 & & & & & \\
\hline Theridiidae & Lasaeola oceanica Simon, 1833 & 0.009 & 0.000 & & & & 0.002 & & \\
\hline Linyphiidae & $\begin{array}{l}\text { Savigniorrhipis acoreensis } \\
\text { Wunderlich, } 1992\end{array}$ & 0.306 & 0.005 & & & & & & \\
\hline Linyphiidae & $\begin{array}{l}\text { Lepthyphantes acoreensis } \\
\text { Wunderlich, } 1992\end{array}$ & 0.000 & 0.046 & 0.008 & $P$ & 0.006 & & & \\
\hline Tetragnathidae & Sancus acoreensis (Wunderlich, 1992) & 0.042 & 0.002 & & & & 0.000 & & \\
\hline Salticidae & Neon acoreensis Wunderlich, n.sp. & 0.001 & 0.002 & 0.002 & & & & 0.000 & \\
\hline Dictynidae & Dictyna acoreensis (Wunderlich, 1992) & 0.010 & & & & & & & 0.016 \\
\hline Linyphiidae & Acorigone acoreensis (Wunderlich, 1992) & 0.012 & 0.003 & 0.002 & & & & & \\
\hline Linyphiidae & Minicia floresensis Wunderlich, 1992 & 0.015 & 0.001 & 0.008 & & & 0.001 & & \\
\hline Linyphiidae & Walckenaeria grandis (Wunderlich, 1992) & 0.001 & 0.003 & 0.003 & & & & & \\
\hline Linyphiidae & Porrhomma borgesi Wunderlich, n.sp. & 0.000 & 0.003 & 0.001 & $\mathrm{P}$ & 0.006 & & & \\
\hline Theridiidae & $\begin{array}{l}\text { Rugathodes pico (Merrett \& } \\
\text { Ashmole, 1989) }\end{array}$ & & & & $\mathrm{P}$ & & & & \\
\hline Linyphiidae & Agyneta rugosa Wunderlich, 1992 & & 0.000 & & & & & & \\
\hline Linyphiidae & Turinyphia cavernicola Wunderlich, n.sp. & & & & $\mathrm{P}$ & & & & \\
\hline Linyphiidae & Agyneta depigmentata Wunderlich, n.sp. & & 0.049 & 0.041 & & & & & \\
\hline Clubionidae & $\begin{array}{l}\text { Cheiracanthium floresense Wunderlich, } \\
\text { sp. nov. }\end{array}$ & 0.003 & & & & & & & \\
\hline Linyphiidae & Acorigone zebraneus Wunderlich, n.sp. & & 0.001 & & & & & & \\
\hline Clubionidae & $\begin{array}{l}\text { Cheiracanthium } \\
\text { jorgeense Wunderlich, n.sp. }\end{array}$ & 0.000 & & & & & & & \\
\hline Oonopidae & Orchestina furcillata Wunderlich, n.sp. & & 0.000 & & & & & & \\
\hline
\end{tabular}

Table 4 The relative abundance of 22 endemic spider species in each of eight possible land-use types. For caves only the presence is recorded. The rarest species are marked (see text).

intensive pastures and fruit orchards the spider communities are dominated by specimens of introduced species (Fig. 31).

What is the role of each individual species in the abovedescribed patterns, and which endemic spider species are truly abundant or scarce, and which are habitat specialists or habitat generalists? The information concerning the most abundant species is summarised in Table 5 .

There are some clear and very interesting patterns:

(1) The most abundant species in canopy habitats (native laurisilva and fruit orchards) are only dominant in those habitats ('canopy specialists').
(2) Native forest canopy is the only habitat in which the dominant species are only indigenous species (endemic or native).

(3) Three habitats harbour at least four similar dominant species: epigean native (laurel) and exotic (plantations) forest communities and natural grassland.

(4) The four most abundant species in native forests and exotic forests are the same, two of the species are introduced spiders.

(5) The most abundant species in semi-natural and intensive pasture are the same, the only difference is the inclusion of the endemic Pardosa acorensis (LYCOSIDAE) in the semi-natural pasture dominant species. 


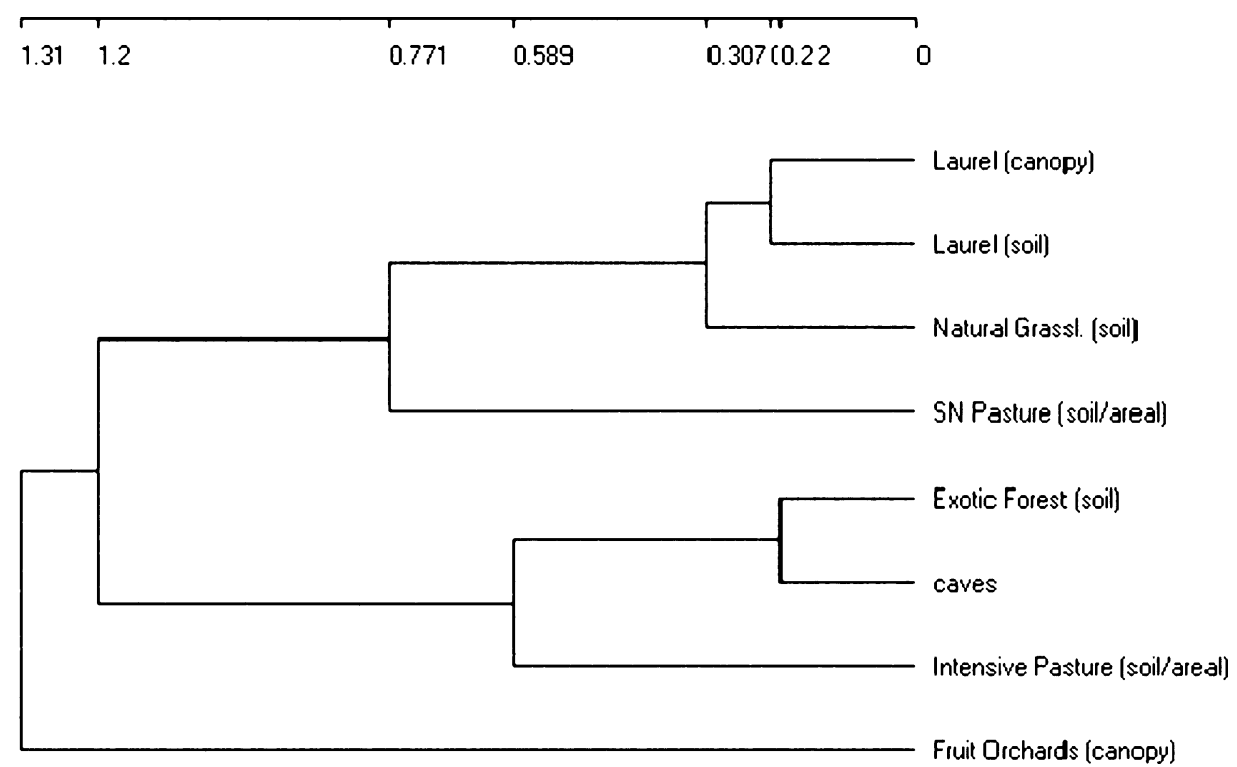

Figure 29 Dendrogram of land-use types (habitats) based on presence/absence of endemic spiders.

(6) The introduced Lepthyphantes tenuis (LINYPHIIDAE) and the endemic Pardosa acorensis (LYCOSIDAE) are the only spider species that are common in at least four of the seven evaluated habitats (true generalist species).

(7) Two species, the native Lepthyphantes miguelensis (LINYPHIIDAE) and the introduced Oedothorax fuscus (LINYPHIIDAE), are the only species that are the top dominants in two different habitats.

The commonest of all the Azorean spiders listed in Table 5 totalled 26 species, that is $21 \%$ of the Azorean known species. Of those 26 species 54\% (14 species) are indigenous (i.e. endemic or native). Moreover, a total of seven endemic species (30\% of the endemics) are truly common in at least one of the habitats. But what about the other endemic species? Above we showed that some species are restricted to only one or two islands. In Fig. 32 (see also Table 4) we show that the species that occur on few islands tend to be habitat specialists, and species with wider distribution tend to occur in more habitats $(\mathrm{r}=0.81 ; \mathrm{p}<0.0001)$. Therefore a group of eight endemic spider species is truly rare, both in distribution, abundance and also in habitat specialisation (Table 4). Six out of the eight species are described as new to science in this paper belong to this group of rare species, which comes as no surprise since they were discovered after several years of standardised sampling in seven of the Azorean islands in different native and non-native habitats. Those species are restricted to native habitats and are the true rare species in the known assemblage of 23 endemic spiders of the Azores.

For many of the endemic Azorean spiders adapted to natural grasslands, years of pasture intensification in these islands had no particular impact, since they could occur in semi-natural pastures with low input in pesticides (see Borges, 1999). This is the case of the common Minicia floresensis Wunderlich, Lasaeola oceanica Simon, Rugathodes acoreensis Wunder- lich, Neon acoreensis Wunderlich and Pardosa acoreensis Simon. Some endemic spiders seem to be also adapted to nonnative habitats, occurring mainly in native forests but also frequently in exotic plantations and fruit orchards (see Table 4) These preferences are displayed by Pardosa acoreensis Simon, Rugathodes acoreensis Wunderlich and Dictyna acoreensis (Wunderlich).

However, all the other remaining endemic spiders are mainly adapted to native habitats like volcanic caves (Rugathodes pico (Merrett \& Ashmole), Turinyphia cavernicola Wunderlich), natural grassland (Pisaura acoreensis Wunderlich, Walckenaeria grandis (Wunderlich), Typhochrestus acoreensis Wunderlich) and Laurisilva forest (Lepthyphantes acoreensis Wunderlich, Savigniorrhipis acoreensis Wunderlich, Acorigone acoreensis (Wunderlich), Acorigone zebraneus Wunderlich, Agyneta depigmentata Wunderlich, Porrhomma borgesi Wunderlich, Agyneta rugosa Wunderlich, Cheiracanthium floresense Wunderlich, Cheiracanthium jorgeense Wunderlich, Orchestina furcillata Wunderlich).

In their natural environment the greatest threats to spiders are habitat destruction and pesticides. As a consequence of the impact invasive plants that are altering the soil cover and structure in the Azores, species like Lepthyphantes acoreensis Wunderlich, Acorigone zebraneus Wunderlich, Agyneta depigmentata Wunderlich, Porrhomma borgesi Wunderlich and Agyneta rugosa Wunderlich could be at risk of having its main habitat seriously reduced.

As showed by Borges et al. (2006) invasions of alien arthropod species are a current and future environmental threat in the Azores, creating a pattern of biotic homogenisation that is of great contemporary concern. However, inconclusive evidence suggests that non-indigenous species are limited to those sites under anthropogenic influence located mainly in marginal places, but the rate of expansion of those species to high 
$\mathbf{2 7 8}$ Paulo A.V. Borges \& Joerg Wunderlich

a

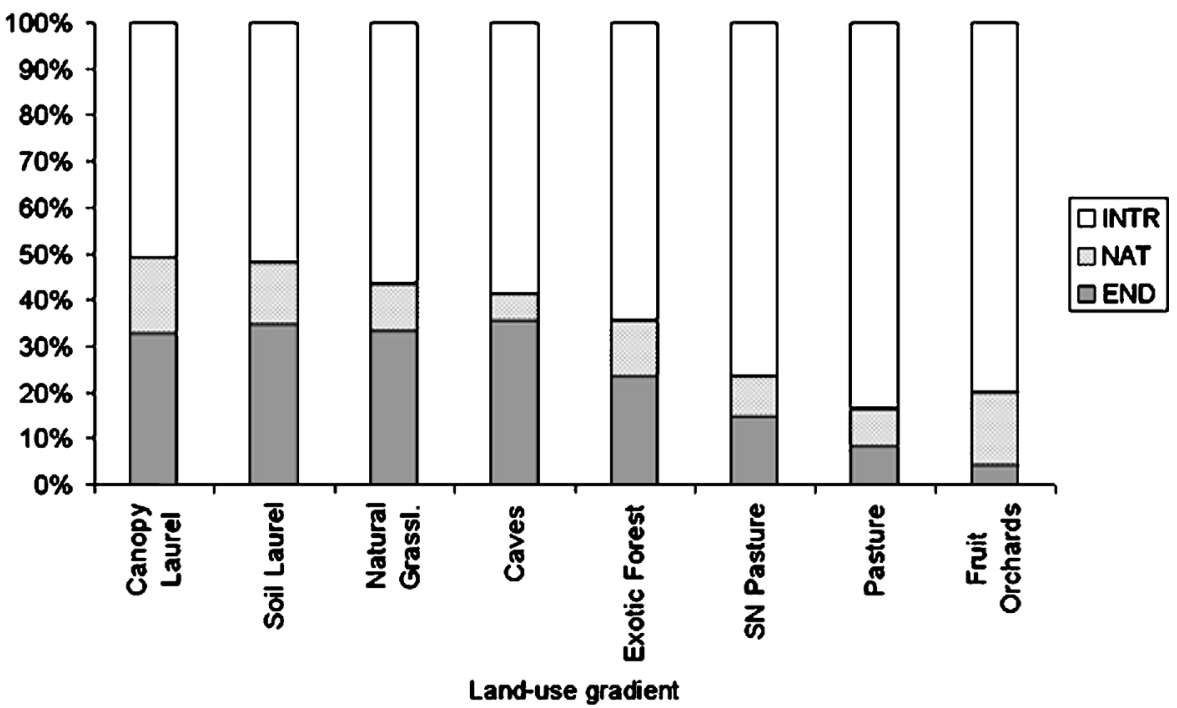

b

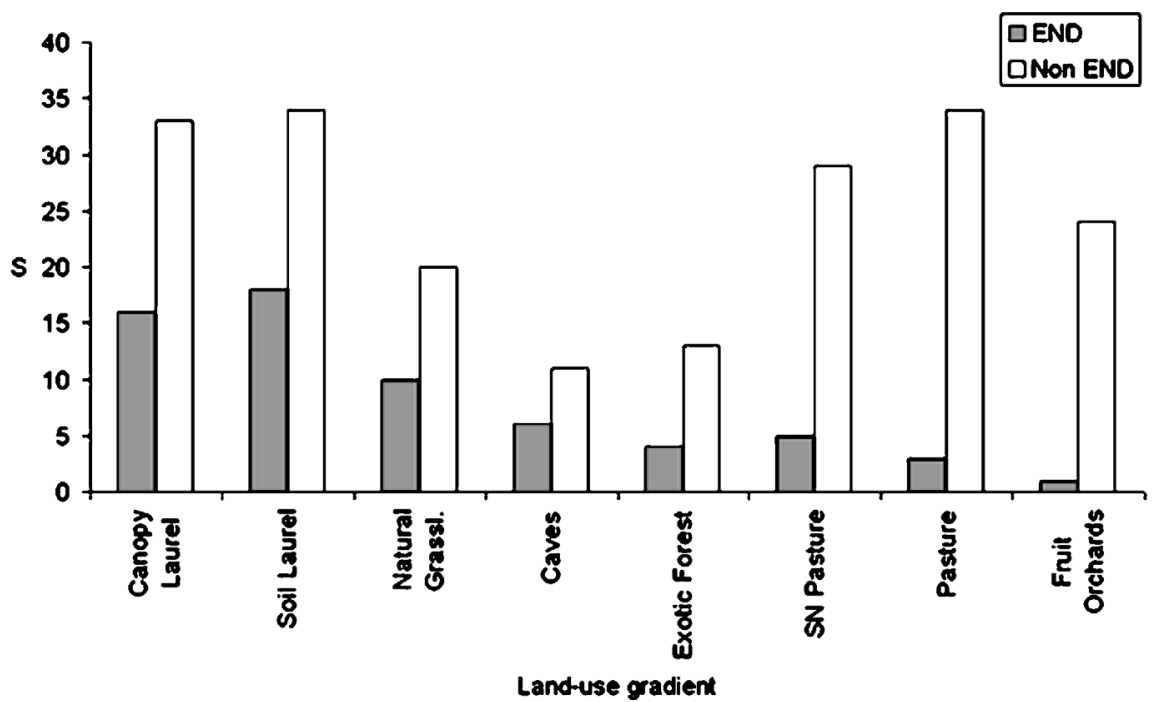

Figure 30 (a) Frequency histogram of species distributions showing the proportion of endemic (END), native (NAT) and introduced (INTR) spider species known in the nine Azorean islands; (b) Number of endemic (END) and introduced (INTR) spider species in each habitat.

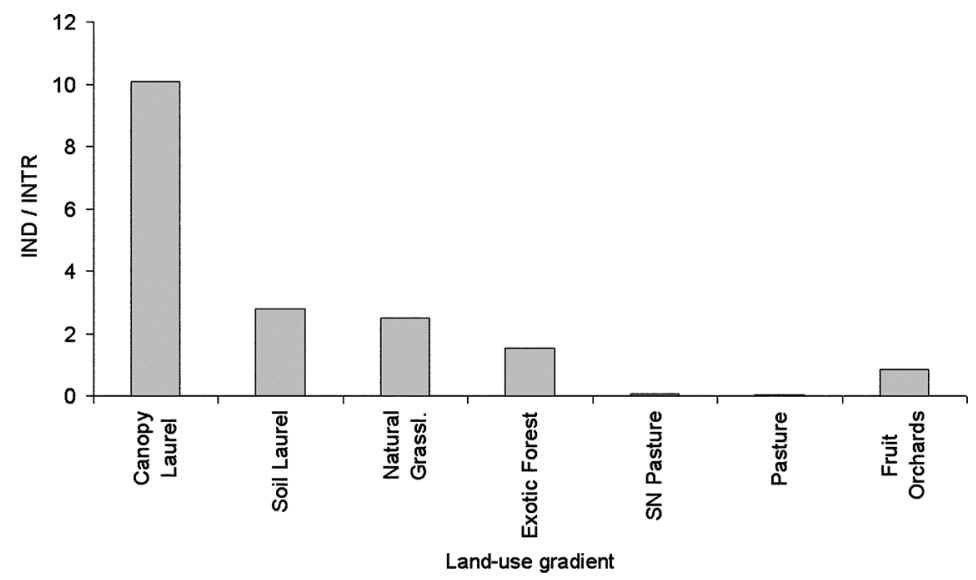

Figure 31 Relative abundance of indigenous spider species in each habitat. 


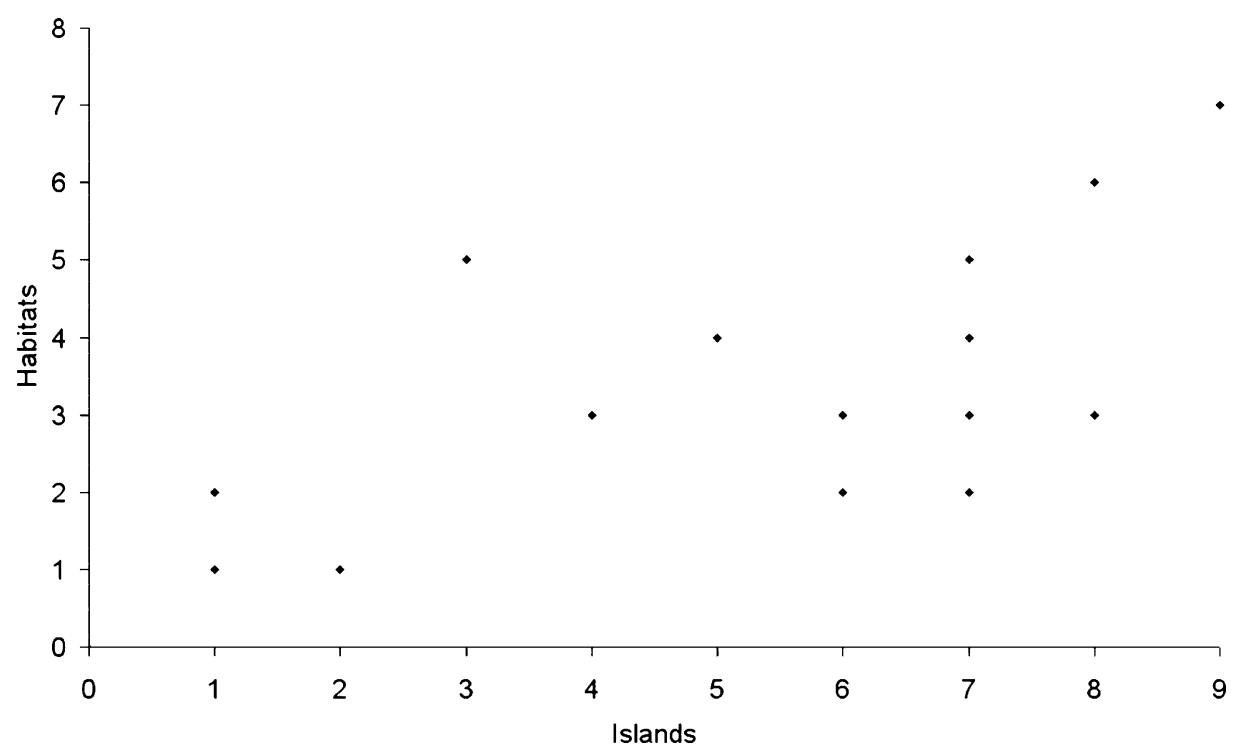

Figure 32 Scatter plot relating the number of habitats and the number of islands from which each the 23 Azorean spider endemic species are known.

altitude core pristine sites has still to be tested (Borges et al., 2006).

The 23 currently known Azorean endemic spider species are probably the survivors of 500 years of major human habitat alterations in the Azores. However, species adapted to cave life are still in danger as a consequence of pasture development and consequent lava-tube destruction. Moreover, all the grassland species could be at risk if pollution, predominantly that coming from pesticides, increases as a consequence of changing agricultural policy sometime in the future.

Species able to live in the canopies of native and endemic Azorean trees (e.g. Rugathodes acoreensis Wunderlich, Neon acoreensis Wunderlich, Gibbaranea occidentalis Wunderlich, Sancus acoreensis (Wunderlich), Dictyna acoreensis (Wunderlich), Savigniorrhipis acoreensis Wunderlich, Acorigone acoreensis (Wunderlich), Pisaura acoreensis Wunderlich, Cheiracanthium floresense Wunderlich, Cheiracanthium jorgeense Wunderlich) are probably the species with a lower risk factor, since most of the canopy arthropod species are composed of native endemic taxa (Borges et al., unpubl. data). However, exotic plant species in the Azores are already threatening entire ecosystems, as is the case of Clethra arborea Aiton in Pico da Vara (São Miguel). The effects of this invasion on individual endemic spider species in Laurel forest at Pico da Vara remain to be tested.

\section{Conclusions}

Until recently the Azorean archipelago was characterised as harbouring few endemic spider species. However, in the past decade efforts in the survey of the arthropod fauna in remote places (e.g. dense laurel forest in high altitude and inaccessible places) and unsampled habitats (e.g. tree canopies, lava tubes), have challenged this view. The Azores has a rich and generally unappreciated endemic arthropod biodiversity (see Borges et al., 2005d), and we showed that the endemic spider fauna is now an important component of Azorean biodiversity. Inventories have, to date, recorded 122 species of spiders, 23 of which are endemic, including eight new species described in this contribution. The species accumulation curve does not show any evidence of saturation, and we estimated that only about $79 \%$ of all the Azorean endemic spiders have already been discovered.

The slope of the SAR for the indigenous fauna is high, which probably implies some historical extinction in the smaller islands. What remains of the natural ecosystems in the Azores is now highly fragmented (Borges et al., 2006), but we showed that, in spite of the dramatic land-use changes in historical times, the proportion of indigenous species is still high in native habitats, particularly in native tree canopies where the endemic spiders dominate in abundance.

Most endemic spider species are restricted to native forest fragments and natural grassland, but at least $30 \%$ of those species are dominant in abundance. About eight endemic species are quite rare, being restricted to one or two islands, restricted to native habitats, and with small populations.

Invasive exotic spiders could be major agents of change in natural communities, since they could eliminate native or endemic relatives through competition. Therefore, the great proportion of introduced species in the Azorean spider fauna is of great concern.

Despite the historically widespread human destruction and influence on land-use changes of Azorean native habitats at low and middle altitudes, the canopies of native and endemic trees still common in high altitude protected native forests seem to be free of exotic species. Thus, canopy spider communities could be considered as unchanged and probably open a window to the once pristine spider communities in the Azores.

The greatest challenge facing the Azorean Environment Bureau is the maintenance and correct management of the current pristine areas of native forests, native grasslands and cave systems, avoiding the destructive effects of invasive plants 
$\mathbf{2 8 0}$ Paulo A.V. Borges \& Joerg Wunderlich

\begin{tabular}{|c|c|c|c|}
\hline Land-use (Habitat) & Species & Col. & RA \\
\hline \multirow[t]{6}{*}{ Laurel (canopy) } & Savigniorrhipis acoreensis Wunderlich & $\mathrm{E}$ & 0.31 \\
\hline & Lathys dentichelis (Simon) & $\mathrm{N}$ & 0.28 \\
\hline & Rugathodes acoreensis Wunderlich & $E$ & 0.07 \\
\hline & Gibbaranea occidentalis Wunderlich & $E$ & 0.06 \\
\hline & Xysticus cor Canestrini & $\mathrm{N}$ & 0.05 \\
\hline & Sancus acoreensis (Wunderlich) & $\mathrm{E}$ & 0.04 \\
\hline \multirow[t]{6}{*}{ Laurel (soil) } & Lepthyphantes miguelensis Wunderlich & $\mathrm{N}$ & 0.38 \\
\hline & Pardosa acorensis Simon & $E$ & 0.15 \\
\hline & Lepthyphantes tenuis (Blackwall) & I & 0.13 \\
\hline & Dysdera crocata C. L. Koch & I & 0.09 \\
\hline & Agyneta depigmentata Wunderlich & $\mathrm{E}$ & 0.05 \\
\hline & Lepthyphantes acoreensis Wunderlich & $\mathrm{E}$ & 0.05 \\
\hline \multirow[t]{6}{*}{ Natural grassl. (soil) } & Pardosa acorensis Simon & $E$ & 0.42 \\
\hline & Lepthyphantes schmitzi (Kulczynski) & $\mathrm{N}$ & 0.13 \\
\hline & Tenuiphantes miguelensis Wunderlich & $\mathrm{N}$ & 0.09 \\
\hline & Oedothorax fuscus (Blackwall) & I & 0.09 \\
\hline & Lepthyphantes tenuis (Blackwall) & 1 & 0.05 \\
\hline & Agyneta depigmentata Wunderlich & $E$ & 0.04 \\
\hline \multirow[t]{5}{*}{ Exotic forest (soil) } & Lepthyphantes miguelensis Wunderlich & $\mathrm{N}$ & 0.36 \\
\hline & Pardosa acorensis Simon & $E$ & 0.19 \\
\hline & Lepthyphantes tenuis (Blackwall) & I & 0.18 \\
\hline & Dysdera crocata C. L. Koch & 1 & 0.09 \\
\hline & Agyneta decora (O. P.-Cambridge) & I & 0.05 \\
\hline \multirow[t]{7}{*}{ SN pasture (soil/areal) } & Oedothorax fuscus (Blackwall) & I & 0.26 \\
\hline & Lepthyphantes tenuis (Blackwall) & I & 0.19 \\
\hline & Erigone atra (Blackwall) & I & 0.14 \\
\hline & Erigone dentipalpis (Wider) & I & 0.12 \\
\hline & Erigone autumnalis Emerton & I & 0.11 \\
\hline & Achaearanea acoreensis (Berland) & I & 0.06 \\
\hline & Pardosa acorensis Simon & $E$ & 0.04 \\
\hline \multirow[t]{6}{*}{ Intensive pasture (soil/areal) } & Oedothorax fuscus (Blackwall) & 1 & 0.39 \\
\hline & Lepthyphantes tenuis (Blackwall) & I & 0.12 \\
\hline & Erigone autumnalis Emerton & I & 0.12 \\
\hline & Erigone dentipalpis (Wider) & I & 0.11 \\
\hline & Achaearanea acoreensis (Berland) & I & 0.09 \\
\hline & Erigone atra (Blackwall) & I & 0.08 \\
\hline \multirow[t]{6}{*}{ Fruit orchards (canopy) } & Nigma puella (Simon) & 1 & 0.32 \\
\hline & Clubiona decora Blackwall & $\mathrm{N}$ & 0.20 \\
\hline & Entelecara schmitzi Kulczynski & $\mathrm{N}$ & 0.16 \\
\hline & Metellina merianae (Scopoli) & I & 0.08 \\
\hline & Macaroeris diligens (Blackwall) & $\mathrm{N}$ & 0.08 \\
\hline & Steatoda grossa (C.L. Koch) & 1 & 0.04 \\
\hline
\end{tabular}

Table 5 The commonest spider species ( $>4 \%$ in relative abundance, RA) in the various habitats (land-use types). EEndemic; $\mathrm{N}$ - native; I - Introduced.

and animals. We know which species are rare, where they should be preserved, but an effort to acquire information on their basic biology is urgently needed.

\section{Supplementary Material}

The following supplementary material is available for this article on Cambridge Journals Online: http://www.journals.cup.org/abstract_S1477200008002648.

Table S1 Physical features of the Azorean islands.
Table S2 Additional Material per taxon.

Table S3 UTM coordinates, altitude, month and year of sampling and habitat of the studied transects in the Azores.

Appendix S1. Distribution of the Azorean spider species by the nine islands.

\section{Acknowledgements}

The biological investigations that form the basis for this manuscript have been facilitated by the support of many organisations and 
individuals. First and foremost, we would like to acknowledge the continuous support of Eduardo Carqueijeiro, 'Director Regional do Ambiente' (Secretaria Regional do Ambiente e do Mar do Governo Regional dos Açores). The entomological scientific expeditions to the various Azorean islands over the past years were made possible by the generous support of Manuel Loureiro, 'Director dos Serviços Florestais' (1998-2000), through the Project 'Reservas Florestais dos Açores: Cartografia e Inventariação dos Artrópodes Endémicos dos Açores' (PROJ. 17.01 - 080203).

We wish to thank Regina Meneses for her kind review of our English. We also want to thank P. Cardoso and J. Hortal for comments on earlier versions of this manuscript.

Thanks are also due to C. Aguiar, J. Amaral, G. André, A. Arraiol, C. Gaspar, S. Jarroca, C. Melo, F. Pereira, H. Mas i Gisbert, A. Rodrigues, A. Santos, A. Serrano, L. Vieira and A. Vitorino for their valuable contribution to field and/or laboratory work.

\section{References}

Agostinho, J. 1966. The topography and natural features of the Azores archipelago and their influence on the bird life. In: BANNERMAN, D.A. \& BANNERMAN, W.M., Eds., Birds of the Atlantic Islands III. A History of the Birds of the Azores. Oliver and Boyd, London, pp. 1-9.

Ashmole, N.P., Oromí, P., Ashmole, M.J. \& Martín, J.L. 1996. The invertebrate fauna of early successional volcanic habitats in the Azores. Boletim do Museu Municipal do Funchal 48, 5-39.

BAERT, L. \& JOCQUÉ, R. 1993. A tentative analysis of the spider fauna of some tropical oceanic islands. Memoirs of the Queensland Museum 33, 447-454.

BARRETO, S., Borges, P.A.V. \& GuO, Q. 2003. A Typing error in the Tokeshi's test of bimodality. Global Ecology and Biogeography 12, 173-174.

BASSET, Y. 1991. The taxonomic composition of the arthropod fauna associated with an Australian rainforest tree. Australian Journal of Zoology 39, 171-190.

BASSET, Y. 1999. Diversity and abundance of insect herbivores collected on Castanopsis acuminatissima (Fagaceae) in New Guinea: relationships with leaf production and surrounding vegetation. European Journal of Entomology 96, 381-391.

Borges, P.A.V. 1992. Biogeography of the Azorean Coleoptera. Boletim do Museu Municipal do Funchal 44, 5-76.

BorGES, P.A.V. 1999. A list of arthropod species of sown and seminatural pastures of three Azorean islands (S. Maria, Terceira and Pico) with some conservation remarks. Açoreana 9, 13-34.

BorGES, P.A.V. \& BROWN, V.K. 1999. Effect of island geological age on the arthropod species richness of Azorean pastures. Biological Journal of the Linnean Society 66, 373-410.

Borges, P.A.V. \& BROWN, V.K. 2001. Phytophagous insects and web-building spiders in relation to pasture vegetation complexity. Ecography 24, 68-82.

Borges, P.A.V. \& BROWN, V.K. 2004. Arthropod community structure in pastures of an island archipelago (Azores): looking for local-regional species richness patterns at small-scales. Bulletin of Entomological Research 94, 111-121.

Borges, P.A.V. \& Oromí, P. 1994. The Azores. In: JuberthiE C. \& DECU V., Eds., Encyclopaedia Biospeleologica. Tome I. pp. 605-610. Sociétè de Biospéleologie, Moulis.

Borges, P.A.V. \& OROMÍ, P. in press. The Azores. In: JuberTHIE, C. \& DECU, V., Eds., Encyclopaedia Biospeleologica. Tome Ia Amérique et Europe. Sociétè de Biospéleologie, Moulis.

Borges, P.A.V. \& Wunderlich, J. 2005. Araneae. In: Borges, P.A.V., CunHa, R., Gabriel, R. Martins, A.M.F., Silva, L. \& VIEIRA, V., Eds., A List of the Terrestrial Fauna (Mollusca and Arthropoda) and Flora (Bryophyta, Pteridophyta and Spermatophyta) from the Azores. Direcção Regional de Ambiente and Universidade dos Açores, Horta, Angra do Heroísmo and Ponta Delgada, pp. 178-180.
Borges, P.A.V., ENghoff, H., ERber, D., IlHarco, F.A., Monserrat, V.J., Quartau, J.A., Ribes, J., SERrano, A.R.M., VieIRA, V., WUNDERLICH, J. \& ZUR STRASSEN, R. 2000b. New records for the Azorean arthropod fauna. Açoreana 9, 117-138.

BORgES, P.A.V., SERRANO, A.R.M. \& QUARTAU, J.A. 2000a. Ranking the Azorean Natural Forest Reserves for conservation using their endemic arthropods. Journal of Insect Conservation 4, 129147.

Borges, P.A.V., Aguiar, C., Amaral, J., Amorim, I.R., ANDré, G., Arraiol, A., Baz, A., Dinis, F., Enghoff, H., Gaspar, C., Ilharco, F., Mahnert, V., Melo, C., Pereira, F., QuARTAU, J.A., RibeIro, S., Ribes, J., SERRANO, A.R.M., SOUSA, A.B., Strassen, R.Z., Vieira, L., Vieira, V., Vitorino, A. \& WUNDERLICH, J. 2005a. Ranking protected areas in the Azores using standardized sampling of soil epigean arthropods. Biodiversity and Conservation 14, 2029-2060.

Borges, P.A.V., CunHA, R., GABriel, R., Martins, A.F., Silva, L. \& VIEIRA, V. (eds.) 2005b. A list of the terrestrial fauna (Mollusca and Arthropoda) and flora (Bryophyta, Peridophyta and Spermatophyta) from the Azores. Direcção Regional do Ambiente and Universidade dos Açores, Horta, Angra do Heroísmo and Ponta Delgada, 318 pp.

Borges, P.A.V., Cunha, R., Gabriel, R., Martins, A.F., Silva, L., VIEIRA, V., DinIS, F., LOURENÇO, P. \& PINTO, N. 2005d. Description of the terrestrial Azorean biodiversity. In: BORGES, P.A.V., Cunha, R., Gabriel, R., Martins, A.M.F., SiLva, L. \& VieirA, V., Eds., A List of the Terrestrial Fauna (Mollusca and Arthropoda) and Flora (Bryophyta, Pteridophyta and Spermatophyta) from the Azores. Direcção Regional de Ambiente and Universidade dos Açores, Horta, Angra do Heroísmo and Ponta Delgada, pp. 21-68.

Borges, P.A.V., Oromí, P., Dinis, F. \& Jarroca, S. 2005c. Coleoptera. In: Borges, P.A.V., CUNHA, R., GABRIEL, R., MARTINS, A.M.F., SILVA, L. \& VIEIRA, V., Eds., A List of the Terrestrial Fauna (Mollusca and Arthropoda) and Flora (Bryophyta, Pteridophyta and Spermatophyta) from the Azores. Direcção Regional de Ambiente and Universidade dos Açores, Horta, Angra do Heroísmo and Ponta Delgada, pp. 197-207.

Borges, P.A.V., Lobo, J.M., AzEVEdo, E.B., GASPar, C., Melo, C. \& NUNES, L.V. 2006. Invasibility and species richness of island endemic arthropods: a general model of endemic vs. exotic species. Journal of Biogeography 33, 169-187.

CABRERO-SAÑUDO, F.J. \& LOBO, J.M. 2003. Estimating the number of species not yet described and their characteristics: the case of Western Palaearctic dung beetle species (Coleoptera, Scarabaeoidea). Biodiversity and Conservation 12, 147-166.

CARDOSO, P. 2004. The use of arachnids (class Arachnida) in biodiversity evaluation and monitoring of natural areas. Ph.D. Thesis, Universidade de Lisboa, Lisboa.

CARDOSO, P. \& CRESPO, L.C. in press. In: Borges, P.A.V., ABREAU, C., Aguiar, A.M.F., Carvalho, P. Jardim, R., Melo, I., OliVeira, P., SERgio, C., Serrano, A. R. M. \& Vieira, P., Eds., A list of the terrestrial fauna and flora of Madiera. Direcção Regional do Ambiente da Madiera and Universidade dos Açores, Funchal and Angra do Heroísmo.

COLwEll, R.K. \& CODDINGTON, J.A. 1994. Estimating terrestrial biodiversity through extrapolation. Philosophical Translations of the Royal Society of London 345, 101-118.

DEELEMAN-REINHOLD, C.L. 2001. Forest Spiders of South East Asia. Brill, Leiden, $591 \mathrm{pp}$.

DENIS, J. 1964. Spiders from the Azores and Madeira. Boletim do Museu Municipal do Funchal 18, 68-102.

DIAS, E. 1996. Vegetação Natural dos Açores: Ecologia e Sintaxonomia das Florestas Naturais. Ph.D. Thesis, Universidade dos Açores, Angra do Heroísmo.

DOLPHIN, K. \& QUICKE, D.L.J. 2001. Estimating the global species richness of an incompletely described taxon: an example using parasitoid wasps (Hymenoptera: Braconidae). Biological Journal of the Linnean Society 73, 279-286. 
DREPA 1988. Açores, projecção demográfica de 1980 a 2000. DREPA 2/88. Angra do Heroísmo.

EMERSON, B.C. 2002. Evolution on oceanic islands: molecular phylogenetic approaches to understanding pattern and process. Molecular Ecology 11, 951-966.

FrANÇA, Z., CRUZ, J.V., NUNES, J.C. \& FORJAZ, V.H. 2003. Geologia dos Açores: uma perspectiva actual. Açoreana 11, 11-140.

GASTON, K.J. 1994. Rarity. Chapman \& Hall, London.

HAMmOND, P.M. 1994. Species inventory. In: GroombridGe, B., Ed., Global Biodiversity: Status of the Earths Living Resources. Chapman and Hall, London, pp. 17-39.

HENDERSON, P.A. \& SEABY, R.M.H. 2002. Species Diversity and Richness-Projecto Mamirauá, Version 3.0. Pisces Conservation Ltd. www.pisces-conservation.com.

HENDERSON, P.A. \& SEABY, R.M.H. 2004. CAP - Community Analysis Package, Version 3.0. Pisces Conservation Ltd. www.piscesconservation.com

Hortal, J., Borges, P.A.V. \& GASPAR, C. 2006. Fitting species accumulation curves in arthropod data at different spatial scales. Journal of Animal Ecology 75, 274-287.

IZQuIERdo, I., MARTIN, J.L., ZuRITA, N. \& ARECHAVALETA, M. (Eds.) 2001. Lista de especies silvestres de Canarias (hongos, plantas y animales terrestres) 2001. Consejería de Política Territorial y Medio Ambiente del Gobierno de Canarias.

IZQUIERDO, I., MARTIN, J.L., ZURITA, N. \& AREChAVALETA, M. (Eds.) 2004. Lista de especies silvestres de Canarias (hongos, plantas y animales terrestres. 2nd edn, Consejería de Política Territorial y Medio Ambiente del Gobierno de Canarias.

KARSHOLT, O. \& VIEIRA, V. 2005. Lepidoptera. In: Borges, P.A.V. CunHA, R., GABriel, R., MARTINS, A.M.F., SilVA, L. \& VIEIRA, V., Eds., A List of the Terrestrial Fauna (Mollusca and Arthropoda) and Flora (Bryophyta, Pteridophyta and Spermatophyta) from the Azores. Direcção Regional de Ambiente and Universidade dos Açores, Horta, Angra do Heroísmo and Ponta Delgada, pp. 207210.

LEVY, G. 1998. The ground-spider genera Setaphis, Trachyzelotes, Zelotes and Drassyllus (Araneae: Gnaphosidae) in Israel. Israel Journal of Zoology 44, 93-158.

MARTINS, A.M.F. 1993. The Azores - Westernmost Europe: Where evolution can be caught red-handed. Boletim do Museu Municipal do Funchal, Suppl. 2, 181-198.

NUNES, J.C. 1999. A actividade vulcânica na ilha do Pico do Plistocénico Superior ao Holocénico: mecanismo eruptivo e Hazard vulcânico. Ph.D Thesis, Universidade dos Açores, Ponta Delgada.

PLATNICK, N.I. 1998. Advances in Spider Taxonomy 1992-1995. New York Entomological Society.

REAL, R., OlIVERO, J., GUERRERO, J.C., VARGAS, J.M.Y \& MÁRQUEZ, A.L. 1999. Contrastación de hipótesis explicativas de la distribución de la diversidad específica de Aranas (Arachnida, Araneae) en las Islas Canarias. Boletin de la Sociedad Entomológica Aragonesa 26, 573-581.

Ribeiro, S.P., Borges, P.A.V., Gaspar, C., Melo, C., Serrano, A.R.M., Amaral, J., Aguiar, C., AndrÉ, G. \& Quartau, J.A.
2005. Canopy insect herbivores in the Azorean Laurisilva forests: key host plant species in a highly generalist insect community. Ecography 28, 315-330.

RosenZWEIG, M.L. 1995. Species Diversity in Space and Time. Cambridge University Press, Cambridge.

Santos, A.M.C., Borges, P.A.V., Hortal, J., Rodrigues, A.C., Medeiros, C., AZEvedo, E.B., Melo, C. \& LoPES, D.J.H. 2005. Diversidade da fauna de insectos fitófagos e de inimigos naturais em culturas frutícolas da ilha Terceira, Açores: a importância do maneio e da heterogeneidade ambiental. In: LOPES, D., PEREIRA, A., Mexia, A., Mumford, J. \& Cabrera, R., Eds., A Fruticultura na Macaronésia - O Contributo do projecto INTERFRUTA para o seu desenvolvimento. Angra do Heroísmo, pp. 115134.

SChOENER, T.W., Clobert, J., LegendRe, S. \& SPILlER, D.A. 2003. Life-history models of extinction: a test with island spiders. American Naturalist 162, 558-573.

Silva, L., Pinto, N., Press, B., Rumsay, F., Carine, M., HenderSON, S. \& SJÖGREN, E. 2005. List of vascular plants (Pteridophyta and Spermatophyta). In: Borges, P.A.V., CunHA, R., GABRIEL, R., MARTINS A.M.F., SILVA, L. \& VIEIRA, V., Eds., A List of the Terrestrial Fauna (Mollusca and Arthropoda) and Flora (Bryophyta, Pteridophyta and Spermatophyta) from the Azores. Direcção Regional de Ambiente and Universidade dos Açores, Horta, Angra do Heroísmo and Ponta Delgada, pp. 131-156.

SILVA, L. \& SMITH, C.W. 2004. A characterization of the nonindigenous flora of the Azores Archipelago. Biological Invasions 6, 193-204.

SKERL, K.L. 1999. Spiders in conservation planning: a survey of US natural heritage programs. 9. Journal of Insect Conservation 3, 341-347.

TOKESHI, M. 1992. Dynamics and distribution in animal communities; theory and analysis. Researches in Population Ecology 34, 249 273.

WIEHLE, H. 1960. Spinnentiere oder Arachnoidea (Araneae). XI. Micryphantidae-Zwergspinnen. Tierwelt Deutschlands 47, i-xi, $1-620$.

Wise, D.H. 1995. Spiders in Ecological Webs. Cambridge University Press, Melbourne.

WundERLICH, J. 1972. Zur Kenntnis der Gattung Walckenaeria BLACKWALL 1833 unter besonderer Berücksichtigung der europäischen Subgenera und Arten (Arachnida: Araneae: Linyphiidae). Zoologishe Beiträge (N. F.) 18, 371-427.

WundERLICH, J. 1987. Die Spinnen der Kanarischen Inseln und Madeiras. Taxonomy and Ecology 1, 1-435.

WunderLICH, J. 1992. Die Spinnen-Fauna der Makaronesischen Inseln - Taxonomie, Ökologie, Biogeographie und Evolution. Beiträge zur Aranealogie 1, 1-619.

WUNDERLICH, J. 1993. The Macaronesian cave-dwelling spider fauna (Arachnida: Araneae). Memoires of the Queensland Museum 33, 681-686.

WUNDERLICH, J. 1995. Zu Ökologie, Biogeographie, Evolution und Taxonomie einiger Spinnen der Makaronesischen Inseln. (Arachnida: Araneae). Beiträge zur Aranealogie 4, 385-437. 